\title{
WestVirginiaUniversity
}

THE RESEARCH REPOSITORY @ WVU

Graduate Theses, Dissertations, and Problem Reports

2002

\section{Expression and regulation of c-myb in B-lymphocyte development}

Candice LaShawn Damiani

West Virginia University

Follow this and additional works at: https://researchrepository.wvu.edu/etd

\section{Recommended Citation}

Damiani, Candice LaShawn, "Expression and regulation of c-myb in B-lymphocyte development" (2002). Graduate Theses, Dissertations, and Problem Reports. 1699.

https://researchrepository.wvu.edu/etd/1699

This Dissertation is protected by copyright and/or related rights. It has been brought to you by the The Research Repository @ WVU with permission from the rights-holder(s). You are free to use this Dissertation in any way that is permitted by the copyright and related rights legislation that applies to your use. For other uses you must obtain permission from the rights-holder(s) directly, unless additional rights are indicated by a Creative Commons license in the record and/ or on the work itself. This Dissertation has been accepted for inclusion in WVU Graduate Theses, Dissertations, and Problem Reports collection by an authorized administrator of The Research Repository @ WVU.

For more information, please contact researchrepository@mail.wvu.edu. 


\title{
EXPRESSION AND REGULATION OF C-MYB IN B-LYMPHOCYTE DEVELOPMENT
}

\author{
Candice LaShawn Damiani \\ Dissertation Submitted to the School of Medicine at West Virginia University \\ in Partial Fulfillment of the Requirements for the Degree of \\ Doctor of Philosophy \\ In \\ Microbiology, Immunology, and Cell Biology
}

Kenneth S. Landreth, Ph.D., Chair John B. Barnett, Ph.D. Laura F. Gibson, Ph.D.

David Weissman, M.D.

Eric H. Westin, M.D.

Department of Microbiology, Immunology, and Cell Biology

Morgantown, West Virginia

2002

Keywords: Myb, Bone Marrow, Lymphopoiesis, Hematopoiesis, Pro-B Cell, Stromal Cell

Copyright 2002 


\section{ABSTRACT \\ EXPRESSION AND REGULATION OF C-MYB IN B-LYMPHOCYTE DEVELOPMENT}

\section{Candice L. Damiani}

B lymphocytes are continually produced in bone marrow from pluripotential hematopoietic stem cells. Lymphopoiesis is characterized by a series of highly regulated genotypic and phenotypic changes resulting in immunocompetent effector cells which express cell surface immunoglobulin. Our laboratory has focused on defining extracellular signals regulating lymphoid progenitor cell survival, proliferation, and differentiation. These studies have demonstrated that pro-B cell survival, proliferation, and differentiation are regulated by interactions with fibroblastic stromal cells in the hematopoietic microenvironment. However, specific molecular mechanisms by which stromal cells regulate B lymphoid development are largely unknown. In an attempt to better understand molecular mechanisms regulating maturation in this lineage, we developed a panel of pro-B cell clones from 14-day murine fetal liver. These pro-B cell clones remain dependent on stromal cells for survival, do not form tumors, and reconstitute $B$ lymphocytes in severe combined immunodeficient (SCID) mice. In vitro, pro-B cell clones continuously proliferate and do not differentiate. We noted that pro B cell lines were characterized by expression of high levels of the oncogene c-myb. Although several laboratories have proposed a role for c-myb in regulation of hematopoiesis, virtually nothing is known about the function of c-myb in normal $\mathrm{B}$ lineage cells. To investigate the role of c-myb in the survival, proliferation, and differentiation of $B$ lineage cells, we utilized a stromal cell dependent pro-B cell line that expresses mRNA and protein for c-myb. Experiments utilizing RT-PCR and Western blot analysis reveal that c-myb is regulated in pro-B cells by stromal cells, specifically by stromal cell adhesion contacts. Both DMSO and antisense oligonucleotides were used to downregulate c-myb protein to determine the role this intracellular regulator plays in B lymphocyte development. Our investigations revealed that downregulation of c-myb did not affect pro-B cell survival but did interrupt both pro-B cell proliferation and differentiation. In vivo investigations in mice carrying homozygous mutations of the cmyb gene indicate that lymphopoiesis is severely diminished in embryonic knockout animals. These data suggest a central role for c-myb in proliferation and differentiation of developing B lymphocytes. 


\section{DEDICATION}

I would like to dedicate this dissertation to the people who were the wind beneath my wings. First, I dedicate this work to my precious Mamma and Daddy. You sacrificed daily so that I might be able to achieve my dreams. Thank you for always letting Alexis stay with you whenever I needed it. While I can never repay you for your unfailing love and support, just know that there will be many extra jewels in your heavenly crown and that I love you dearly. To my brother and sister, I thank you for letting me have the lime light sometimes (or all of the time!) and for loving me even though I was a bossy big sister. Terra, I remember a time when I was at the bottom, and my little sister was the one there to lift me up, set on the porch swing with me, and take a walk with me every night. I will never forget that. And, to the rest of the wonderful family that God has so richly blessed me with. To my late Papa Jim Lusk, Papa John White, and Mama Gladys White, I wish I could share this with you but I know that you are somewhere in heaven rejoicing with the angles. I can't wait to see you again. Granny Jane, you are the rock of the family. Thank you for all of the prayers and for having the best Grandma's house in the world. Nancy and Don, Teresa and Jerry, Elijah and Misty, Kathy and Ray, Chelsea and Jordan, Todd, Jasmyne, and Amber, Thank you for understanding all the times I had to miss birthday parties and forgot to send cards. Thank you for your support, including prayers, long phone conversations when I just needed to talk, and even money when the rent needed paid. Last, but not least, this dissertation is dedicated to my wonderful husband Thomas and my daughter Alexis. You guys have been my rock. You have held my hand, listened to me gripe, and give me shoulders when I needed to cry. Tom, you have supported me unfailingly, cooked dinner many (many) nights when I was working or too tired, kept groceries in the house, gotten Alexis on or off the bus every day (well, except for that one incident where the strange mother brought her home), given up the computer, and even put off your own work so I could do mine. And, I know you approached the throne on my behalf many times. Thank you. I love you with all of my heart. Alexis, you are my sunshine. I know it hasn't always been easy when mommy had to work and she couldn't play dinosaur monopoly. Thank you for being such a good and patient little girl. You are my pumpkin pie.

Most of all family, I thank you for your love. You all have always believed in me, and I appreciate that more than you can know. Dear family, it must have been cold there in my shadow sometimes, to never have sunlight on your face, it might have appeared to go unnoticed, but please know, that you are the wind beneath my wings. I love you. 


\section{ACKNOWLEDGEMENTS}

There are so many people that were vital to this work that it is hard to know where to begin. First, I have to thank my mentor, Dr. Ken Landreth. I know I haven't always been the easiest graduate student to work with, and we don't agree on everything (or anything except good country music), but I have learned so much from you. You are a fabulous scientist and I am amazed at the wealth of knowledge that you possess. Thanks for letting me come into your laboratory and introducing me to the wonderful world of the bone marrow. And, thank you for pushing me farther and harder than I would have liked. Because you were tough on me, I am a better scientist and a stronger person.

I would also like to thank my committee members, Dr. John Barnett, Dr. Laura Gibson, Dr. Eric Westin, and Dr. David Weissman. You have been instrumental to my graduate work. I was privileged to have each of you on my committee.

An extra special thank you goes out to Debbie Piktel and Sarah Dodson. Where would I be without you two? Not only have you been great lab mates, you have become fabulous friends. Thank you for your unfailing support and for your friendship; they have been invaluable.

Another special thank you goes to Ina Gordon, Emily Hickman, Michelle Spruill, Jan Phillips, Cathy Boyle, and Wendy Virtue. I know that your support and prayers made this possible. I am blessed to have each of you in my life.

I would also like to thank the MICB department and all of the graduate students that have been there during my graduate career. You all have been wonderful to laugh with and to commiserate with. Good luck to all of you.

Finally, I would like to thank Mrs. Bobbi Houck for being the best high school biology teacher in the world. You laid a firm science foundation for me many years ago and instilled a love of science deep within me; they have been instrumental to the rest of my learning. And, I would like to thank Dr. Kathy Gregg, Dr. Jeanne Sullivan, and Dr. Carl Colson. The education I received from you at Wesleyan was second to none. I could not have been better prepared for graduate school. Thank you for teaching solid science, maintaining high standards, and guiding me to graduate school. 


\section{LIST OF FIGURES}

Introduction

Figure 1. Sequential Progression of Murine Hematopoiesis

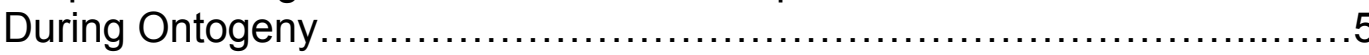

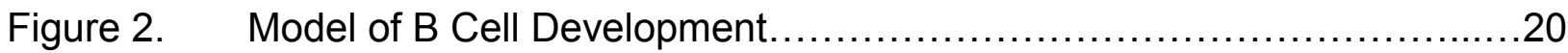

\section{Chapter 2}

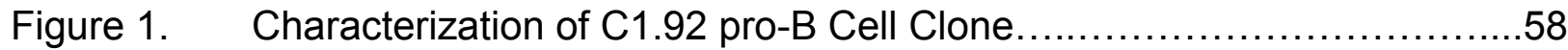

Figure 2. Half-Life of C-myb mRNA in Pro-B Cells.................................60

Figure 3. Half-Life of C-myb Protein in Pro-B Cells ................................61

Figure 4. Stromal Cells Regulate C-myb Expression...............................63

Figure 5. Stromal Cells Regulate C-myb Expression via Adhesion

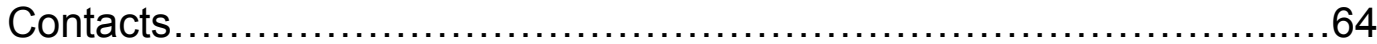

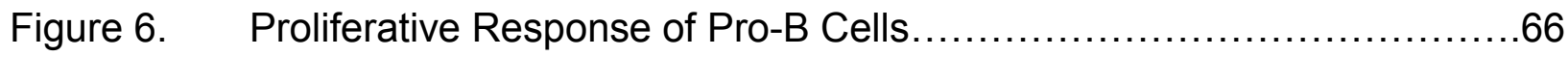

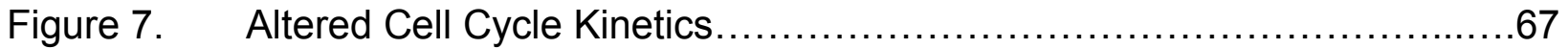

Figure 8. Down-Regulation of C-myb Is Associated with Pro-B Cell

Differentiation.

\section{Chapter 3}

Figure 1. Effect of DMSO on C-myb Expression in Pro-B Cells.....................87

Figure 2. DMSO Treatment Does Not Decrease Cell Viability .......................88

Figure 3. Inhibition of C-myb Results in Decreased Pro-B Cell Expansion

Culture.

Figure 4. Downregulation of C-myb is Associated with Pro-B Cell

Differentiation.

Figure 5. Stromal Cell C-myb Levels are Not Altered by DMSO

Treatment

Figure 6. DMSO Treatment of Stromal Cells Does Not Alter IGF-I

Expression. 
Figure 7. DMSO Treatment of Stromal Cells Does Not Alter IL-7

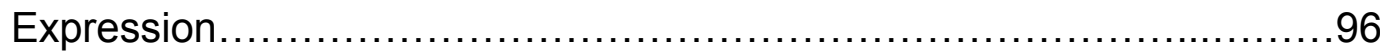

Figure 8. Stromal Cell Ig Gene Rearrangement Status is Not Altered by

DMSO Treatment.

Figure 9. Regulation of C-myb Expression in Pro-B Cells Using Antisense

Oligonucleotides

Figure 10. Antisense Oligonucleotide Treatment Does Not Decrease

Cell Viability. 100

Figure 11. Inhibition of C-myb Results in Decreased Pro-B Cell Expansion in Culture.

Figure 12. Inhibition of C-myb Results in a Decreased Response to IL-7 102

\section{Chapter 4}

Figure 1. PCR Strategy to Detect Targeted C-myb Allele.

Figure 2. CFU-GM Progenitor Cells are Present but Drastically Decreased in C-myb Knockout Mice.

Figure 3. Mutations in C-myb Ablate Clonable, IL-7 Responsive Pro-B

Cell Potential. 126

Figure 4. PCR Strategy to Detect Targeted A-myb Allele 128

Figure 5. CFU-GM Progenitor Cells Are Present in A-myb Knockout Mice 130

Figure 6. A-myb Mutation Does Not Alter Pro-B Cell Frequency.

\section{LIST OF TABLES}

\section{Chapter 4}

Table 1. Cellular Composition of C-myb Fetal Livers 125 


\section{TABLE OF CONTENTS}

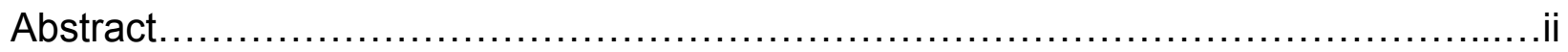

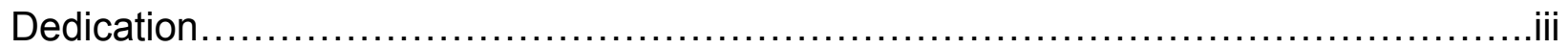

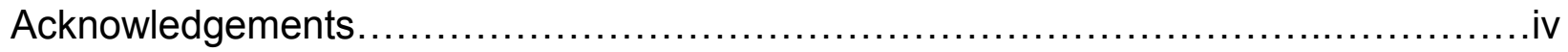

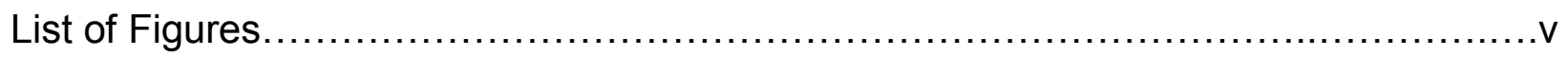

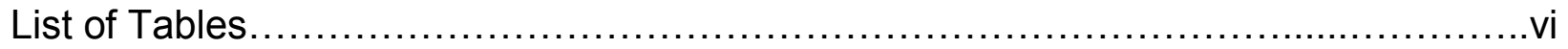

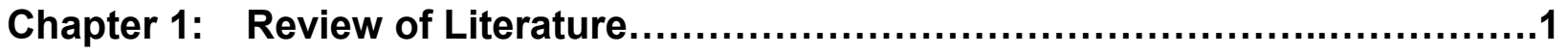

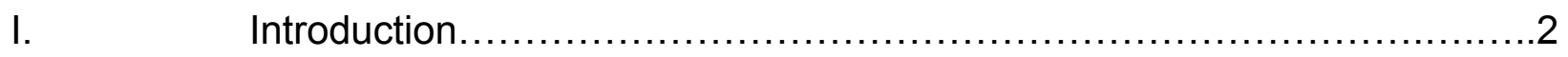

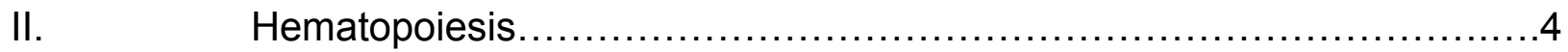

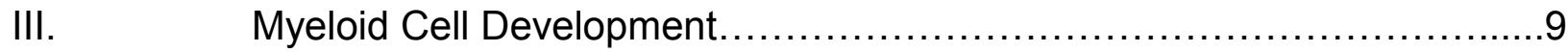

IV. $\quad$ Regulation of Myeloid Cell Development by C-myb ........................10

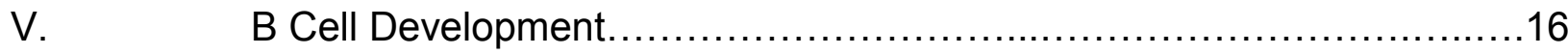

VI. Regulation of Lymphoid Cell Development by C-myb ....................26

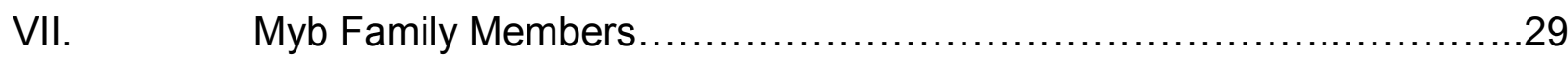

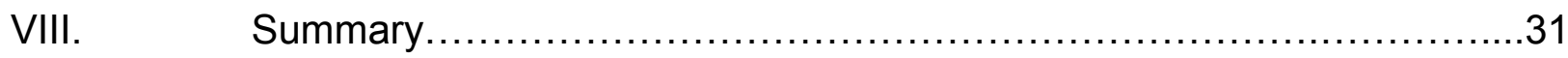

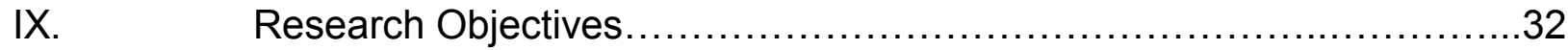

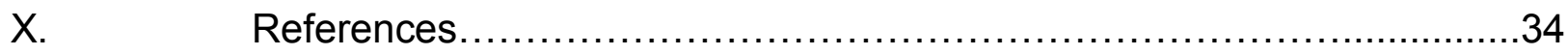

Chapter 2: Stromal Cells Regulate Expression of the Proto-oncogene C-myb in IL-7 Dependent Pro-B Cells....................................49

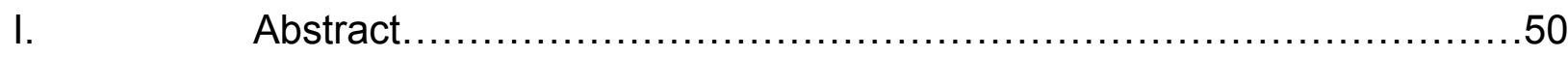

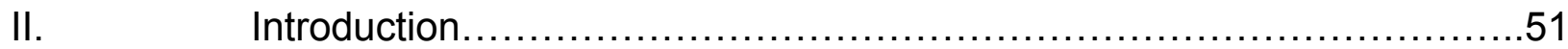

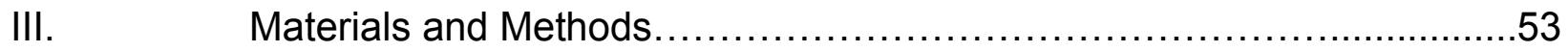

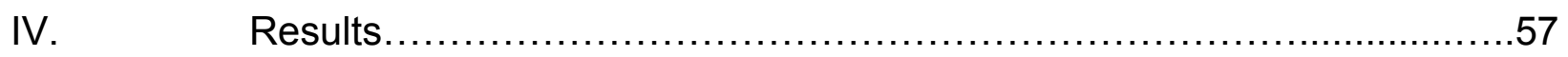

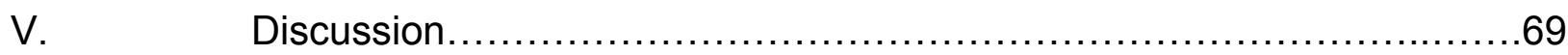

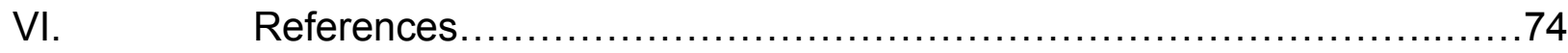

Chapter 3: C-myb Regulates Proliferation and Differentiation of IL-7

Dependent Murine Pro-B Cells ........................................78

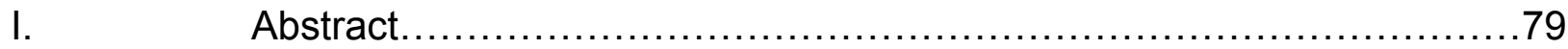




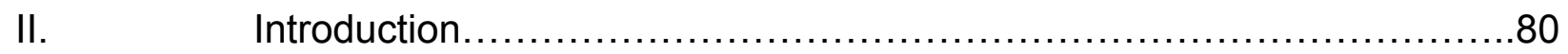

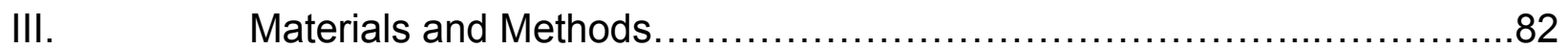

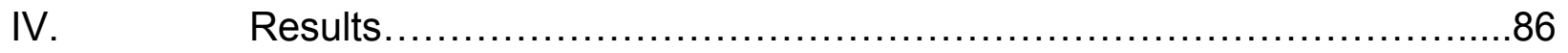

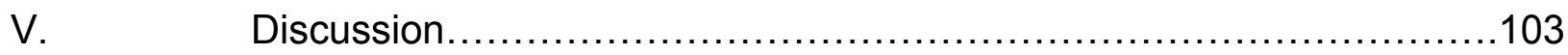

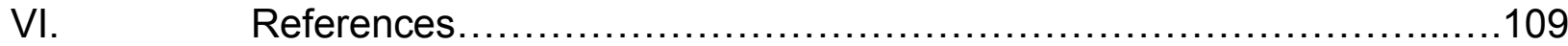

Chapter 4: Loss of A-myb and C-myb Differentially Impact B Lymphopoiesis in Murine Fetal Liver......................................112

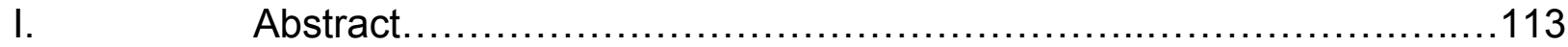

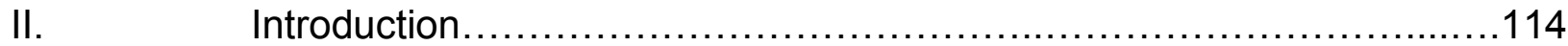

III. Materials and Methods..........................................................

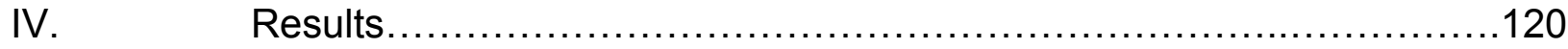

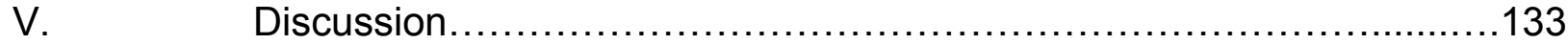

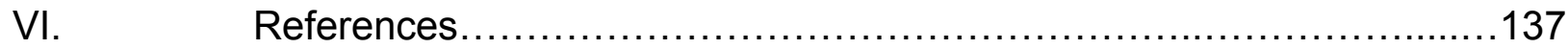

Chapter 5: General Conclusions and Discussion.................................140

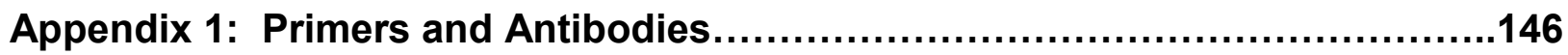

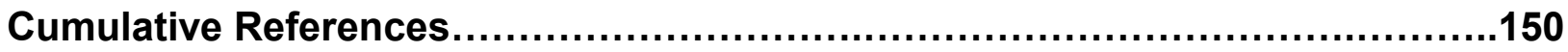


CHAPTER 1

REVIEW OF LITERATURE 


\section{INTRODUCTION}

Hematopoiesis is the continual development of red and white blood cells from pluripotential hematopoietic stem cells. The hematopoietic system is a dynamic system consisting of hematopoietic stem cells (HSC) that are retained in blood forming tissues throughout life. HSCs have the ability to both self-renew as well as constantly give rise to the different types of mature blood cells, including cells of the erythroid, myeloid, and lymphoid lineages (Kincade, 1989). During embryonic development, hematopoietic stem cells migrate from the aorta/gonad/mesonephros (AGM) region through a series of tissue sites. In the fetal liver, hematopoietic stem cells mature and differentiate to form committed lymphoid and myeloid progenitor cells. Progenitor cells are distinguished from HSC's by progressive loss of self-renewal capacity and restriction of developmental options. Lymphoid and myeloid progenitors subsequently differentiate through a series of committed developmental stages to form effector cells. Effector cells leave hematopoietic tissues, have a finite lifespan, and are continuously repopulated from committed progenitor cell populations in hematopoietic tissues.

Bone marrow is established as the primary site of hematopoiesis shortly before birth and this remains the primary hematopoietic organ throughout postnatal life. Bone marrow is characterized by packed hematopoietic cells interspersed with a meshwork of non-hematopoietic cells termed stromal cells. Fibroblastic stromal cells within the bone marrow are required for normal hematopoiesis. Stromal cells support early cell development through cell adhesion interactions that bind receptors on developing hematopoietic cells. In addition, stromal cells secrete hematopoietic cytokines into the marrow environment, including interleukin-7 and c-kit ligand (stem cell factor), which stimulate lymphocyte development (Billips, 1992). These secreted stromal cell products are necessary for continued hematopoiesis (Dorshkind, 1990).

In addition to cellular events, it has become evident that molecular mechanisms are also involved in controlling gene expression, proliferation and differentiation in the hematopoietic system. Different developmental fates of individual cells must be strictly controlled to keep the immune system balanced. On the molecular level, the hematopoietic system is useful for studying how decisions are made to differentiate 
along one of several alternative pathways and how characteristic patterns of lineage specific gene expression are generated. The importance of underlying regulatory mechanisms is underscored by the fact disruption of these controls can lead to various diseases, such as leukemia.

The Myb family of proteins is a group of transcription factors that bind DNA and were first identified as part of avian myeloblastosis virus. The oncogene responsible for the transformation in avian leukemia is $\mathrm{v}-m y b$. V-myb protein is a constitutively active, mutated, and truncated form of C-myb, a product of the c-myb proto-oncogene. The $c-$ myb proto-oncogene encodes a $75 \mathrm{kDa}$ nuclear protein that binds to a consensus sequence of DNA [(T/C)AAC (T/G)G ] (Bidenknapp, 1988). C-myb expression is high in immature hematopoietic cells, and levels of c-myb decrease as immature cells differentiate to function (Lipsick, 1996). C-myb is also over expressed in many forms of leukemia. In 1982, Westin et al investigated c-myb expression in a human promyelocytic leukemic cell line and determined that overexpression of c-myb inhibited differentiation of the cell line (Westin 1982). These data were the first to suggest that cmyb dysregulation inhibited normal progression through lineage development and that appropriate expression of c-myb was required for normal myelopoiesis. Based on this, a critical role for c-myb in myelopoiesis was proposed. C-myb must be expressed in immature myeloid cells in order for proliferation to occur, but must then be downregulated for terminal differentiation of myeloid cells. Since c-myb is expressed in all immature hematopoietic cells, it was hypothesized that c-myb may play a pivotal role in the development of other blood cell types as well. Gewirtz demonstrated that inhibition of c-myb expression using anti-sense oligonucleotides resulted in growth arrest of hematopoietic cells (Gewirtz, 1988). The development of a mouse model with a homozygous mutant c-myb gene confirmed these data. Animals with homozygous interruption of c-myb transcription were normal at day 13 of gestation, but by day 15 were severely anemic and expired in utero. These animals exhibited a complete loss of myelo and erythropoiesis in the fetal liver (Mucenski, 1991). These in vivo observations further suggested that c-myb is normally required for the maintenance of myelopoiesis as well as erythropoiesis. The role of c-myb in lymphopoiesis, however, has been more poorly defined. 
Survival, proliferation, and differentiation of B lymphocytes depend on a set of regulatory signals from the hematopoietic microenvironment provided in bone marrow. Expansion of pro-B cells is dependent on the cytokine interleukin-7 (IL-7) in conjunction with a series of co-stimulatory cytokines including insulin-like growth factor-1 (IGF-1) (Gibson, 1993). Stem cell factor, or c-kit ligand, is expressed by stromal cells and binds to the tyrosine kinase receptor c-kit expressed on hematopoietic cells. Murine models deficient in c-kit or c-kit ligand result in failure of fetal liver hematopoiesis (Nagasawa, 1996). Expression of both the anti-apoptotic gene $b c /-2$ and the pro-apoptotic gene bax in pro-B cells is also regulated by stromal cells (Gibson, 1996).

In this study, we addressed the role of c-myb in B lymphopoiesis. The aims of this project were to explore normal expression patterns of c-myb in developing B lymphocytes, to determine whether the hematopoietic microenvironment regulated expression of c-myb in these cells, to determine the effect of c-myb down regulation on lymphocyte differentiation, and to determine if loss of myb impacts B lymphopoiesis in the fetal liver.

\section{HEMATOPOIESIS}

Developmental hematopoiesis. Hematopoiesis describes the continual development of red and white blood cells from a small population of pluripotential hematopoietic stem cells. Murine experimental systems have been extensively utilized to study the process of hematopoiesis. Insight into embryonic murine hematopoiesis has proven to be extremely informative since it has been determined that murine and human fetal hematopoiesis display many parallels. (Ghia et al, 1998). Embryogenesis extends over a 21-day period in the murine system. During this time hematopoiesis is initiated, sequentially progresses through other fetal organ systems, and eventually resides in the bone marrow as depicted in Figure 1. 


\begin{tabular}{|c|c|c|c|c|c|c|}
\hline Fertilization & $\begin{array}{l}\text { Initiation of } \\
\text { Hematopoiesis }\end{array}$ & $\begin{array}{c}\text { Onset of } \\
\text { Fetal Liver } \\
\text { Hematopoiesis }\end{array}$ & $\begin{array}{c}\text { Peak of } \\
\text { Hematopoiesis }\end{array}$ & $\begin{array}{l}\text { Involution of } \\
\text { Fetal Liver } \\
\text { Hematopoiesis }\end{array}$ & $\begin{array}{c}\text { Onset of Bone } \\
\text { Marrow } \\
\text { Hematopoiesis }\end{array}$ & Birth \\
\hline & $\begin{array}{c}\text { Yolk Sac } \\
\text { (extraembryonic) }\end{array}$ & & & & & \\
\hline & $\begin{array}{c}\text { Paraaortic } \\
\text { Splanchnopleura } \\
\text { (intraembryonic) }\end{array}$ & Fetal Liver & Fetal Liver & Spleen & $\begin{array}{l}\text { Bone } \\
\text { Marrow }\end{array}$ & $\begin{array}{l}\text { Bone } \\
\text { Marrow }\end{array}$ \\
\hline Day 0 & Day 7 & Day 10 & Day 12 & Day 15 & Day 17 & Day 21 \\
\hline
\end{tabular}

Figure 1. Sequential Progression of Murine Hematopoiesis During Ontogeny 
Hematopoiesis initiates extraembryonically in hemangioblasts, or blood islands of the yolk sac, at approximately day 7 of murine gestation (Metcalf and Moore, 1970). Within the mouse embryo, the paraaortic splanchnopleura (P-Sp) is endowed with hematopoietic potential (Godin, 1993 and Medvinsky, 1993). The P-Sp comprises the dorsal aorta and surrounding mesoderm. This region develops into the aorta/gonad/mesonephros (AGM) region, which continues to possess hematopoietic potential (Cumano et al, 2001; Moore et al, 1970). It is proposed that multipotent progenitors may arise simultaneously in the P-Sp/AGM region and in the yolk sac. On day 10 of gestation, hematopoietic cells from the AGM region and/or the yolk sac travel through the blood stream into the fetal liver. In mammals, the fetal liver is the principal site of hematopoiesis during mid and late gestation. Multipotent progenitors in the fetal liver express the cell surface markers AA4.1 and Sca-1, and lack expression of lineage specific markers (Jordan, 1995). Fetal liver hematopoiesis can be divided into four stages: the onset of hematopoiesis (day 10), the expansion of hematopoiesis (day 1112), the peak of hematopoiesis (day 13-14), and the involution of hematopoiesis (after day 15) (Sasaki, 2000). By day 15, the spleen begins to function as a subsidiary hematopoietic organ until just after birth (Cumano et al, 2001a; Morrison, 1995). The bone marrow becomes a hematopoietically active site on day 17 as cells from the fetal liver traverse into the marrow environment. The bone marrow functions as the primary site of hematopoiesis after birth (Cumano et al, 2001a).

Hematopoietic stem cells. The first suggestion that stem cells were responsible for hematopoiesis was in the late 1890s by Ehrlich (Ehrlich, 1879; Ehrlich, 1898). Ehrlich first conceptualized an ancestral stem cell that was capable of dividing to maintain a constant population while also producing progeny that could mature into various cells of the blood system. From a smear of triacid-stained bone marrow, he noticed one particular cell type he described as a "primitive large basophilic mononuclear cell with a vesicular nucleus and few or no granules". He termed this cell the Myelozyt, or marrow cell, and suggested that it was the precursor of granulocytes but not lymphocytes. This dualistic theory of development was challenged by Pappenheim who, in 1899, used an improved staining method to detect a "relatively 
featureless primitive" cell that he coined the Lymphoidozt (Pappenheim, 1989; Pappenheim, 1900). Pappenheim suggested a monophyletic concept of development; he proposed that the lymphoidozyt was actually the source of all blood cell development (Wintrobe, 1980).

Hematopoietic stem cells were further studied in response to a clinical quandary. Patients with cancer needed to receive high doses of chemotherapy to eradicate cancerous cells; however, this treatment often resulted in lethality. A radio-protective cell was needed to overcome this lethality. The radio-protective cell would be able to rapidly reconstitute hematopoietic activity sufficient to rescue a lethally irradiated recipient from hematopoietic failure. The task, however, was locating this cell. This question was first addressed in 1949 when Jacobsen et al showed that lead shielding of hematopoietic tissues during lethal irradiation prevented death (Jacobson, 1949). This suggested that radio-protective cells resided somewhere within hematopoietic tissues. Then, in 1951, Lorenz showed that infusion of syngenic marrow after irradiation also protected patients from death (Lorenz, 1951). Together, these data suggested that radio-protective cells were located in hematopoietic tissues, specifically in the bone marrow. Till and McCulloch further expanded this hypothesis in 1961. They discovered that the bone marrow contained progenitor cells capable of giving rise to myeloid, erythroid, and megakaryocytic cell colonies in the spleens of irradiated hosts (Till and McCulloch, 1961). Hematopoietic cells were injected into lethally irradiated mice and, after ten days of recovery, hematopoietic nodules had formed on the surface of the spleen. Morphologic examination of the spleen revealed the nodules were composed of immature erythroid and myeloid cells. Based on these observations, Siminovitc (1963) proposed that within the bone marrow there existed a cell population capable of multilineage differentiation, self-renewal, and radioprotection (Siminovitc, 1963). Prior to Siminovitc's theory, Osgood, in 1957, had proposed that there existed a population of cells that underwent asymmetric divisions, forming a daughter cell that would mature into a specialized blood cell while also forming a replacement stem cell during the same division (Osgood, 1957). These cells described by Osgood and Siminovitc were termed hematopoietic stem cells. Following the discovery of Till and McCulloch, Wu et al (1967) tracked stem cell development (using induced chromosomal aberrations) and 
determined that each nodule that developed on the spleen of a reconstituted irradiated host was a clone of cells derived from a single precursor cell. However, neither group had identified Siminovitc's proposed stem cell population that could reconstitute both the myeloid and lymphoid lineage. Then, in 1977, Abramson et al finally identified a pluripotential stem cell that could mature into both myeloid and lymphoid lineage cells. Again, they used chromosomal aberrations to track the progeny of stem cells. Their model suggested the existence of a pluripotential stem cell compartment, with multilineage reconstitution capabilities, as well as restricted stem cell compartments, committed to development in a single lineage (Abramson, 1977).

Pluripotential hematopoietic stem cells are the most primitive cells involved in blood cell development. These stem cells originate in the P-Sp of the developing embryo and then migrate to the fetal liver (Godin et al, 1999). Beginning on day 17 of gestation, hematopoietic stem cells seed the bone marrow microenvironment and produce all hematopoietic cell populations in postnatal animals. It is estimated that hematopoietic stem cells represent up to $0.05 \%$ of cells within the bone marrow (Spangrude et al, 1988).

Hematopoietic progenitor cells. Progenitor cells are distinguished from HSCs by being a lineage-committed population that has lost the capacity to self-renew. Lineage-committed progenitor cells are progeny from stem cells that have begun to differentiate into mature cells but are at very early stages of cell development. It was hypothesized that the commitment to differentiate in the myeloid or lymphoid lineage was irreversible once commitment had occurred. This was confirmed in 1997 when Kondo et al identified a clonogenic common lymphoid progenitor from murine bone marrow. This Lin IL- $^{-} \mathrm{R}^{+}$Thy-1 $1^{-} \mathrm{Sca}-1^{\mathrm{lo}} \mathrm{C}$-kit ${ }^{10}$ population exhibited lymphoid-restricted reconstitution capacity while lacking myeloid differentiation potential (Kondo, 1997). Three years later, Akashi et al isolated an IL-7R $\alpha^{-}$Lin $^{-}$C-kit ${ }^{+}$Sca- $1^{-}$FcyR ${ }^{10}$ CD $34^{+}$cell population that demonstrated myeloid lineage restriction with no lymphoid potential (Akashi, 2000). The authors suggested that the common lymphoid progenitor (CLP) and the common myeloid progenitor (CMP) represented the earliest branch point between the lymphoid and myeloid lineages. The CLP and the CMP then undergo 
differentiation events themselves, become more mature committed cells, and eventually develop into end cells. The CLP differentiates into both T and B cells of the immune system. Myeloid end cells include erythrocytes, platelets, monocytes, neutrophils, eosinophils, and basophils.

Recent literature from Lu et al has called the accepted dogma of hematopoietic progression into question (Lu et al, 2002). Work from their laboratory indicates that no CLP exists in the fetal liver. Rather, they suggest that a common myelolymphoid progenitor (CMLP) and a common myeloerythroid progenitor (CMEP) are the first branch points from the hematopoietic stem cell. Their system detected progenitor cells with myeloid/erythroid/lymphoid potential (thought to be the HSC), myeloid potential, myeloid/erythroid potential, myeloid/lymphoid potential, myeloid/T cell potential, and myeloid/B cell potential. However, no cells with only lymphoid ( $T$ and $B$ cell) potential were detected. These data are reminiscent of data presented in 1977 by Abramson where no CLP could be detected. This disputes the developmental scheme proposed by Weissman and colleagues described above (Kondo, 1997 and Akashi, 2000). Therefore, although this dissertation presents an overall view of the currently accepted dogma in hematopoietic development, new data are constantly emerging which challenge current thinking.

\section{MYELOID CELL DEVELOPMENT}

Regulation of hematopoietic events has been extensively studied in the myeloid lineage. Myeloid progenitor cells differentiate into at least 6 morphologically and functionally recognizable cell types. Developing myeloid progenitor cells have characteristics of a myeloblast, promyelocyte, and finally differentiated end cells. Differentiation of myeloid progenitors into more mature myeloid cells is characterized by an anti-proliferative state in which cells withdraw from the cell cycle into the $G_{0}$ phase (Boyd 1984). This cell cycle withdrawal is accompanied by down-regulation of the cmyc oncogene (Westin, 1982), rapid induction of the c-fos oncogene (Barzilay, 1987),

and decreased expression of histone genes (Brelvi, 1987). Concurrently, the cell acquires a morphologically differentiated phenotype. Differentiated myeloid cells have 
condensed nuclei, loss of nucleoli, and altered cell surface receptors. Myeloid differentiation has primarily been studied using tumor cell models comprised of cells blocked in a specific hematopoietic differentiation state. Use of tumor cell models

allows the study of specific stages of hematopoiesis since tumor cells are "frozen" in a particular developmental stage. The HL-60 cell line is an in vitro model system of myeloid cell differentiation that is particularly useful. HL-60 cells are a human leukemic cell line established from the peripheral blood leukocytes of a patient with acute promyelocytic leukemia. HL-60 cells are primarily promyelocytes arrested in an immature proliferative state, but they can be induced to terminally differentiate by a variety of agents including DMSO and butyric acid (Collins, 1977).

\section{REGULATION OF MYELOID CELL DEVELOPMENT BY C-MYB}

The Myb family of proteins is a group of transcription factors that bind DNA. This family was first identified in the avian myeloblastosis virus. The oncogene responsible for the transformation seen in the avian leukemia is v-myb. The V-myb protein was found to be a constitutively active, mutated, and truncated form of C-myb, a product of the c-myb gene. The c-myb gene is highly conserved throughout evolution. C-myb has been identified in all types of eukaryotes, including vertebrates, fungi, insects, and plants (Ness, 1996). The c-myb proto-oncogene encodes a $75 \mathrm{kDa}$ nuclear protein, comprised of 636 amino acids, that is expressed in most hematopoietic tissues (Gonda, 1983 and Westin, 1982). In addition, an $89 \mathrm{kDa}$ c-myb protein has been identified that is an alternatively spliced mRNA product. The $89 \mathrm{kDa}$ protein has 363 base pairs inserted between exons 9 and 10, termed region 9A, for a total of 999 amino acids (Rosson et al, 1987). C-myb exhibits a sequence-specific DNA binding activity, binding in vitro to the consensus sequence $[(T / C) A A C(T / G) G]$, where the first $A$, third $C$, and fifth $G$ are involved in very specific interactions (Bidenkapp, 1988 and Tanikawa, 1993). C-myb appears to function as a regulator of transcription by mediating interactions between specific DNA sequences and other protein components of the transcription machinery. The modular structure of the $\mathrm{C}$-myb protein is similar to that of many other transcription factors. C-myb proteins have a DNA binding domain at the amino 
terminus, a centrally-located transactivation domain, and a negative regulatory domain at the carboxy terminus (Ness, 1996).

C-myb DNA binding domain. The hallmark of the Myb family of proteins is their unique DNA binding domain. The first one-third of the protein consists of three tandem, 50 amino acid direct repeats termed R1, R2, and R3. The three repeats resemble a homeodomain composed of three connected alpha helices. Within the tandem repeats, there is a periodic occurrence of tryptophans that form a hydrophobic core that maintains the alpha helix motif (Saikumar, 1990). Each repeat has three tryptophans that are separated by 18 or 19 amino acid residues (Anton 1988). The regularly spaced tryptophan repeat is functionally and structurally unique in the Myb family of proteins. Mutation of tryptophan residues significantly decreases Myb's sequence specific DNA binding activity (Kanei-Ishii, 1990).

Deletion analysis has shown that R2 and R3 are absolutely required for DNA binding, but R1 is dispensable. R1 may be involved in stabilizing the interaction between R2R3 and target DNA (Tanikawa, 1993). Alternatively, it is hypothesized that R1 may recognize specific flanking regions adjacent to the core binding site and increase the DNA binding affinity of Myb (Dini, 1993). The R2R3 region of the Myb binding domain binds both to DNA and cellular proteins. The R2R3 region is very highly conserved between members of the Myb family, as well as between very divergent species. The third helix of R2 and R3 is a recognition helix. These helices lie in the major groove of the DNA and make site-specific contacts important for sequence recognition. The third helix of $R 2$ is in contact with the third helix of $R 3$ enabling $R 2$ and R3 to cooperatively bind specific DNA sequences (Kanei-Ishii, 1995).

C-myb transactivation domain. The transactivation domain of C-myb is downstream of the DNA binding domain, roughly located in the middle of the protein, and encompasses a stretch of 85 amino acids. This stretch of amino acids contains a cluster of acidic residues and a cluster of leucine residues termed the heptad leucine repeat region (HLR). This area is poorly conserved throughout the Myb family, and little is known about this region of C-myb (Sakura, 1989). Recent mutational analyses 
in yeast by Wang and Lipsick have revealed new information regarding this domain. $80 \%$ of the residues within the transactivation domain can be substituted by other amino acids without loss of transactivation function. However, there are non-mutable residues located in the acidic and the HLR regions. Alanine substitutions of pairs of acidic residues within the HLR reduced the transcriptional activation of this domain in yeast and animal cells. Although substitution of the acidic residues resulted in reduced activity, substitution of leucines within the HLR did not affect transcriptional activation ability. In addition, a single threonine (259) located between the acidic region and the HLR would not tolerate substitution. Mutation of threonine259 resulted in decreased domain function. Although these studies reveal the importance of the acidic residues within the transactivation domain, the functional importance of many individual residues within the domain remain unknown (Wang and Lipsick, 2002).

C-myb negative regulatory domain. The C-myb negative regulatory domain contains a putative leucine zipper motif with one isoleucine and three leucine residues (Bedenkapp, 1988). Deletion of this c-terminal region results in an increase in the transactivational activity of the protein, as well as an increase in the DNA binding activity of the mutated protein (Sakura, 1989 and Ramsay, 1991). Many cellular proteins have been shown to bind the leucine zipper of C-myb and exhibit negative regulation (Kanei-Ishii, 1992 and Favier, 1994). In addition, the C-myb binding domain can interact specifically with the C-myb leucine zipper and form a Myb dimer. Once the C-myb dimer has formed, it cannot bind to DNA. These data indicate that intramolecular interactions between the two ends of C-myb can serve to negatively regulate Myb activation (Nomura, 1993). In addition to the leucine zipper, it has been shown that two subdomains of the negative regulatory domain (NRD1 and NRD2) can also regulate C-myb. NRD1 is upstream of the leucine zipper while NRD2 is downstream of the leucine zipper. Deletion of either NRD1 or NRD2 increases the DNA binding capacity of Myb (Kanei-Ishii, 1995). Other experiments have shown that truncating the N-terminal domain of C-myb also results in increased DNA binding ability. This implies that the $\mathrm{N}$-terminal domain is also participating in the negative regulation of C-myb. It is hypothesized that C-myb may fold back on itself and allow the two 
regulatory ends to interact (Ramsay, 1995). This phenomenon would explain how the deletion of either end of the C-myb protein leads to activation. The regulation of C-myb DNA binding activity is complex, requiring multiple subdomains in the C-terminal negative regulatory domain as well as a region in the $\mathrm{N}$-terminal domain.

The proteins encoded by the Myb genes can be divided into two classes: those involved in the general housekeeping function of mature hematopoietic cells and those having growth, survival, or differentiation activities. The Myb family of proteins is unique due to their ability to regulate the growth and differentiation of many cell types. Myb proteins are linked with critical cell fate decisions including proliferation, differentiation, cell cycle control, and gene expression. C-myb regulates many genes and promoters, including CD34, mim-1, cdc-2, c-myc, IGF-1, CD4, GATA-1, IL-3R $\alpha$, and c-myb (Melotti, 1994; Ness, 1989; Ku, 1993; Evans, 1990; Reiss, 1991; Siu, 1992; Aurigemma, 1992; Miyajima, 1995; and Nicolaides, 1991). C-myb is primarily expressed in immature hematopoietic cells, but it is also expressed in primary fibroblasts (Sczylik, 1993), endothelial cells (Brown, 1992), and Sertoli cells (Page, 1995). Overexpression of cmyb has also been detected in breast cancer and colon carcinomas (Guerin, 1990 and Greco, 1994). Although c-myb is primarily found in hematopoietic cells, the majority of the genes c-myb regulates are markers of maturity and differentiation. With this pattern of expression and regulation it is possible that c-myb induces differentiation rather than blocking it by activating differentiation specific genes. 
C-myb is primarily expressed in primitive hematopoietic cell tissues, the most immature hematopoietic cells, and hematopoietic tumor cell lines. When early hematopoietic cells are stimulated to differentiate, there is a significant decline in c-myb expression associated with cellular maturation. This was first demonstrated by Westin et al in 1982. These investigators established that expression of c-myb was correlated with specific stages of myeloid differentiation (Westin, 1982). In 1988, Clark et al investigated myb expression in a murine erythroleukemia cell line and demonstrated that constitutive expression of exogenously introduced c-myb inhibited erythroid differentiation (Clark, 1998). Although all these data implicate c-myb as a regulator of hematopoiesis, they did not definitively establish that c-myb regulated hematopoietic cell proliferation and/or differentiation.

Gewirtz and Calabretta confirmed the importance of c-myb in hematopoiesis using an in vitro system. In their experiments, they depleted normal human bone marrow cells of adherent macrophages and $T$ lymphocytes. They exposed the bone marrow mononuclear cells to c-myb antisense oligonucleotides and analyzed colony formation. Exposure to c-myb antisense oligonucleotides resulted in a decrease in myeloid, erythroid, and megakaryocytic colony formation. In addition to a decrease in colony number, there was also a marked decrease in colony size indicating that c-myb expression is also relevant to understanding the proliferation of progenitor cells. These experiments demonstrated that c-myb played a critical role in regulating normal hematopoiesis in vitro (Gewirtz and Calabretta, 1988, Gewirtz, 1991). These results clearly established that loss of c-myb inhibited myeloid cell development, but they did not examine what effect over-expression of c-myb would have on myeloid cell development. Clarke had shown that c-myb over expression would inhibit the terminal differentiation of erythroid cells. McClinton and collaborators further expanded upon Clarke's earlier findings. They investigated the effects of ectopic over expression of cmyb at different times during the induction process using a Friend virus-infected MEL cell line. The MEL cell line is an early erythroid precursor model system that can be induced to differentiate into mature erythroid cells using chemical inducers, including erythropoietin and DMSO. When MEL cells are induced to differentiate, c-myb mRNA is biphasically downregulated during early and late stages of differentiation. C-myb mRNA 
is significantly down-regulated during the early differentiation stage that occurs within hours after chemical treatment. C-myb rebounds to basal levels after 24 hours, corresponding with the beginning of the middle stage of MEL cell differentiation. In subsequent days, during the late stage of differentiation, c-myb is down-regulated until it reaches a maximum low when terminal differentiation occurs (Kirsch, 1986 and Ramsay, 1986). McClinton introduced an inducible metallothionein promoter driven cmyb gene into MEL cells and expressed c-myb during different phases of differentiation. Expression of c-myb during the early phase of differentiation did not have an affect on MEL cell maturation, indicating that early down-regulation of c-myb is not necessary for differentiation. However, if c-myb was continuously expressed during the entire induction phase, differentiation was completely blocked indicating that late downregulation of c-myb is critical for terminal differentiation of MEL cells (McClinton, 1990).

Recently, in 2001, Chen and Bender demonstrated that MEL cells could be induced to differentiate into a more mature cell by introducing an inducible dominant interfering myb allele (MEnT). After induction of MEnT in MEL cells, transfected cells began differentiating and ceased proliferating with no chemical induction necessary. These experiments were used to argue that downregulation of c-myb alone in MEL cells is sufficient to induce terminal differentiation (Chen and Bender, 2001). Taken together these data suggested a critical role for $c-m y b$ in myeloid and erythroid hematopoiesis: down regulation of c-myb is required for terminal differentiation of myeloid and erythroid cells. This pattern of expression suggests that c-myb plays a pivotal role in the development of blood cells. The development of a mouse model with a homozygous mutant c-myb gene confirmed these data.

Mucenski et al generated a mouse model heterozygous for a mutated c-myb gene. A vector was constructed with a neomycin resistance gene inserted in opposite transcriptional orientation into the sixth c-myb exon. The construct was introduced, by electroporation, into stem cells and cells containing the construct were identified by G418 selection. Embryonic stem cells with the construct were implanted into pseudopregnant female mice. The altered c-myb allele was passed to progeny animals and the affect of the alteration was examined. Mice heterozygous for mutant c-myb appeared phenotypically normal after birth. Animals that were homozygous null for the 
C-myb protein were normal at day 13 of gestation. They were present in appropriate numbers and had developed brains, kidneys, lungs, hearts, and limb buds. However, by day 15 , mutant mice were pale in color, severely anemic, and expired in utero. At days 12.5-13.5 of gestation, hematocrit levels in wild type and mutant mice were $35 \%$. By day 15.5, there was a 10-fold decrease in the numbers of hematocrits in the c-myb null mice. Null mice had hematocrit levels of $5 \%$ whereas wild-type animals had $40 \%$. It is at this time in embryogenesis that the anatomic site of erythropoiesis moves from the AGM region into the fetal liver. Erythrocytes derived from the AGM can be morphologically differentiated from fetal liver derived erythrocytes; erythrocytes from the AGM region remain nucleated and are larger than those from the fetal liver. Examination of peripheral blood at day 12 revealed normal numbers of nucleated erythrocytes, indicating that early intraembryonic erythropoiesis in the AGM was normal. However, there was a significant defect in fetal hepatic erythropoiesis. Animals exhibited a complete loss of erythropoiesis in the fetal liver. This indicates that c-myb mutant mice are unable to switch the site of fetal erythropoiesis from the AGM region to the liver (Mucenski, 1991). These observations further suggest that $c-m y b$ is responsible for the maintenance of myelo and erythropoiesis. Although c-myb has been shown to be critical in the development of erythroid and myeloid precursors, less work has been done on the role of c-myb in the normal development of lymphocytes.

\section{B CELL DEVELOPMENT}

The bone marrow is the primary site of postnatal B lymphocyte development in mammals. The bone marrow microenvironment is composed of a complex meshwork of stromal cells, developing lymphopoietic cells, and extracellular matrix. In addition, the cells within the microenvironment release cytokines and colony-stimulating factors. These components interact in an amazingly complex way to support the survival, proliferation, and differentiation of B lymphocytes. How the bone marrow microenvironment, particularly bone marrow stromal cells, regulates the development of $B$ lineage cells is not completely understood. The bone marrow contains $B$ lineage cells at all stages of development, from the earliest progenitors to the most mature $B$ cells. B 
lymphopoiesis in the bone marrow occurs in parallel with myelopoiesis and erythropoiesis. The daily production of $B$ cells in adult mammals is very high; an estimated $5 \times 10^{7}$ B lymphocytes are generated per day in mice (Landreth et al, 1981, Rahal and Osmond, 1981).

B lymphopoiesis is characterized by the ordered progression of a stem cell through a series of tightly controlled, systematic genotypic and phenotypic changes resulting in formation of mature $B$ cells. In order to survive this developmental process, B lymphocytes must fulfill several criteria including a single productive immunoglobulin (Ig) rearrangement at the heavy chain loci as well as a productive light chain gene rearrangement. The initial gene rearrangements occur in the heavy chain genes. This requires the joining of a $D_{H}$ (diversity) to a $J_{H}$ (joining) locus. Following the $D_{H}-J_{H}$ joining, the $D J_{H}$ segment is juxtaposed to one of many $V_{H}$ (variable) regions. As the heavy chain gene is transcribed, post transcriptional processing removes the noncoding sequence present between the rearranged $\mathrm{V}_{\mathrm{H}}-\mathrm{D}_{\mathrm{H}}-\mathrm{J}_{\mathrm{H}}$ segment and the constant $(C)$ locus, resulting in expression of the $\mu$ heavy chain (V-D-J- $\left.C_{\mu}\right)$. Following heavy chain protein translation, light chain gene rearrangement occurs. This process entails joining one of several light chain $\mathrm{J}$ segments to a $\mathrm{V}$ segment. The kappa light chain rearranges first. If both kappa light chain rearrangements are non-productive, lambda light chain rearrangement occurs. If a kappa rearrangement is productive, lambda light chain rearrangement is inhibited. Once the light chain gene is rearranged and transcribed, the $\mu$ heavy chain associates with the light chain and the assembled Ig molecule is expressed on the cell surface (Yancopoulos and Alt, 1986 and Oettinger et al, 1999). As $B$ lymphocytes undergo these genotypic alterations, the cell also acquires a number of cell surface markers that can be used to determine discrete stages along the developmental pathway. Various approaches for identifying and describing cells at different stages of $B$ lymphoid development have been proposed based both on cell surface phenotype and genotype. Because of this, several different nomenclatures have been established for the classification of B cell developmental stages. The earliest identified cell committed to development in the B lymphocyte lineage is the common lymphoid progenitor (CLP) that was identified by the Weissman laboratory (Kondo et al, 1997). The stages following the CLP have been described in detail by two different 
schemes based on phenotypic changes that occur during B cell development. Dennis Osmond proposed one nomenclature scheme (Osmond, 1990). Osmond grouped precursor (cytoplasmic $\mu^{-}$) B cells into 3 classes based on expression of $\mathrm{TdT}$, an intranuclear enzyme expressed during the rearrangement of the variable region of the heavy chain of the immunoglobulin gene, and the tyrosine phosphatase B220, an isoform of CD45RA. Early pro-B cells are $\mathrm{TdT}^{+} \mathrm{B} 220^{-}$, intermediate pro-B cells are $\mathrm{TdT}^{+}$ $\mathrm{B}_{220^{+}}$and late pro-B cells are $\mathrm{TdT}^{-} \mathrm{B}^{2} 20^{+}$. Pre-B cells are characterized by being $\mathrm{B}^{2} 20^{+}$as well as $\mathrm{C}^{+}$. Large pre-B cells are large mitotically active cells that divided into small non-dividing small pre-B cells. The small pre-B cells then mature into nondividing, $\mathrm{B}^{2} 20^{+}, \mathrm{IgM}^{+}$immature $\mathrm{B}$ lymphocytes. Hardy and colleagues proposed a different scheme (Hardy et al, 1991). Hardy utilized a PCR based strategy to detect the status of $\mathrm{lg}$ gene rearrangement and then correlated gene rearrangement with phenotype (CD43, Heat Stable Antigen (CD24), and BP-1 expression). The first genetic event in $B$ lineage cells is rearrangement of the $D$ and $J$ segments of the heavy chain immunoglobulin gene. By Hardy's proposed terminology, this cell is termed a progenitor (pro-) $\mathrm{B}$ cell. Pro-B cells are $\mathrm{B} 22 \mathrm{O}^{\mathrm{lo}}$ and $\mathrm{CD} 43^{+}$. In vitro, pro-B cells have long-term proliferative capacity in the presence of stromal cells and interleukin-7 (IL-7). He further divided the pro-B cell stage into Fraction $A$, Fraction $B$, Fraction $C$, and Fraction $C$ ' based on BP-1 and heat stable antigen (HSA) expression. Fraction A cells are the most primitive and lack expression of either HSA or BP-1. Fraction B cells express HSA but not BP-1 while Fraction $C$ cells express both HSA and BP-1. Fraction C' differs from Fraction $\mathrm{C}$ by expressing higher levels of HSA. Cells are classified as pre-B cells once complete rearrangement of the heavy chain immunoglobulin gene (the $\mathrm{V}$ segment is joined to the D-J segment) occurs and the heavy chain is expressed in the cytoplasm of the developing cell. During the pre-B cell stage the heavy chain, $\mu$, is expressed on the surface of the cell in conjunction with a surrogate light chain. The surrogate light chain is comprised of two molecules, $V$ pre $B$ and $\lambda 5$. The surrogate light chain is expressed on the surface of the pre-B cell in conjunction with $\lg \alpha$ and $\beta$. The pre-B cell has lost some of its proliferative capacity and is less dependent on stromal cells and IL-7. In addition, the pre-B cell has lost expression of CD43 on the cell surface. Then, the light chain genes of the pre-B cell rearrange. After a functional rearrangement has 
occurred, the heavy and light chains are expressed on the surface of the cell. Phenotypically, cells lose expression of the IL-7 receptor but acquire cell surface expression of immunoglobulin ( $\operatorname{lgM})$. This cell is now classified as an immature or virgin $B$ cell. Immature B cells then leave the bone marrow where a small fraction enters the peripheral B cell pool. After antigen stimulation, the immature B cell further differentiates into a mature $B$ cell expressing $\lg M$ and $\lg D$ on the cell surface.

Hardy and Hayakawa proposed a model for B cell development based on the Osmond scheme, the early Hardy scheme, and other cell surface markers that have recently been discovered on the surface of developing B lymphocytes. The current model proposes 6 developmental stages following the CLP: pre-pro-B (Fraction A), pro-B (Fraction $B / C$ ), large pre-B (Fraction $C^{\prime}$ ), small pre-B (Fraction $D$ ), new-B (Fraction $E$ ), and mature $\mathrm{B}$ (Fraction F). Pre-pro-B cells are $\mathrm{B}_{220^{+}}, \mathrm{CD}^{2} 3^{+}, \mathrm{HSA}^{\mathrm{lo}}, \mathrm{C}^{-\mathrm{kit}^{\mathrm{lo}}}$, $\mathrm{Tdt}^{+}$, $\mathrm{AA} 4.1^{+}, \mathrm{IL}-7 \mathrm{R} \alpha^{+}, \mathrm{CD} 19^{-}$, and have immunoglobulin genes in germline configuration.

Pro-B cells retain the markers that pre-pro-B cells have but they also acquire CD19, $\lg \alpha$ and $\beta$, surrogate light chain, Rag 1 and 2 , and higher levels of HSA. These cells either have their Ig genes in germline configuration or have rearranged the $\mathrm{D}$ and $\mathrm{J}$ loci of the heavy chain gene. The large pre-B cell population phenotypically resembles pro-B cells, but they have acquired BP-1 on the cell surface. However, this cell population has rearranged the $\mathrm{V}, \mathrm{D}$, and $\mathrm{J}$ loci of the heavy chain genes while the light chain genes remain in germline configuration. The small pre-B cell acquires the expression of CD25 and $\mu$ heavy chain, while increasing existing levels of HSA. This population looses expression of CD43, c-kit, surrogate light chain, and TdT. At this stage of development, $B$ lymphocytes rearrange either the kappa or lambda light chain of the immunoglobulin gene. New B cells no longer express BP-1, IL-7R $\alpha, C D 25$, Rag 1, or Rag 2. New B cells have completely rearranged heavy and light chains and they express mu and kappa or lambda. Mature B cells are characterized by the loss of AA4.1 as well as a decrease in HSA expression (Hardy and Hayakawa, 2001). Since this is the most recent model proposed that considers all the genotypic and phenotypic changes that occur in B lymphopoiesis, this work will refer to stages in B cell development based upon this developmental scheme (see Figure 2). 


\begin{tabular}{|c|c|c|c|c|c|c|c|c|}
\hline & & & re-pro E & Pro-B & Large pre-B & Small pre-B & New B & Mature B \\
\hline AA4.1 & + & + & + & + & + & + & + & \\
\hline B220 & & & + & + & + & + & + & + \\
\hline CD43 & + & + & + & + & + & & & \\
\hline HSA & lo & lo & med & med & hi & hi & hi & lo \\
\hline BP-1 & & & & & + & + & & \\
\hline C-kit & + & + & lo & + & + & & & \\
\hline IL-R $\alpha$ & & + & lo & + & + & + & & \\
\hline CD19 & & & & + & + & + & + & + \\
\hline CD25 & & & & & + & + & & \\
\hline $\lg \alpha / \beta$ & & & & + & + & + & + & + \\
\hline SLC & & & & + & + & & & \\
\hline $\operatorname{Rag} 1 / 2$ & & & & + & & + & & \\
\hline TdT & & + & + & + & & & & \\
\hline \multicolumn{9}{|c|}{$\mathrm{V}_{\mathrm{H}}-\mathrm{D}_{\mathrm{H}}-\mathrm{J}_{\mathrm{H}}$ Rearranged } \\
\hline & & & & & & $V_{L}-J_{L}$ Rearr & ged & \\
\hline
\end{tabular}

Figure 2. Model of B lineage development. Model depicts hematopoietic stem cell development (HSC) through mature B cell development. Expression of cell surface markers and progression of immunoglobulin gene rearrangement are shown. Cell surface markers are described as follows: 


$\begin{array}{ll}\text { AA4.1 } & \text { Cell surface antigen recognized by the AA4.1 antibody } \\ \text { B220 } & \text { 220kD from of CD45 restricted to expression in B lineage cells } \\ \text { CD43 } & \text { Leukosyalin } \\ \text { HSA } & \text { Heat stable antigen } \\ \text { BP-1 } & \text { B lineage restricted glycoprotein } \\ \text { C-kit } & \text { Stem cell factor receptor } \\ \text { IL-7R } \alpha & \alpha \text { chain of the interleukin-7 (IL-7) receptor } \\ \text { CD19 } & 90 \text { kD B cell specific cell surface antigen } \\ \text { CD25 } & \text { Interleukin-2 (IL-2) receptor } \alpha \text { chain } \\ \text { Ig } \alpha / \beta & \text { Anchor the pre-B cell receptor and assist in signaling } \\ \text { SLC } & \text { Surrogate light chain of the pre-B cell receptor } \\ \text { Rag 1/2 } & \text { Recombinase activating genes } \\ \text { TdT } & \text { Terminal deoxynucleotidyl transferase; gene encoding machinery for } \\ & \text { immunoglobulin gene rearrangement; expressed only in bone marrow }\end{array}$

Adapted from Hardy and Hayakawa, 2001. 
The survival, proliferation, and differentiation of B lymphocytes depend on the hematopoietic microenvironment provided in the bone marrow. This microenvironment provides both particular cell types and cytokines that are necessary for B lymphocyte maturation. In particular, B cells in the bone marrow develop in close association with surrounding, non-hematopoietic, fibroblastic mesenchymal stromal cells found in the intrasinusoidal spaces of the bone marrow, indicating that cell-to-cell contact may be necessary for B cell development. In fact, studies of the bone marrow have revealed a close, physical association is maintained between stromal cells and developing blood cells (Chen and Weiss, 1975). Experiments to delineate the interactions between stromal cells and B lymphocytes have only been possible in recent years. The development of long term cultures of B lymphocytes, as well as the development of stromal cell lines that could support lymphoid cultures in vitro, were required to allow stromal cell/B cell interactions to be dissected (Whitlock and Whitte, 1982 and Johnson and Dorshkind, 1986). The observed close association between early B cells and adherent stromal cell layers led to investigations of the adhesion interactions occurring between the two cell types. It is now apparent that adhesion contacts are necessary for retaining lymphopoietic cells in the marrow environment and for promoting their continued survival. One essential adhesion molecule found on stromal cells is vascular cell adhesion molecule-1 (VCAM-1 or CD106). VCAM-1 is a 170 kDa glycoprotein expressed on the surface of stromal cells that belongs to the immunoglobulin supergene family. VCAM-1 is the ligand for VLA-4, a heterodimer belonging to the integrin family, expressed on the surface of lymphopoietic and myelopoietic cells. The importance of this interaction was demonstrated when antibody that blocked the VLA-4 molecule expressed on lymphoid cells ablated adherence of lymphoid cells to bone marrow stromal cells (Miyake et al, 1991 and Kina et al, 1991).

Literature had clearly indicated that stromal cells were responsible for regulating the survival of early B cells (Johnson and Dorshkind, 1986). To more clearly describe these interactions, Gibson and colleagues described a murine pro-B cell line, C1.92, from day 14 fetal liver that required stromal cells and IL-7 for continued growth. They demonstrated that the model murine pro-B cell line was completely dependent upon stromal cells for continued survival (Gibson, 1993). When cultured in the presence of 
the cloned stromal cell line, S10, for 24 hours pro-B cells maintained high cell viability. However, when pro-B cells were cultured in media alone for 24 hours, their viability was reduced to $5 \%$, indicating that pro-B cells require survival factors provided by stromal cells. Gibson then looked at expression of the proto-oncogene bcl-2, a known antiapoptotic molecule. When pro-B cells were removed from stromal cell culture, there was a rapid decrease in $b c /-2$ mRNA and a corresponding rapid increase in mRNA levels for bax, a known pro-apoptotic molecule. These results suggested that stromal cells control the survival of progenitor B cells by regulating pro- and anti-apoptotic factors (Gibson, 1996).

Previous experiments had demonstrated conclusively that stromal cells were involved in the regulation of $B$ lineage cell survival. However, the factors necessary to promote $B$ cell proliferation and differentiation had still not been elucidated. It was possible that, in addition to providing adhesion interactions and survival signals, stromal cells may also provide proliferative and differentiative signals. The first important interaction to be elucidated was reported in 1988 by Namen et al who demonstrated conclusively that B cell progenitor proliferation was stimulated by a $25 \mathrm{kD}$ stromal cell derived cytokine termed interleukin-7 (IL-7) (Namen et al, 1988). The importance of IL7 in B cell development is underscored by experiments that show blocking the IL-7R or neutralization of IL-7 in the bone marrow results in a developmental B cell block (Sudo et al, 1993 and Grabstein et al, 1993). This observation was confirmed in 1994 when a targeted gene disruption of the IL-7R severely arrested B cell development in the bone marrow of mutant mice (Peschon et al, 1994).

Other cytokines were shown to be important in 1990 when Billips et al demonstrated that the cytokines interleukin-1 (IL-1) and interleukin-4 (IL-4) regulated stromal cell support of pre-B cells. They showed that treating a cloned stromal cell line, S17, with IL-4 or IL-1 completely abrogated the ability of S17 to support pro-B cell development. These data indicated that cytokine levels in the microenvironment influence B cell development, and stromal cells can be the targets of local cytokine influence (Billips et al, 1990). Billips continued to investigate the role of stromal cells in $B$ lymphopoiesis by determining the effect of stromal cell derived cytokines on B cell proliferation and differentiation. IL-7 was known to be the major proliferative cytokine 
produced by stromal cells. It was also known that stromal cells produce other cytokines, including c-kit ligand (KL) (Huang et al, 1990). KL, also known as stem cell factor, serves as a ligand for the tyrosine kinase receptor c-kit that is expressed on hematopoietic cells. Murine models deficient in c-kit or $\mathrm{KL}$ resulted in prenatal lethality in at days 13 to 15 of gestation due to loss of fetal liver hematopoiesis (Russell, 1979). Experiments Billips performed indicated that KL synergized with IL-7 to provide a strong proliferative stimulus to B220+ B-lineage cells. However neither of these cytokines, individually nor in combination, could induce the maturation of $\mathrm{B}^{2} 2 \mathrm{O}^{-}$cells into $\mathrm{B}^{-} 2 \mathrm{O}^{+}$ cells; differentiation of progenitor $B$ cells into pre-B cells required the presence of stromal cells. These data were critical in demonstrating that stromal cells provide separate proliferative and differentiative signals to developing $B$ lineage cells (Billips et al, 1992).

Further experiments revealed that stromal cell derived insulin growth factor-1 (IGF-1) could also potentiate the proliferative effects of IL-7 on B lymphocytes, similar to the synergy observed between IL-7 and KL (Landreth et al, 1992). To further delineate specific stages of $B$ lymphopoiesis that respond to IL-7, KL, and IGF-1, Gibson et al used the murine pro-B cell model, C1.92, discussed previously. These pro-B cells were dependent on stromal cells and IL-7 for continued growth. Gibson demonstrated that IL-7 was absolutely necessary for pro-B cell expansion in culture; however the addition of recombinant KL, IGF-1, or KL/IGF-1 significantly increased the proliferation of the pro-B cells as evidenced by increased tritiated thymidine uptake (Gibson et al, 1993).

Flt3 ligand (FL) is another early hematopoietic growth factor expressed by stromal cells. Like KL and IGF-1, FL stimulated little proliferative activity on its own but could synergize with IL-7 to stimulate progenitor B cell proliferation (Ray et al, 1996). Together, these results suggest that pro-B cell expansion is depended on at least four stromal cell derived cytokines; IL-7 delivers the primary proliferative signal while $\mathrm{KL}$, IGF-1 and FL synergize with IL-7 to increase proliferation. Another chemokine that is expressed constitutively by bone marrow stromal cells is stromal cell derived factor-1 (SDF-1). SDF-1 was shown to stimulate the proliferation of B cell progenitors in vitro (Nagasawa, 1994). Nagasawa continued to explore the function of SDF-1 in lymphopoiesis by developing a mutant mouse model harboring a targeted disruption in 
the SDF-1 gene. The majority of mice lacking the SDF-1 gene expired in utero at day 18.5 of embryogenesis. In mutants that were born, significantly reduced numbers of pro-B and pre-B cells were observed, indicating that SDF-1 was required for the expansion of early B lymphocytes (Nagasawa, 1996). Together, all of these data emphasize the importance of stromal cell derived proliferative signals to normal development of B lymphocytes.

Although signals that regulate B cell proliferation have been proposed, it is clear that these same signals are not solely responsible for directing $B$ cell maturation. On their own, IGF-1 and FL could not stimulate pro-B cell proliferation, although they could cooperate with IL-7 to increase proliferation. However, further insights into these two molecules revealed that they had yet another function. When Landreth et al investigated stromal cell derived IGF-1, they found that treatment of bone marrow cultures with recombinant IGF-1 resulted in cytoplasmic $\mu$ heavy chain expression while treatment with anti-IGF-1 antibody completely ablated stromal cell stimulated pro-B cell differentiation. IGF-1 was necessary and sufficient to stimulate B cell differentiation (Landreth et al, 1992). Ray demonstrated that FL also had an important role in B lineage differentiation. He reported that, in the absence of stromal cells, the growth factor combination of Flt3 ligand, IL-7, and IL-11 was able to support B cell differentiation from early progenitor cells (Ray et al, 1996). These data suggest that FL and IGF-1 play a dual role in B cell development; they potentiate IL-7 induced proliferation and promote $\mathrm{B}$ cell maturation.

Taken together, these data revealed that B cell development is critically dependent on stromal cells and the bone marrow microenvironment. Stromal cell regulation of $\mathrm{B}$ cell development is extremely multifaceted, and in vitro experimental systems may never be completely representative of the complexity of the bone marrow microenvironment. Although many of the mechanisms through which this regulation is exerted have been discovered, the entire scope of genes that stromal cells may regulate, and the specific mechanisms by which stromal cells exert this regulation, are largely unknown. 


\section{REGULATION OF LYMPHOID DEVELOPMENT BY C-MYB}

As previously discussed, several investigators have proposed that c-myb plays a pivotal role in the maturation and development of myeloid cells. However, the role of cmyb in the development of lymphoid cells is less clear. Bender et al (1987) demonstrated that constitutive expression of c-myb was necessary to maintain pre-B leukemic cells in culture and that down regulation of c-myb correlated with partial differentiation of these cells as evidenced by $\mathrm{J}$ chain secretion and decreased levels of $\mathrm{N}-m y c$ and BP-1. This indicated that, as in myeloid cell development, c-myb downregulation was required prior to differentiation (Bender, 1987). Using both the pre$B$ cell lymphoma line that Bender used, as well as a B cell lymphoma line, Catron et al investigated the cell cycle regulation of c-myb mRNA in murine B lymphoid tumors. They found that c-myb expression in the pre-B cell lymphoma was constitutive, but cell cycle regulated in the more mature $B$ cell lymphoma line. The authors suggested that $c-$ myb may be constitutively expressed in immature, highly proliferative cells but cell cycle regulated in more mature, differentiated cells, therefore exerting its effects by switching from a constitutive to a cell cycle mode of regulation as lymphoid cells mature (Catron et al, 1992).

Most work done on the role of c-myb in lymphoid development has focused on T lymphocytes. During $T$ cell development, the earliest committed $T$ cell precursor that migrates from the bone marrow to the does not express CD4, CD8, or the $T$ cell antigen receptor (TCR) (triple negative cell). The most immature double negative (DN) thymocyte is CD44 ${ }^{\mathrm{lo}} \mathrm{CD} 25^{-}$. These cells retain the ability to develop into $\mathrm{T}$ and $\mathrm{B}$ lymphocytes as well as NK and dendritic cells (Guidos et al, 1989, Wu et al, 1991). This cell then matures into the $C D 44^{+} \mathrm{CD} 25^{-}$population that begins to rearrange $\mathrm{T}$ cell receptor $\beta$ genes (Godfrey et al, 1993). During T cell receptor gene rearrangement, the DN cell acquires CD25 and becomes $C D 44^{+} \mathrm{CD} 25^{+}$. After the $\mathrm{T}$ cell expresses a functional T cell receptor $\beta$ chain, CD25 is downregulated and CD4 and CD8 are coexpressed on the surface of the cell. The $\mathrm{CD} 4^{+} \mathrm{CD} 8^{+}$cell is termed a double positive (DP) thymocyte. The DP stage is the time when thymocytes undergo the repertoire selection process (Bevan et al, 1994). T cells surviving the selection process then 
downregulate either CD4 or CD8 to become mature single positive (SP) T cells (Robey and Fowlkes, 1994). During T cell maturation, c-myb is expressed at high levels in immature thymocytes found in the thymic cortex (Churilla et al, 1989). As in myeloid development, c-myb levels decrease in T cells as they mature. However, when resting $\mathrm{T}$ cells in the periphery are stimulated to proliferate after antigen exposure, c-myb becomes active again (Stern and Smith, 1986). As the activated T cells undergo G1 progression c-myb expression peaks, indicating that c-myb expression is required for entry into S phase (Gewirtz, 1989).

Direct study of c-myb in thymocyte development has been complicated by the embryonic lethality of the c-myb null mouse. In order to circumvent this problem, Badiani et al used a Myb DNA-binding domain linked to the Drosophila Engrailed transcription repressor domain to act as a dominant interfering Myb. This allowed investigation of the effects of loss of c-myb expression on T cell development. When the dominant negative myb was expressed in transgenic mice, $T$ cell development was severely disrupted. The thymii of myb deficient animals were very small, malformed, and had 20 times less thymocytes than normal. Flow cytometric analysis revealed that thymic cells in c-myb deficient mice were arrested at the DN to DP transition. This stage in thymocyte development is characterized by rapid expansion and loss of c-myb inhibited this process of proliferative expansion. In addition, thymocytes isolated from these animals were compromised in their proliferative response to mitogen stimulation, consistent with the notion that c-myb is involved in thymocyte proliferation (Badiani et al, 1994). Salomoni et al used a CTLL-2 T-cell line to further determine the function of Cmyb in T cell development. When IL-2 dependent, cytotoxic T lymphocytes (CTLL-2) were transfected with constitutively active myb or c-myb antisense, CTLL-2 cells proliferated when exposed to low levels of IL-2 and were less susceptible to apoptosis induced by dexamethasone or withdrawal of IL-2. Although c-myb overexpression did not confer IL-2 independence, it did lower the threshold of IL-2 necessary for CTLL-2 cell proliferation and survival. The resistance to apoptosis observed in cells with overexpressed c-myb was also accompanied by an up-regulation of $b c l-2$ expression. CTLL-2 cells expressing the antisense construct were not able to proliferate in low levels of IL-2 and they underwent apoptosis more quickly after treatment with 
dexamethasone or withdrawal of IL-2 than did control cultures. These data suggest that c-myb is involved in regulating the survival of T cells and that c-myb may protect $\mathrm{T}$ cells from apoptosis by inducing bcl-2 expression (Salomoni, 1997).

RAG-1 and RAG-2 gene products are essential components of site-specific DNA recombination events in lymphocytes (Oettinger, 1990). These molecules make up the recombinase complex which recognizes specific nucleotide sequences flanking rearranging gene segments, termed recombination signal sequences (RSS), and introduce DNA breaks between these signals and DNA segments (Gellert et al, 1997). RAG-1 and RAG-2 are expressed at high levels in the earliest $T$ and $B$ cell progenitors until assembly of the $T$ cell receptor $\beta$ chain or the lg heavy chain gene is complete (Grawunder et al, 1995 and Wilson et al, 1994). A mutation in either the RAG-1 or RAG-2 gene completely blocks lymphocyte development at an early progenitor stage by preventing V-D-J recombination (Mombaerts et al, 1992 and Shinikai et al, 1992). Since Rag $1^{-1-}$ mice are unable to generate mature lymphocytes due to lack of a functional antigen receptor gene rearrangements, implanting ES cells from c-myb wild type or null animal allowed the role of c-myb in lymphopoiesis to be directly examined (Allen et al, 1999). C-myb wild type ES cells implanted into Rag deficient animals developed into mature lymphocytes bearing cell surface immunoglobulin. Conversely, c-myb ${ }^{-/}$ embryonic stem cells implanted into Rag $1^{-1-}$ animals were not able to reconstitute the spleen with mature $B 220^{+} \mathrm{mlgM}^{+} \mathrm{B}$ cells and less mature $\mathrm{B} 220^{+} \mathrm{CD} 43^{+}$cells could not be detected in the bone marrow. This indicates that ES hematopoietic stem cells from c-my $b^{-/}$animals cannot commit to $\mathrm{B}$ lineage development. It was also determined that C-myb -/- ES cells were not capable of TCR gene rearrangements, resulting in a developmental block at the $\mathrm{CD} 44^{\mathrm{lo}} \mathrm{CD} 25^{-}$double negative $\mathrm{T}$ cell stage. These data indicate the early developmental progression of both $\mathrm{T}$ and $\mathrm{B}$ lymphocytes is dependent on c-myb (Allen et al, 1999).

Since both the expression of c-myb and the RAG genes are necessary for lymphocyte development, Wang et al looked at the role of c-myb in regulating RAG gene expression. C-myb is known to regulate a wide variety of genes, and Wang et al identified a consensus c-myb binding site within the RAG-2 promoter region. Investigation of this site revealed that c-myb could transactivate RAG-2 by binding to 
this region and that this transactivation was critical for RAG-2 activity in T lymphocytes (Wang et al, 2000). These data correlate well with observation that immature thymocytes in the cortex express RAG-1 and RAG-2, since they are undergoing V-D-J recombination at the TCR loci, as well as high levels of c-myb mRNA. It was not known, however, if c-myb regulated RAG expression in developing $B$ cells as well as in T cells. Kishi et al determined that c-myb does bind to the RAG-2 promoter in B cells. But, c-myb binds cooperatively with the $B$ lineage specific transcription factor Pax- 5 to synergistically activate the RAG-2 promoter in B cells. In addition, their studies revealed that there is direct protein-protein interaction between c-myb and Pax-5, and that this interaction required the C-terminal region of $c-m y b$. This is the first evidence that the hematopoietic specific transcription factor c-myb can cooperate with a B lineage specific transcription factor, such as Pax-5, to activate genes necessary for lymphoid development (Kishi et al, 2002). These data suggest that c-myb is essential for RAG-2 activation in both $B$ and $T$ lymphocytes and therefore regulates the process of antigen receptor gene rearrangements.

The majority of information presented here describes the role of c-myb in T cell development and parallels cannot always be drawn between $\mathrm{T}$ and $\mathrm{B}$ lymphoid maturation. B lymphocytes develop in conjunction with stromal cells in the bone marrow microenvironment. Because of this, the regulation of c-myb in B lymphocyte development may differ greatly from that of $T$ lymphocytes. Stromal cells have been shown to regulate many other genes involved in B cell development, and they may also be involved in the regulation of c-myb. Our work is intended to investigate the role of cmyb in B lymphoid development and to better understand the role that stromal cells may play in regulating c-myb.

\section{MYB FAMILY MEMBERS}

In addition to c-myb, there are two other members of the Myb family of proteins. Like c-myb, both a-myb and b-myb are thought to be involved in the regulation of cellular proliferation. A-myb and b-myb share extensive sequence homology with cmyb, but they are expressed in a number of different tissues. Some tissues, however, 
express more than one member of the myb family. A-myb and b-myb also encode for nuclear DNA binding proteins that are 95kDa (751 amino acids) and 93kDa (704 amino acids) respectively. All 3 members of the Myb family have a similar structure. Like Cmyb, A- and B-myb have a DNA binding domain, transactivation domain, and a regulatory domain. A-myb has a negative regulatory domain like C-myb while B-myb has only a regulatory domain. In addition, all Myb family members bind to the same consensus DNA sequence, but they have distinct preferences for nucleotides flanking the core binding site (Howe and Watson, 1991 and Golay et al, 1994). This differential binding may explain the distinctive biological functions of the Myb family genes.

A-myb is expressed in a tissue-specific fashion. The A-myb protein is primarily found in breast epithelial cells of pregnant mice and in male germ cells. A-myb has also been detected in ovaries, brain, and germinal center B cells (Mettus et al, 1994, Trauth et al, 1994). DeRocco et al showed in 1997 that mice over expressing the A-myb protein develop hyperplasia of the spleen and lymph nodes. These mice exhibited increased DNA synthesis and a polyclonally expanded B cell population (DeRocco et al, 1997). Development of a homozygous null mutant mouse deficient in a-myb revealed knockout mice are smaller and grow at a decreased rate than wild type littermates. As the mice mature, the males become sterile. Female a-myb mutant mice can carry and deliver offspring, but they exhibit abnormal mammary function and are not able to nurse the pups. Taken together, these data suggest that a-myb may serve as a mediator of proliferation in certain cell types (Toscani et al, 1997).

$\mathrm{B}-m y b$ is the least conserved member of the Myb family. Unlike a- and c-myb, bmyb does not demonstrate tissue tropism. Expression of B-myb protein has been found ubiquitously in all tissues studied (Golay et al, 1991 and Kamano et al, 1995). B-myb is the only member of the Myb family expressed during very early (before day 10) murine embryogenesis (Sitzmann et al, 1996). In 1992, Arsura and colleagues used b-myb antisense oligonucleotides to inhibit the proliferation of myeloid and lymphoid cells. Expression of b-myb is correlated directly with the induction of cellular proliferation in $\mathrm{B}$ and $\mathrm{T}$ lymphocytes, and over expression of b-myb results in increased numbers of cells in S phase of the cell cycle (Golay et al, 1991 and Lam et al, 1992). Thus, alterations in the amount of b-myb present in cells correlates with altered cellular proliferation. 


\section{SUMMARY}

The current literature ascribes an important role to c-myb in hematopoiesis. C$m y b$ is expressed in immature hematopoietic cells and highly proliferative cells. C-myb is necessary for the proliferation of myeloid and erythroid cells. Down regulation of cmyb is critical for the maturation of myeloid and erythroid progenitors into mature end cells. Over expression of c-myb retains myeloid cells in a proliferative state and inhibits differentiation. In lymphocyte development, c-myb is required for the proliferation of thymocytes. C-myb over expression promotes the survival of $T$ cells when treated with dexamethasone by up regulating the anti-apoptotic $b c l-2$ gene. C-myb also regulates $T$ cell differentiation by binding to the RAG-2 gene that controls antigen receptor gene rearrangement. Less is known about the role of c-myb in B lymphocyte development. B lymphocytes are dependent on stromal cells for signals that regulate survival, proliferation, and differentiation. We have developed an early pro-B cell line that is dependent on stromal cells and IL-7 for continued survival and proliferation as a model to study stromal cell/B cell interactions. These cells continue to proliferate in culture, but have not been shown to differentiate in vitro. The work presented in this dissertation will demonstrate that the pro-B cell line, $\mathrm{C} 1.92$, is characterized by c-myb expression. Our work will determine the degradation kinetics of c-myb mRNA and protein in pro-B cells and compare that with the known kinetics of c-myb in myeloid cells. Furthermore, our work aims to determine whether stromal cells are responsible for maintaining c-myb expression in pro-B cells and whether specific adhesion contacts are responsible for this maintenance rather than stromal cell cytokines. In addition, these studies will determine whether c-myb is an intracellular regulator of proliferation and differentiation in early pro-B cells, or an intracellular regulator of cell survival. Finally, we will investigate c-myb knockout mice to better understand how loss of c-myb expression during embryonic development impacts fetal liver lymphopoiesis. We will also utilize a mouse model deficient for a-myb to determine if one member of the myb family can compensate for the loss of another member during fetal lymphopoiesis. 


\section{RESEARCH OBJECTIVES}

The main goal of the work presented in this dissertation is to understand the role of c-myb in development of B lymphocytes. Current literature has clearly established a putative role for c-myb in proliferation and differentiation of a vast array of developmental cell types, including erythroid, myeloid, and T lymphoid cells. However, there is a significant lack of fundamental information about the role of myb in B lymphoid development. This project will explore the normal expression patterns of myb in developing $B$ lymphocytes, determine if the hematopoietic microenvironment is able to regulate the expression of myb during lymphopoiesis, and determine the role c-myb plays in B lymphocyte maturation. This dissertation will address the following objectives:

1. Determine the normal expression patterns of c-myb in cells of the developing $B$ lineage. The following studies investigate the expression of $c-$ myb in progenitor B cells. It is well documented that immature myeloid cells require expression of c-myb early in development for normal proliferative capacity, but also require c-myb to be downregulated for terminal differentiation. This study will determine whether developing B lymphocytes also require molecular changes in c-myb for normal proliferation and differentiation. In addition, this study will determine the half-life of c-myb mRNA and protein in progenitor B cells and compare that with the known degradation kinetics of c-myb in myeloid cells. Knowing the half-life of c-myb mRNA and protein will allow this work to examine c-myb regulation at biologically relevant time points.

\section{Determine whether stromal cells regulate the expression of $c-m y b$ in pro-B} cells. The role of bone marrow stromal cells as regulatory elements of $B$ cell development has been firmly established since they are known to regulate several genes expressed by developing B lymphocytes. These studies will determine whether stromal cells maintain c-myb levels in highly proliferative, pro$B$ cells. Stromal cells regulate gene expression both by adhesion contacts and by producing numerous cytokines. We will determine whether c-myb mRNA 
levels are maintained by specific stromal cell adhesion contacts or by stromal cell derived cytokines.

3. Determine whether $c-m y b$ is an intracellular regulator of proliferation in developing B lymphocytes. C-myb is known to be a regulator of proliferation in myeloid, erythroid, and T cells. Several studies have also indicated that c-myb regulates proliferation in transformed murine B cells. These studies will determine if $c-m y b$ regulates proliferation of $B$ cell progenitors.

4. Determine whether $c-m y b$ is an intracellular regulator of differentiation in developing B lymphocytes. Recently studies have demonstrated that c-myb binds to the RAG-2 promoter (Kishi et al, 2002), suggesting that c-myb may regulate maturation of pro-B cells. We will determine whether down regulation of c-myb is required for gene rearrangement of heavy chain immunoglobulin genes.

5. Determine if $\mathbf{c}-\mathbf{m y b}$ is an intracellular regulator of cell survival in developing B lymphocytes. C-myb is known to decrease the sensitivity of $T$ cells to cytokine withdrawal and protect them from apoptotic death. In addition, c-myb over expression correlates with an increase in the expression of the antiapoptotic $b c l-2$ gene in T cells. We will determine whether down regulation of cmyb impacts pro-B cell survival and onset of apoptosis and cell death.

6. Evaluate B lymphopoiesis in myb knockout models. C-myb knockout mice die at day 15 of embryogenesis due to loss of erythropoiesis in the fetal liver. We will determine whether loss of c-myb during embryonic development affects B cell development. In addition, we will utilize animals with mutant a-myb to determine if loss of another myb family member significantly alters B lymphopoiesis in developing embryos. 


\section{REFERENCES}

Abramson S, Miller, RG, Phillips, RA: The identification in adult bone marrow of pluripotent and restricted stem cells of the myeloid and lymphoid systems. J Exp Med $145: 1567,1977$

Akashi K, Traver D, Miyamota T, Weissman IL: A clonogenic common myeloid progenitor that gives rise to all myeloid lineages. Nature 404:193, 2000

Allen RD, Bender TP, Siu G: c-Myb is essential for early T cell development. Genes and Dev13: 1073, 1999

Anton IA, Frampton J: Tryptophans in myb proteins. Nature 336:719, 1988

Arsura M, Introna M, Passerini F, Mantovani A, Golay J: B-myb antisense oligonucleotides inhibit proliferation of human hematopoietic cell lines. Blood 79:2708, 1992

Aurigemma RE, Blair DG, Ruscetti SK: Transactivtion of erythroid transcription factor GATA-1 by a myb-ets-containing retrovirus. J Virol 66:3056, 1992

Badiani P, Corbella P, Kioussis D, Marvel J, Weston K: Dominant interfering alleles define a role for c-Myb in T-cell development. Genes and Dev 8:770, 1994

Barzilay J, Kushtai G, Plaksin D, Feldman M, Eisenbach L: Expression of major histocompatibility class I genes in differentiating leukemic cells is temporally related to activation of c-fos proto-oncogene. Leukemia 1:198, 1987

Bender TP, Kuehl WM: Differential expression of the c-myb proto-oncogene marks the pre-B cell/B cell junction in murine B lymphoid tumors. J Immunol 139:3822, 1987 
Bevan MJ, Hogquist KA, Jameson SC: Selecting the T cell receptor repertoire.

Science 264:796, 1994

Bidenkapp H, Borgmeyer U, Sippel AE, Klempnauer KH: Viral myb oncogene encodes a sequence specific DNA binding activity. Nature 335:835, 1988

Billips LG, Petitte D, Landreth KS: Bone marrow stromal cell regulation of $B$ lymphopoiesis: interleukin-1 (IL-1) and IL-4 regulate stromal cell support of pre-B cell production in vitro. Blood 75:611, 1990

Billips LG, Petitte D, Dorshkind K, Narayanan R, Chiu C-P, Landreth KS: Differential roles of stromal cells, interleukin-7, and kit-ligand in the regulation of $B$ lymphopoiesis. Blood 79:1185, 1992

Boyd AW, Sullivan JR: Leukemic cell differentiation in vivo and in vitro: arrest of proliferation parallels the differentiation induced by the antileukemic drug Harringtonine. Blood 63:384, 1984

Brelvi ZS, Studzinski GP: Coordinate expression of c-myc, c-myb, and histone H4 genes in reversibly differentiating HL 60 cells. J Cell Physiol 131:43, 1987

Brown KE, Kindy MS, Sonenshein GE: Expression of the c-myb proto-oncogene in bovine vascular smooth muscle cells. J Biol Chem 267:4625, 1992

Catron KM, Purkerson JM, Isakson PC, Bender TP: Constitutive versus cell cycle regulation of c-myb mRNA expression correlates with developmental stages in murine $B$ lymphoid tumors. J Immunol 148:934, 1992

Chen J, Bender TP: A novel system to identify myb target promoters in friend murine erythroleukemia cells. Blood Cell Mol Disease 27:429, 2001 
Chen LT, Weiss L: The development of vertebral bone marrow of human fetuses. Blood 46:389, 1975

Churilla AM, Braciale TJ, Braciale VL: Regulation of T lymphocyte proliferation. Interleukin 2-mediated induction of c-myb gene expression is dependent on T lymphocyte activation state. J Exp Med 170:105, 1989

Clark MF, Kukowska-Latallo JF, Westin E, Smith M, Prochownik EU: Constitutive expression of a c-myb cDNA blocks friend murine erythroleukemia cell differentiation. Mol Cell Biol 8:884, 1988

Collins SJ, Gallo RC, Gallagher RE: Continuous growth and differentiation of human myeloid leukaemic cells in suspension culture. Nature 27:347, 1977

Cumano A, Ferraz JC, Klaine M, Di Santo JP, Godin I: Intraembryonic, but not yolk sac hematopoietic precursors, isolated before circulation, provide long-term multilineage reconstitution. Immunity 15:477, 2001

Cumano A, Godin I: Pluripotent hematopoietic stem cell development during embryogenesis. Curr Opin Immunol 13:166, 2001 a

DeRocco SE, lozzo R, Ma XP, Schwarting R, Peterson D, Calabretta B: Ectopic expression of A-myb in transgenic mice causes follicular hyperplasia and enhanced $B$ lymphocyte proliferation. PNAS 94:3240, 1997

Dini PW, Lipsick JS: Oncogenic truncation of the first repeat of c-Myb decreases DNA binding in vitro and in vivo. Mol Cell Biol 13:7334, 1993

Dorshkind K: Regulation of hemopoiesis by bone marrow stromal cells and their products. Annu Rev Immunol 8:111, 1990 
Ehrlich P: Ueber die specifischen Granulationen des Blutes. Arch Anat Physiol, Physiol Abt 571, 1879

Ehrlich P, Lazarus A: Normale und Pathologische Histologie des Blutes, vol 1, Die Anamie, Vienna, Holder , 1898

Evans JT, Moore TL, Kuehl WM, Bender T, Ting JPY: Functional analysis of c-Myb protein in T-lymphocytic cell lines shows that it trans-activates the c-myb promoter. Mol Cell Biol 10:5747, 1990

Favier D, Gonda TJ: Detection of proteins that bind to the leucine zipper motif of c-Myb. Oncogene 9:305, 1994

Gellert M: Recent advances in understanding V(D)J recombination. Adv Immunol 64:39, 1997

Gewirtz AM, Anfossi G, Venturelli D, Valpreda S, Sims R, Calabretta: G1/S transition in normal human T-lymphocytes required the nuclear protein encoded by c-myb. Science 245:180, 1989

Gewirtz AM, Calabretta B: Role of the c-myb and c-abl protooncogenes in human hematopoiesis. Ann NY Acad Sci 628:63, 1991

Gewirtz AM: Antisense oligonucleotides therapeutics for human leukemia. Curr Opin Hematol 5:59, 1998

Gewirtz AM, Calabretta B: A c-myb antisense oligodeoxynucleotide inhibits normal human hematopoiesis in vitro. Science 242: 1303, 1988

Ghia P, Boekel E, Rolink AG, Melchers F: B-cell development: a comparison between mouse and man. Immunol Today 19:480, 1998 
Gibson LF, Piktel D, Landreth KS: Insulin-like growth factor-1 potentiates expansion of interleukin-7-dependent pro-B cells. Blood 82:3005, 1993

Gibson LF, Piktel D, Narayanan R, Nunez G, Landreth KS: Stromal cells regulate bcl-2 and bax expression in pro-B cells. Exp Hematol 24:628, 1996

Godfrey DI, Kennedy J, Suda T, Zlotnik A: A developmental pathway involving four Phenotypically and functionally distinct subsets of CD3-CD4-CD8-triple-negative adult mouse thymocytes defined by CD44 and CD25 expression. J Immunol 150:4244, 1993

Godin IE, Garcia-Porrero JA, Coutinho A, Dieterlen-Lievre F, Marcos MA: Para-aortic splanchnopleura from early mouse embryos contains B1a cell progenitors. Nature 364:67, 1993

Godin I, Garcia-Porrero JA, Dieterlen-Lievre F, Cumano A: Stem cell emergence and hematopoietic activity are incompatible in mouse intraembryonic sites. J Exp Med 190:43, 1999

Golay J, Capucci A, Arsura M, Casetellano M, Rizzo V, Introna M: Expression of C-myb and $\mathrm{B}-m y b$, but not A-myb, correlates with proliferation in human hematopoietic cells. Blood 7:149, 1991

Golay J, Loffarelli L, Luppi M, Castellano M, Introna M: The human A-myb protein is a strong activator of transcription. Oncogene 9:2469, 1994

Gonda TJ, Bishop JM: Structure and transcription of the cellular homolog (c-myb) of the avian myeloblastosis virus transforming gene (v-myb). J Virol 46:212, 1983

Grabstein KH, Waldschmidt TJ, Finkelman FD, Hess BW, Alpert AR, Boiani NE, Namen $A E$, Morrissey PJ: Inhibition of murine $B$ and T lymphopoiesis in vivo by an antiinterleukin 7 monoclonal antibody. J Exp Med 178:257, 1993 
Grawunder U, Rolink A, Melchers F: Induction of sterile transcription from the kappa L chain gene locus in $\mathrm{V}(\mathrm{D}) \mathrm{J}$ recombinase-deficient progenitor $\mathrm{B}$ cells. Int Immunol $7: 1915,1995$

Greco C, Gandolfo GM, Mattei F, Gradilone F, Gradilone A, Alvino S, Pastore LI, Casale V, Casole V, Casole P, Grassi A, Cianciulli AM: Detection of c-myb genetic alterations and mutant p53 serum protein in patients with benign and malignant colon lesions. Anticancer Res 14:1433, 1994

Guidos CJ, Wissman IL, Adkins B: Developmental potential of CD4-8-thymocytes. Peripheral progeny include mature CD4-8-T cells bearing alpha beta T cell receptor. J Immunol 142:3773, 1989

Gurein M, Sheng ZM, Andrieu N, Riou G: Strong association between c-myb and estrogen-receptor expression in human breast cancer. Oncogene 5:131, 1990

Hardy RR, Carmack CE, Shinton SA, Kemp JD, Hayakawa K: Resolution and characterization of pro-B and pre-pro-B cell stages in normal mouse bone marrow. $\mathrm{J}$ Exp Med 173:1213, 1991

Hardy RR, Hayakawa K: B cell development pathways. Annu Rev Immunol 19:595, 2001

Howe KM, Watson RJ: Nucleotide preferences in sequence-specific recognition of DNA by c-myb protein. Nucleic Acids Res 19:3913, 1991

Huang E, Nocka K, Beire DR, Chu T-Y, Buck J, Lahm H-W, Wellner D, Leder P, Besmer P: The hematopoietic growth factor $\mathrm{KL}$ is encoded at the $\mathrm{SI}$ locus and is the ligand of the c-kit receptor, the gene product of the W locus. Cell 63:225, 1990 
Jacobsen LO, Marks EK, Robson MJ, et al: Effect of spleen protection on mortality following x-irradiation. J Lab Clin Med 34:1538, 1949

Johnson A, Dorshkind K: Stromal cells in myeloid and lymphoid long-term bone marrow cultures can support multiple hemopoietic lineages and modulate their production of hemopoietic growth factors. Blood 68:1348, 1986

Jordan CT, Astle CM, Zawadzki J, Mackarehtschian K, Lemischka IR, Harrison DE: Long-term repopulating abilities of enriched fetal liver stem cells measured by competitive repopulation. Exp Hematol 23:1011, 1995

Kamano H, Burk B, Noben-Trauth K, Klempnauer KH: Differential splicing of the mouse B-myb gene. Oncogene 11:2575, 1995

Kanei-IshiiC, Sarai A, Sawazaki T, Nakagoshi H, He DN, Ogata K, Nishimura Y, Ishii S: The tryptophan cluster: a hypothetical structure of the DNA-binding domain of the myb protooncogene product. J Biol Chem 265:19990, 1990

Kanei-Ishii C, Macmillan EM, Nomura T, Sarai A, Ramsay RG, Aimoto S, Ishii S, Gonda $\mathrm{TJ}$ : Transactivation and transformation by Myb are negatively regulated by a leucine zipper structure. PNAS 89:3088, 1992

Kanei-Ishii C, Nomura T, Ogata K, Sarai A, Yasukawa T, Tashiro S, Takahashi T, Tanaka Y, Ishii S: Structure and function of the proteins encoded by the myb gene family. 1995

Kina T, Majumdar AS, Heimfeld S, Kaneshima H, Holzmann B, Katsura Y, Weissman IL: Identification of a 107-kD glycoprotein that mediates adhesion between stromal cells and hematolymphoid cells. J Exp Med 173:373, 1991 
Kincade PW, Lee G, Peitrangeli CE, Hayashi S, Gimble JM: Cells and molecules that regulate $B$ lymphopoiesis in bone marrow. Annu Rev Immunol 7:111, 1989

Kirsch IR, Bertness V, Silver J, Hollis GF: Regulated expression of the c-myb and cmyc oncogenes during erythroid differentiation. J Cell Biochem 32:11, 1984

Kishi H, Jin ZX, Nagata T, Matsuda T, Saito S, Muraguchi A: Cooperative binding of cMyb and Pax-5 activates the RAG-2 promoter in immature B cells. Blood 99:576, 2002

Kondo M, Weissman IL, Akashi K: Identification of clonogenic common lymphoid progenitors in mouse bone marrow. Cell 91:661, 1997

Ku D-H, Wen S-C, Englehard A, Nicolaides NC, Lipson KE, Marion TA, Calabretta B: C-myb transactivation of cdc2 expression via myb binding sites in the 5' flanking region of the human cd2 gene. J Biol Chem 268:2255, 1993

Lam EW, Robinson C, Watson RJ: Characterization and cell cycle-regulated expression of mouse B-myb. Oncogene 7:1885, 1992

Landreth KS, Rosse C, Clagett J: Myelogenous production and maturation of B lymphocytes in the mouse. J Immunol 127:126, 1981

Landreth KS, Kincade PW, Lee G, Gathings WE, Fu SM: Enrichment of human marrow lymphocytes with monoclonal antibodies to murine antigens. PNAS 79:2370, 1982

Landreth KS, Narayanan R, Dorshkind K: Insulin-like growth factor-1 regulates pro-B cell differentiation. Blood 80:1207, 1992

Lipsick JS: One billion years of Myb. Oncogene 13:223, 1996 
Lorenz E, Uphoff D, Reid TR, et al: Modification of irradiation injury in mice and guinea pigs by bone marrow injections. J Natl Cancer Inst 12:197, 1951

Lu M, Kawamoto H, Datsube Y, Ikawa T, Katsura Y: The common myelolymphoid progenitor: a key intermediate stage in hemopoiesis generating T and B cells. J Immu 169:3519, 2002

McClinton D, Stafford J, Brents L, Bender TP, Duehl WM: Differentiation of mouse erythroleukemia cells is blocked by late up-regulation of a c-myb transgene. Mol Cell Biol 10:705, 1990

Medvinsky AL, Samoylina NL, Muller AM, Dzierzak EA: An early pre-liver intraembryonic source of CFU-S in the developing mouse. Nature 364:64, 1993

Melotti P, Ku DH, Calabretta B: Regulation of the expression of the hematopoietic stem cell antigen CD34: role of c-myb. J Exp Med 179:1023, 1994

Metcalf D, Moore MA: Factors modifying stem cell proliferation of myelomonocytic leukemic cells in vitro and in vivo. J Natl Cancer Inst 44:801, 1970

Mettus RV, Litvin J, Wali A, Toscani A, Latham K, Hatton K, Reddy EP: Murine A-myb: evidence for differential splicing and tissue-specific expression. Oncogene 9:3077, 1994

Miyajima I, Levitt L, Hara T, Bedell MA, Copeland NG, Jenkins NA, Miyajima A: The murine interleukin-3 receptor alpha subunit gene: chromosomal localization, genomic structure, and promoter function. Blood 85:1246, 1995

Miyake K, Medina K, Ishihara K, Kimota M, Auerbach R, Kincade PW: A VCAM-like adhesion molecule on murine bone marrow stromal cells mediates binding of lymphocyte precursors in culture. J Cell Biol 114:557, 1991 
Mombaerts P, lacomini J, Johnson RS, Herrup K, Tonegawa S, Papaioannou VE:

RAG-1-deficient mice have no mature B and T lymphocytes. Cell 68:869, 1992

Moore MA, Metcalf D: Ontogeny of the haemopoietic system: yolk sac origin of in vivo and in vitro colony forming cells in the developing mouse embryo. $\mathrm{Br} \mathrm{J}$ Haematol $18: 279,1970$

Morrison SJ, Uchida N, Weissman IL: The biology of hematopoietic stem cells. Annu Rev Cell Dev Biol 11:35, 1995

Mucenski ML, McLain K, Kier AB, Swerdlow SH, Schereiner CM, Miller TA, Pietryga DW, Scott WJ, Potter SS: A functional c-myb gene is required for normal murine fetal hepatic hematopoiesis. Cell 65:677, 1991

Nagasawa T, Kaisho T, Kishimoto T, Kikutani H: Generation and characterization of a monoclonal antibody that inhibits stromal cell-dependent B lymphopoiesis. J Immunol 152:2788, 1994

Nagasawa T, Hirota S, Tachibana K, Takakura N, Nishikawa S, Kitamura Y, Yoshida N, Kikutani $\mathrm{H}$, Kishimoto $\mathrm{T}$ : Defects of B-cell lymphopoiesis and bone-marrow myelopoiesis in mice lacking the CXC chemokine PBSF/SDF-1. Nature 382:635, 1996

Namen AE, Lupton S, Hjerrild K, Wignall J, Mochizuki DY, Schmierer A, Mosley B, March CJ, Urdal D, Gillis S, Cosman D, Goodwin RG: Stimulation of B-cell progenitors by cloned murine interleukin-7. Nature 333:571,1988

Ness SA, Marknell A, Graf T: The v-myb oncogene product binds to and activates the promyelocyte-specific mim-1 gene. Cell 59:1115, 1989

Ness SA: The myb oncoprotein: regulating a regulator. Biochimica et Biophysica Acta 1288:F123, 1996 
Nicolaides NC, Correa I, Casadevall C, Travali S, Soprano KJ, Calabretta B: The Jun family members, c-Jun and JunD, transactivate the human c-myb promoter via an Ap1like element. J Biol Chem 267:19665, 1991

Nomura T, Sakai N, Sarai A, Sudo T, Kanei-Ishii C, Ramsay RG, Favier D, Gonda TJ, Ishii S: Negative autoregulation of c-myb activity by homodimer formation through the leucine zipper. J Biol Chem 268:21914, 1993

Oettinger MA: V(D)J recombination: on the cutting edge. Curr Opin Cell Biol 11:325, 1999

Oettinger MA, Schatz DG, Gorka C, Baltimore D: RAG-1 and RAG-2, adjacent genes that synergistically activate $V(D) J$ recombination. Science $248: 1517,1990$

Osgood EE: A unifying concept of the etiology of the leukaemias, lymphomas and cancers. J Natl Cancer Inst 18:155, 1957

Osmond DG: B cell development in the bone marrow. Semin Immunol 2:173, 1990

Page KC, Makris JM, Chernin ML: Effects of retinoids on expression of the protooncogene c-myb in rat Sertoli cells. Recent Prog Horm Res 50:465, 1995

Pappenheim A: Abstammung und Entstehung der rotten Blutzelle. Virchows Arch (Pathol Anat) 151:89, 1898

Pappenheim A: Von den gegenseitigen Beziehungen der verschiedenen farblosen Blutzellen zu einander. Virchows Arch (Pathol Anat) 159:40, 1900

Peschon JJ, Morrissey PJ, Grabstein KH, Ramsdell FJ, Maraskovsky E, Gliniak BC, Park LS, Ziegler SF, Williams DE, Ware CB, et al: Early lymphocyte expansion is severely impaired in interleukin 7 receptor-deficient mice. J Exp Med 180:1955, 1994 
Rahal MD, Osmond DG: Maturation of bone marrow lymphocytes. IV. Kinetics of maturation and renewal of lymphocytes expressing la and $\mathrm{H}-2 \mathrm{~K}$ antigens. Immunology 44:463, 1981

Ramsay RG, Ikeda K, Rifkind RA, Marks PA: Changes in gene expression associated with induced differentiation of erythroleukemia: protooncogenes, globin genes, and cell division. PNAS 83:6849, 1986

Ramsay RG, Ishii S, Gonda TJ: Increase in specific DNA binding by carboxyl truncation suggests a mechanism for activation of Myb. Oncogene 6:1875, 1991

Ramsay RG, Morrice N, Van Eeden P, Kanagasundaram V, Nomura T, De Blaquiere J, Ishii S, Wettenhall R: Regulation of c-Myb through protein phosphorylation and leucine zipper interactions. Oncogene 11:2113, 1995

Ray RJ, Paige CJ, Furlonger C, Lyman SD, Rottapel R: Flt3 ligand supports the differentiation of early $B$ cell progenitors in the presence of interleukin-11 and interleukin-7. Eur J Immunol 26:1504, 1996

Reiss K, Travali S, Calabretta B, Baserga R: Growth regulated expression of B-myb in fibroblasts and hematopoietic cells. J Cell Physiol 148:338, 1991

Robey E, Fowlkes BJ: Selective events in T cell development. Annu Rev Immunlo $12: 675,1994$

Rosson D, Dugan D, Reddy EP: Aberrant splicing events that are induced by proviral integration: implications for myb oncogene activation. PNAS 84:3171, 1987

Russell ES: Hereditary anemias of the mouse: a review for geneticists. Adv Genet 20:357, 1979 
Sabin FR: Bone marrow. Physiol Rev 8:191, 1928

Saikumar P, Murali R, Reddy EP: Role of tryptophan repeats and flanking amino acids in myb-DNA interactions. PNAS 87:8452, 1990

Sakura H, Kanei-Ishii C, Nagase T, Nakagoshi H, Gonda TJ, Ishii S: Delineation of three functional domains of the transcriptional activator encoded by the c-myb protooncogene PNAS 86:5758, 1989

Salomoni P, Perrotti D, Martinez R, Franceschi C, Calabretta B: Resistance to apoptosis in CTLL-2 cells constitutively expressing c-Myb is associated with induction of BCL-2 expression and Myb-dependent regulation of bcl-2 promoter activity. PNAS 94:3296, 1997

Sasaki K, Sonoda Y: Histometrical and three-dimensional analyses of liver hematopoiesis in the mouse embryo. Arch Histol Cytol 63:137, 2000

Sczylik C, Skorski T, Ku D-H, Nicolaides NC, Wen S-C, Rudnicka L, Bonati A, Malaguarnera L, Calabretta B: Regulation of proliferation and cytokine expression of bone marrow fibroblasts: role of c-myb. J Exp Med 178:997, 1993

Shinikai Y, Rathbun G, Lam KP, Oltz EM, Stewart V, Mendelsohn M, Charron J, Datta $M$, Young F, Stall AM, et al: RAG-2-deficient mice lack mature lymphocytes owing to inability to initiate $\mathrm{V}(\mathrm{D}) \mathrm{J}$ rearrangement. Cell 68:855, 1992

Siminovitc L, McCulloch EA, Till JE: The distribution of colony-forming cells among spleen colonies. J Cell Comp Physiol 62:327, 1963

Sitzmann J, Noben-Trauth K, Kamano H, Klempnauer KH: Expression of B-Myb during mouse embryogenesis. Oncogene 12:1889, 1996 
Siu G, Wurster AL, Lipsick JL, Hendrick SM: Expression of the CD4 gene requires a Myb transcription factor. Mol Cell Biol 12:1592, 1992

Spangrude GJ, Heimfeld S, Weissman IL: Purification and characterization of mouse hematopoietic stem cells. Science 241:58, 1988

Stern JB, Smith KA: Interleukin-2 induction of T-cell G1 progression and c-myb expression. Science 233:203, 1986

Sudo T, Nishikawa S, Ohno N, Akiyama N, Tamakoshi M, Yoshida H, Nishikawa S: Expression and function of the interleukin 7 receptor in murine lymphocytes. PNAS 90:9125, 1993

Tanikawa J, Yasukawa T, Enari M, Ogata K, Nishimura Y, Ishii S, Sarai A: Recognition of specific DNA sequences by the c-myb protooncogene product: role of three repeat units in the DNA-binding domain. PNAS 90:9320, 1993

Tavassoli M: Studies on hemopoietic microenvironments. Exp Hematol 3:213, 1975

Till JE, McCulloch EA: A direct measurement of the radiation sensitivity of normal mouse bone marrow cells. Radiation Res 14:213, 1961

Toscani A, Mettus RV, Coupland R, Simpkins H, Litvin J, Orth J, Hatton KS, Reddy EP: Arrest of spermatogenesis and defective breast development in mice lacking A-myb. Nature 386:713, 1997

Trauth K, Mutschler B, Jenkins NA, Gilbert DJ, Copeland NG, Klempnauer KH: Mouse A-myb encodes a trans-activator and is expressed in mitotically active cells of the developing central nervous system, adult testis, and B lymphocytes. EMBO J 13:5994, 1994 
Wang D-M, Lipsick JS: Mutational analysis of the transcriptional activation domains of v-Myb. Oncogene 21:1611, 2002

Wang QF, Lauring J, Schlissel MS: c-Myb binds to a sequence in the proximal region of the RAG-2 promoter and is essential for promoter activity in T-lineage cells. Mol Cell Biol 20:9203, 2000

Westin EH, Gallo RC, Arya SK, Eva A, Souza LM, Baluda MA, Aaronson SA, WongStaal F: Differential expression of the amv gene in human hematopoietic cells. PNAS 79:2194, 1982

Whitlock CA, Witte ON: Long-term culture of B lymphocytes and their precursors from murine bone marrow. PNAS 79:3608, 1982

Wilson A, Held W, MacDonald HR: Two waves of recombinase gene expression in developing thymocytes. J Exp Med 179:1355, 1994

Wintrobe MM: Blood, Pure and Eloquent, McGraw-Hill. New York 1980

Wu AM, Till JE, Siminovitch L, McCulloch EA: A cytological study of the capacity for differentiation of normal hemopoietic colony-forming cells. J Cell Physiol 69:177, 1967

Wu L, Antica M, Johnson GR, Scollay R, Shortman K: Developmental potential of the earliest precursor cells from the adult mouse thymus. J Exp Med 174:1617, 1991

Yancopoulos GD, Alt FW: Regulation of the assembly and expression of variableregion genes. Annu Rev Immunol 4:339, 1986 


\section{Chapter 2}

Stromal Cells Regulate Expression of the Proto-oncogene C-myb in Pro-B Cells 


\begin{abstract}
B lymphocytes are continually produced throughout life in the bone marrow from pluripotential hematopoietic stem cells. Lymphopoiesis is characterized by a series of highly regulated genotypic and phenotypic changes that conclude with expression of cell surface immunoglobulin on immunocompetent B cells. Pro-B cell survival, proliferation, and differentiation of $B$ cell progenitors require a series of interactions with fibroblastic stromal cells in the hematopoietic microenvironment. However, specific molecular mechanisms that regulate progression of B lymphoid development are poorly understood. In this study we utilized a pro-B cell clone derived from 14-day fetal liver by continuous in vitro passage in the presence of bone marrow stromal cells and recombinant interleukin-7 (rIL-7). The cloned pro-B cell line remains dependent on the presence of stromal cells for survival, does not form tumors in vivo, and reconstitutes B lymphocytes in severe combined immunodeficient (SCID) mice. However, pro-B cells clones are characterized by rapid and continuous proliferation and high expression levels of the oncogene c-myb. Although several laboratories have proposed a role for c-myb in myelopoiesis, virtually nothing is known about the physiologic function of cmyb in developing $B$ lineage cells. Studies described here are aimed at determining whether stromal cells regulate expression of c-myb in developing B lymphocytes. Pro-B cells removed from stromal cells decreased c-myb mRNA and protein levels. Experiments utilizing a transwell cell culture system demonstrated that stromal cell adhesion was required for maintenance of c-myb expression. Down regulation of c-myb correlated with genotypic maturation, progressive immunoglobulin gene rearrangement, reduced proliferative capacity, and $\mathrm{G}_{0} / \mathrm{G}_{1}$ cell cycle blockade.
\end{abstract}




\section{INTRODUCTION}

Hematopoiesis describes the continual development of functional blood cells from pluripotential hematopoietic stem cells. Hematopoietic stem cells (HSC) retain self-renewal capacity and the potential to generate cells of the erythroid, myeloid, and lymphoid lineages. HSCs primarily reside in the bone marrow of post-natal mammals. However, during embryonic development, hematopoietic stem cells are first found in the aorta/gonad/mesonephros (AGM) region (Kincade, 1989). From the AGM region, HSCs migrate into the liver of the developing embryo (Cumano, 2001; Moore 1970). It is within the fetal liver that hematopoietic stem cells differentiate into committed lymphoid and myeloid progenitor cells (Godin, 1999). Progenitor cells are distinguished from HSCs by loss of self-renewal capacity and commitment to lineage specific development. During postnatal life, lymphoid and myeloid progenitors differentiate through a series of committed developmental stages to form non-proliferating effector cells. Effector cells have a finite lifespan, and they are continuously regenerated from committed progenitor cell populations in hematopoietic tissues.

The bone marrow is established as the primary site of hematopoiesis shortly before birth, and this remains the primary hematopoietic organ throughout postnatal life (Sabin, 1928; Micklem, 1966; Tavassoli, 1975). The bone marrow is composed of packed hematopoietic cells interspersed with a meshwork of non-hematopoietic cells termed stromal cells. Fibroblastic stromal cells within the bone marrow are necessary for hematopoiesis. Stromal cells support early cell development by providing adhesion molecules that interact with receptors on developing hematopoietic cells (Johnson and Dorshkind, 1986; Witte, 1987). In addition, stromal cells secrete cytokines into the marrow environment including interleukin-7 (IL-7) and c-kit ligand (stem cell factor) (Billips, 1992). These stromal cell products are necessary for continued lymphopoiesis (Sudo, 1989; Dorshkind, 1990).

The Myb family of proteins is a group of transcription factors that bind DNA and

were first identified as part of avian myeloblastosis virus. V-myb protein is a constitutively active, mutated, and truncated form of C-myb, a product of the c-myb proto-oncogene. The $c$-myb proto-oncogene encodes a $75 \mathrm{kDa}$ nuclear protein that 
binds to a consensus sequence of DNA [(T/C)AAC (T/G)G ] (Bidenkapp, 1988). C-myb expression is high in the most immature hematopoietic cells, but levels of c-myb decrease as immature cells differentiate into more mature progeny (Lipsick, 1996). Cmyb expression and regulation is necessary for normal hematopoietic development. Inhibiting c-myb expression in hematopoietic cells using anti-sense oligonucleotides causes growth arrest, while over-expressing c-myb results in leukemia (Westin, 1982 and Gewirtz, 1988). In 1982, Westin et al investigated c-myb expression in a human promyelocytic leukemic cell line (HL-60). They determined that myeloid cells could be held in a proliferative state when c-myb was over-expressed and induced to differentiate when c-myb was downregulated (Westin, 1982). These data suggest a critical role for $c-m y b$ in myelopoiesis. The development of a mouse model with a homozygous mutant c-myb gene confirmed these data. Animals with homozygous interruption of c-myb transcription were normal at day 13 of gestation, but by day 15 were severely anemic and expired in utero. These animals exhibited a complete loss of erythropoiesis in the fetal liver (Mucenski, 1991). These in vivo observations substantiate the role of c-myb in maintenance of myelopoiesis. While the importance of c-myb in myelopoiesis has been clearly established, the role of c-myb in lymphopoiesis has been suggested but less defined.

Survival, proliferation, and differentiation of B lymphocytes depend on the hematopoietic microenvironment provided in bone marrow (Dorshkind, 1990). Expansion of pro-B cells is dependent on cytokines produced by bone marrow stromal cells. Interleukin-7 (IL-7) is a stromal cell derived cytokine that provides the major proliferative stimulus for pro-B cells (Lee, 1989; Sudo,1989). Several other bone marrow derived cytokines, including insulin-like growth factor-1 (IGF-1), stem cell factor, and flt-3 ligand, also regulate pro-B cell expansion by synergizing with IL-7 to maximize pro-B cell proliferation (Gibson, 1993 and Ray, 1996). In addition to producing cytokines that regulate proliferation stromal cells produce cytokines, including IGF-1, that regulate differentiation. Stromal cells also regulate the survival of pro-B cells. Adhesion contacts between stromal cells and pro-B cells control expression of the anti-apoptotic bcl-2 gene, as well as the pro-apoptotic bax gene, in pro-B cells (Gibson, 1996). While many of the interactions between stromal cells and pro-B cells have been elucidated, 
the total spectrum of genes and cytokines that influence pro-B cell survival, proliferation, and differentiation has not yet been determined.

In this study, the role stromal cells play in pro-B cell development is further investigated. These experiments are aimed at determining whether stromal cells are responsible for c-myb expression and regulation in pro-B cells. The goals of this project were to explore the normal expression patterns of c-myb in developing B lymphocytes, to determine the expression kinetics of c-myb in pro-B cells, and to determine whether the hematopoietic microenvironment regulated expression of c-myb in these cells. ProB cells cultured without stromal cells down regulated c-myb expression, withdrew from cell cycle, and genotypically matured. These data demonstrate that c-myb expression in pro-B cells is regulated by stromal cells.

\section{MATERIALS AND METHODS}

Cell Lines and Cytokines. A panel of pro-B cell lines was derived from normal Balb/C mice. Isolation of pro-B cell lines has previously been described in detail (Gibson, 1993). Briefly, fetal livers were removed from murine embryos at day 14 of gestation. Fetal livers were dispersed into single cell suspension and the nonadherent cells were passaged in the presence of a cloned bone marrow stromal cell line, $\mathrm{S} 10$, and $50 \mathrm{U} / \mathrm{mL}$ of recombinant murine interleukin-7 (IL-7, Biosource International). The fetal liver cells were then cloned at limiting dilution in the presence of S10 and IL-7. One of the resulting clones, $\mathrm{C} 1.92$, is utilized in these studies. $\mathrm{C} 1.92$ cells were maintained in $\alpha-$ modification of Eagle's medium ( $\alpha$-MEM) supplemented with $5 \%$ fetal calf serum (Summit, loł\# 30P14), 1\% penicillin/streptomycin, 1\% I-glutamine, and $0.1 \% 2$ Mercaptoethanol in the presence of $\mathrm{S} 10$ and $50 \mathrm{U} / \mathrm{mL}$ of IL-7.

S10 stromal cells were a generous gift from Dr. Kenneth Dorshkind (University of California). Isolation and biological characteristics of $\mathrm{S} 10$ have been previously described in detail (Collins and Dorshkind, 1987). S10 cells were maintained in $\alpha$-MEM media, supplemented as described above, and grown to confluence in $75 \mathrm{~cm}^{2}$ flasks. They were passaged weekly by trypsinization $(0.25 \%$, GIBCO). 
Transwell Cell Cultures. C1.92 cells were cultured for 24 hours in 6 well plates directly in contact with a confluent adherent layer of $\mathbf{S 1 0}$ stromal cells or separated from stromal cells in the same culture well by use of a cellulose $0.45 \mu \mathrm{m}$ microporous membrane transwell (Millicell-HA, Millipore, Bedford, MA). All cultures were supplemented with $50 \mathrm{U} / \mathrm{ml}$ IL-7. After 24 hours, cells were harvested, enumerated, and cell viabilities were assessed.

Cell Counts and Viability assay. After incubation with direct stromal cell support, without stromal cell support, or separated from stromal cell support by a transwell, C1.92 cells were removed from culture, diluted with an equal volume of $0.4 \%$ trypan blue (Sigma), and counted in a hemacytometer. Total cells in culture and viability were calculated from hemacytometer counts.

RNA Isolation. After culture, $2 \times 10^{6} \mathrm{C} 1.92$ cells were harvested, washed with $\mathrm{PBS}$, and frozen in liquid nitrogen. Total RNA was extracted using the SNAP RNA isolation kit (Invitrogen). After isolation, RNA was quantitated using a spectrophotometer and quartz cuvettes. $0.1 \mu \mathrm{g}$ of total RNA was amplified simultaneously for c-myb and GAPDH using a one-step RT-PCR reaction (Qiagen). $0.1 \mu \mathrm{g}$ of RNA was combined with 1x Qiagen OneStep RT-PCR Buffer, $400 \mu \mathrm{M}$ of each dNTP, $0.5 \mu \mathrm{g}$ c-myb sense primer, $0.5 \mu \mathrm{g}$ c-myb antisense primer, $1 \mu \mathrm{g}$ GAPDH sense primer, $1 \mu \mathrm{g}$ GAPDH antisense primer, $2 \mu \mathrm{l}$ Qiagen OneStep RT-PCR Enzyme Mix, 5 units RNase inhibitor, and water to a total volume of $50 \mu \mathrm{l}$. C-myb specific primers used were: (sense primer) 5'-GAGCTTGTCCAGAAATATGGTCCGAAG-3' and (antisense primer) 5'GGCTGCCGCAGCCGGCTGAGGGAC-3' (Biosource International). GAPDH amplification was used as a control for template integrity and normalization of data utilizing the following primers: (sense primer) 5'TGAAGGTCGGTGTGAACGGATTTGG-3' and (antisense primer) 5'ACGACATACTCAGCACCGGCCTCAC-3' (Biosource International). RT-PCR amplifications were performed in a GeneAmp PCR System 9700 (Perkin Elmer Applied BioSystems). Reverse transcription was carried out at $50^{\circ} \mathrm{C}$ for 30 minutes. DNA polymerase was activated by heating for 15 minutes at $95^{\circ} \mathrm{C}$. Amplification was performed for 30 cycles with denaturation at $94^{\circ} \mathrm{C}$ for 30 seconds, annealing at $60^{\circ} \mathrm{C}$ for 1 minute, and extension for 1 minute at $72^{\circ} \mathrm{C}$ with an additional 10 minute, $72^{\circ} \mathrm{C}$ 
extension added to the final cycle. PCR products were separated on $2 \%$ ethidium bromide stained gels and visualized using Eagle Eye (Stratagene).

Protein Analysis. To evaluate the influence of stromal cells on C-myb protein levels, C1.92 cells were maintained in normal culture conditions (directly in the presence of S10 and IL-7), in transwell co-cultures, or in media alone. Protein was isolated from $10^{6}$ pro-B cells in Laemmli's buffer and separated on $8 \%$ denaturing polyacrylamide gels. Gels were transferred to PVDF membrane and blocked for 30 minutes in PBS with 5\% dry milk at room temperature. Blots were then probed with a primary monoclonal mouse C-myb antibody (Clone 1.1, Upstate Biotechnology, $1 \mu \mathrm{g} / \mathrm{ml}$ ) or monoclonal mouse GAPDH (glucose-aldehyde-phosphate dehydrogenase) antibody (Research Diagnostics, $0.5 \mu \mathrm{g} / \mathrm{ml}$ ) in PBS with $3 \%$ milk overnight at $4{ }^{\circ} \mathrm{C}$. Blots were then washed with one change of water and probed with a goat $\alpha$-mouse Ig-HRP as the second antibody for 2 hours at room temperature. Blots were washed with one quick wash of water, one 15 minute wash of TBS with $0.1 \%$ Tween, and then 5 vigorous washes in water at room temperature for one minute. ECL plus (Amersham) was used as a chemiluminescent reagent and then blots were exposed to Kodak X-OMAT film. Densitometry analysis was done using Eagle Eye Software.

Determination of $\mathbf{C}$-myb half-life. To determine the half-life of c-myb mRNA, C1.92 cells were cultured for $1,2,4,6,12$, and 24 hours in the presence of S10 stromal cells. Cultures were treated with media alone, $10 \mu \mathrm{g} / \mathrm{ml}$ of the solvent DMSO, or $10 \mu \mathrm{g} / \mathrm{ml}$ of actinomycin D. RNA was isolated from cultured cells and RT-PCR (as described above) was utilized to determine the rate of c-myb mRNA degradation. To determine the half-life of C-myb protein, C1.92 cells were cultured in the presence of S10 stromal cells for $15,30,60$, and 90 minutes. Cultures were treated with media alone, $10 \mu \mathrm{g} / \mathrm{ml}$ of the solvent ethanol, or with $10 \mu \mathrm{g} / \mathrm{ml}$ of cyclohexamide. Degradation of C-myb specific protein from treated cells was analyzed by Western Blotting, with GAPDH as an internal protein loading control (as described above).

Intracellular Fluorescent Staining. For intracellular C-myb staining, $10^{6} \mathrm{C} 1.92$ cells were harvested after being cultured with or without stromal cells for 0 or 8 hours. Cells were washed with ice-cold PBS containing $0.1 \%$ heat inactivated fetal bovine serum (PBS/FBS). Cells were aspirated to dryness, resuspended in $1 \mathrm{ml}$ of paraformaldehyde 
buffer and fixed for 10 minutes at $4{ }^{\circ} \mathrm{C}$. Cells were then washed with PBS/FBS and resuspended in $25 \mu \mathrm{l}$ of permeabilization buffer. $20 \mu \mathrm{g}$ of C-myb specific antibody (UBI, Clone 1.1) or IgG2a isotype antibody (Southern Biotechnology) were added to suspension and incubated for 30 minutes at $4^{\circ} \mathrm{C}$. Cells were then washed with PBS/FBS and incubated for 30 minutes at $4^{\circ} \mathrm{C}$ with a secondary goat $\alpha$-mouse Ig-FITC. After 2 washes of permeabilization buffer, cells were resuspended in $1 \mathrm{ml}$ of permeabilization buffer and analyzed using a flow cytometer (FACScan; Becton Dickinson).

DNA Isolation and Ig gene rearrangement status. DNA was isolated from $10^{6} \mathrm{C} 1.92$ cells using the Easy-DNA isolation kit (Invitrogen). DNA was RNase treated to remove contaminating RNA and resuspended in $100 \mathrm{ml}$ of Tris-EDTA (pH 8). 500 ngs of DNA were used in a PCR reaction (Promega) to determine immunoglobulin (Ig) gene rearrangement status. The Ig heavy chain is assembled from a variable $(V)$ region, a diversity $(\mathrm{D})$ region, a joining $(\mathrm{J})$ region, as well as a constant region (Yancopoulos, 1986). These loci are separated from one another in the germline by intervening sequences, and are joined together upon B cell differentiation. Ig heavy chain gene rearrangement status was determined using primer sets (Hardy, 1991) complementary to the intervening sequence between the $V$ and $D$ section of the heavy chain gene (using primers $D_{F L 16.1} ; 472$ bp amplicon) and between the $D$ and $J$ section of the heavy chain gene (using primers $\mathrm{JH}_{1} ; 1227 \mathrm{bp}$ amplicon). The sequence of primer sets was as follows: $D_{F L 16.1}$ (sense primer) - 5'-GCCTGGGGAGTCACTCAGCAGC-3'; (antisense primer) - 5'-GTGTGGAAAGCTGTGTATCCCC-3' and $\mathrm{JH}_{1}$ (sense primer) - 5'- CCCGGACAGAGCAGGCAGGTGG-3' and (antisense primer) -5'-GGTCCCTGCGCCCCAGACA-3'. Amplification was performed for 35 cycles with denaturation at $95^{\circ} \mathrm{C}$ for 1 minute, annealing at $63^{\circ} \mathrm{C}$ for 3 minutes, and extension for 4 minutes at $72^{\circ} \mathrm{C}$ with an additional 15 -minute extension added to the final cycle. Loss of a $\mathrm{D}_{\mathrm{FL} 16.1}$ or a $\mathrm{JH}_{1}$ amplicon was indicative of gene rearrangement. DNA from identically prepared $\mathrm{S} 10$ was used to confirm germline configuration.

GAPDH ((sense primer) 5'-TGAAGGTCGGTGTGAACGGATTTGG-3' (antisense primer) 5'-ACGACATACTCAGCACCGGCCTCAC-3')) amplification was used as a 
control for template integrity and normalization of data. PCR products were separated on $2 \%$ ethidium bromide stained gels and visualized using Eagle Eye (Stratagene).

Proliferation assay. Following culture with direct stromal cell support, indirect stromal cell support, or no stromal cell support, $10^{5}$ viable C1.92 cells were allocated in 96 well plates coated with S10 and $200 \mu \mathrm{l}$ of $\alpha$-MEM media. Where indicated, IL-7 (50 U/ml) was added to the cultures. Cells were cultured over night for 18 hours, and then pulsed with $1 \mu \mathrm{Ci}{ }^{3} \mathrm{H}-\mathrm{TdR} /$ well. After 6 more hours of culture, cells were harvested onto glass wool fiber strips with an automated cell harvester (Cambridge Instruments, Boston, MA). Radioactive incorporation was determined by liquid scintillation counting in an aqueous fluor (Biosafe-II; Research Products International). Each treatment was repeated in triplicate.

Cell Cycle Analysis. C1.92 cells were cultured with or without stromal cells as previously described. $10^{6}$ cells were fixed in $70 \% \mathrm{EtOH}$ (at $-20^{\circ} \mathrm{C}$ ) and treated with 20 $\mu \mathrm{g}$ RNase A (Sigma) at $37^{\circ} \mathrm{C}$ for 30 minutes. Cells were then stained with $50 \mu \mathrm{g} / \mathrm{mL}$ propidium iodide (PI) (Sigma) to evaluate DNA content. PI stained cells were evaluated using a flow cytometer (FACScan; Becton Dickinson) and analyzed using ModFit Software.

\section{RESULTS}

Expression of c-myb in pro-B cells. C1.92 pro-B cells (Fig. 1a) were cultured in the presence of S10 stromal cells and exogenously added IL-7 (50 U/ml). After culture, expression of c-myb mRNA was evaluated using RT-PCR amplification. As shown in Fig. 1b, C1.92 cells expressed c-myb mRNA. Amplification of GAPDH was used as a control to ensure template integrity. To further confirm the presence of c-myb in pro-B cells, C1.92 cells were assayed for C-myb protein by western blot. As shown in Fig 1c, C1.92 cells expressed C-myb protein that was confirmed by immunohistochemistry and FACS analysis (figure 4b). C1.92 pro-B cells expressed both mRNA and protein for the proto-oncogene c-myb. $\mathrm{S} 10$ stromal cells had no detectable mRNA or protein for c-myb (Fig. 1b and 1c). 


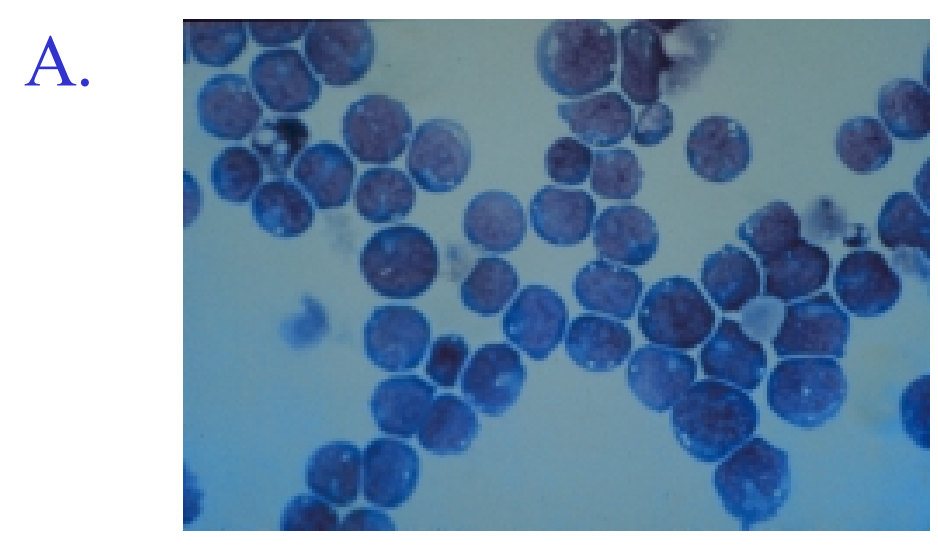

B.

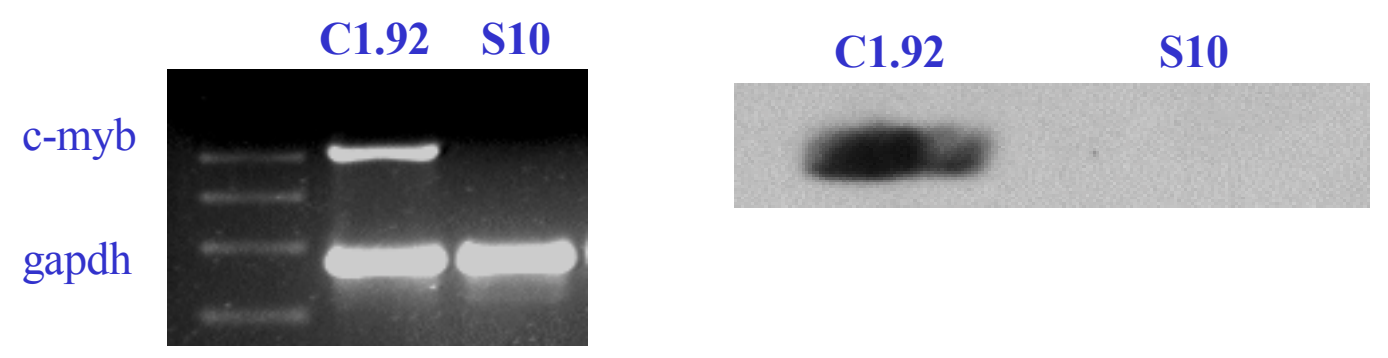

Figure 1. Characterization of C1.92 Pro-B Cell Clone. (A) Cytospin preparation of C1.92 cells in vitro stained with Jenner-Giemsa. Viewed at 100x magnification. (B) RTPCR amplification of c-myb in C1.92 cells. C-myb amplicon is approximately $500 \mathrm{bp}$. GAPDH was used as a control to ensure template integrity. GAPDH amplicon is approximately $300 \mathrm{bp}$. (C) C-myb protein expression in C1.92 cells by Western Blot analysis. 
C-myb mRNA half-life. In order to accurately evaluate changes in c-myb mRNA levels, it was necessary to determine the half-life of c-myb in pro-B cells. To determine the half-life of c-myb mRNA, C1.92 cells were cultured for 1, 2, 4, 6, 12, or 24 hours in the presence of $\mathrm{S} 10$ stromal cells. Cultures treated with media alone or with $10 \mu \mathrm{g} / \mathrm{ml}$ of the solvent DMSO exhibited no change in c-myb expression throughout the time course (Figure 2). C1.92 cells cultured with $10 \mu \mathrm{g} / \mathrm{ml}$ of actinomycin D had a $50 \%$ decrease in c-myb mRNA expression after 6 hours of treatment. After 24 hours of treatment, c-myb mRNA levels decreased to almost undetectable levels (Figure 2). Because the c-myb mRNA seemed to be so stable, it was necessary to confirm the length of the half-life using a different set of RT-PCR primers. Primers were designed in a completely different area (over exon 9A) of the c-myb mRNA message and RT-PCR amplification was performed. Amplification of actinomycin $D$ treated mRNA with the second set of primers confirmed that the half-life of the mRNA message is long-lived, with $50 \%$ of the message being degraded at approximately 11 hours (data not shown). Cell viabilities were determined at every time point for all treatments. No changes in cell viabilities were noted.

C-myb protein half-life. To determine the half-life of C-myb protein, C1.92 cells were cultured in the presence of $\mathrm{S} 10$ stromal cells for $15,30,60$, and 90 minutes. Cultures treated with media alone or with $10 \mu \mathrm{g} / \mathrm{ml}$ of the solvent ethanol exhibited no change in C-myb expression, as determined by Western Blot, throughout the time course (Figure 3). C1.92 cells cultured with $10 \mu \mathrm{g} / \mathrm{ml}$ of cyclohexamide had a $50 \%$ reduction in C-myb protein within 60 minutes of treatment (Fig 3). Cell viabilities were assessed at each time point for every treatment group. No changes in cell viability were seen. 


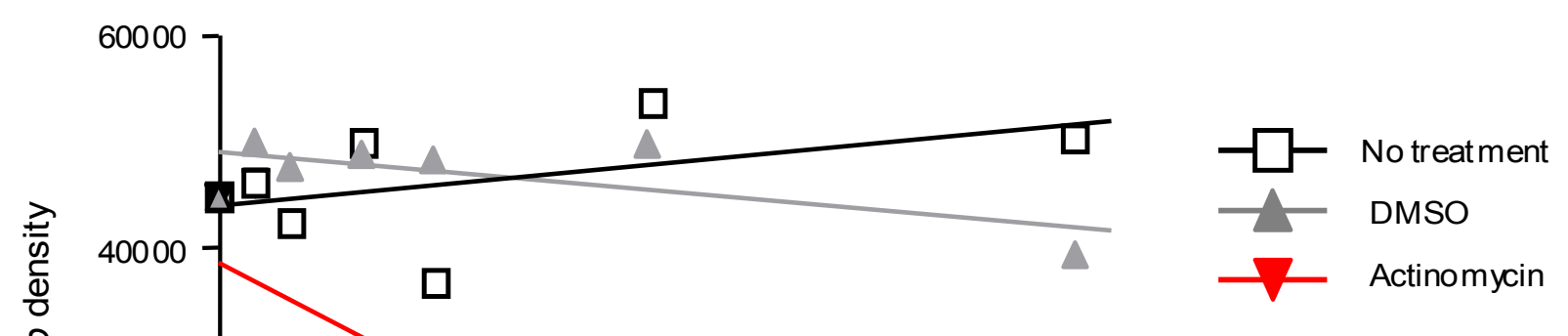

11 hours

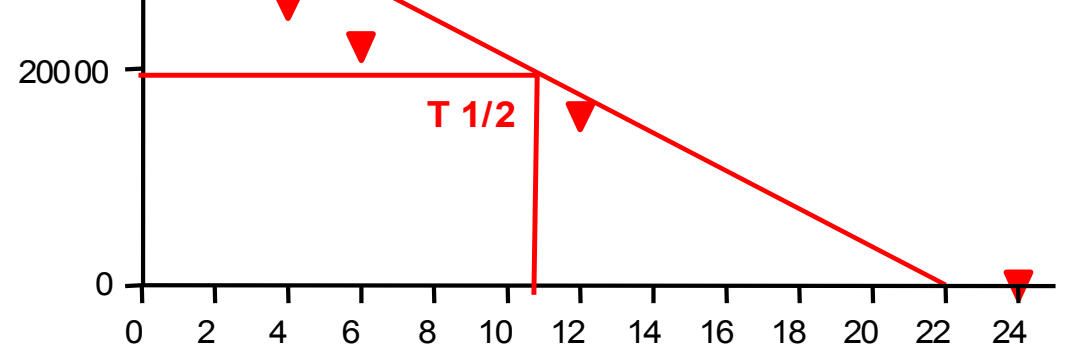

Hours of treatment

Figure 2. Half-life of C-myb mRNA in Pro-B Cells. C1.92 pro-B cell lines were expanded on $\mathrm{S} 10$ stromal cells. After 24 hours of culture, C1.92 cells were treated with $10 \mu \mathrm{g} / \mathrm{ml}$ of DMSO $(\boldsymbol{\Delta}), 10 \mu \mathrm{g} / \mathrm{ml}$ of actinomycin $\mathrm{D}(\boldsymbol{\nabla})$, or left untreated $(\square)$. MRNA was isolated at $0,2,4,6,12$, or 24 hours post treatment. Data shown is one of five replicate experiments. 


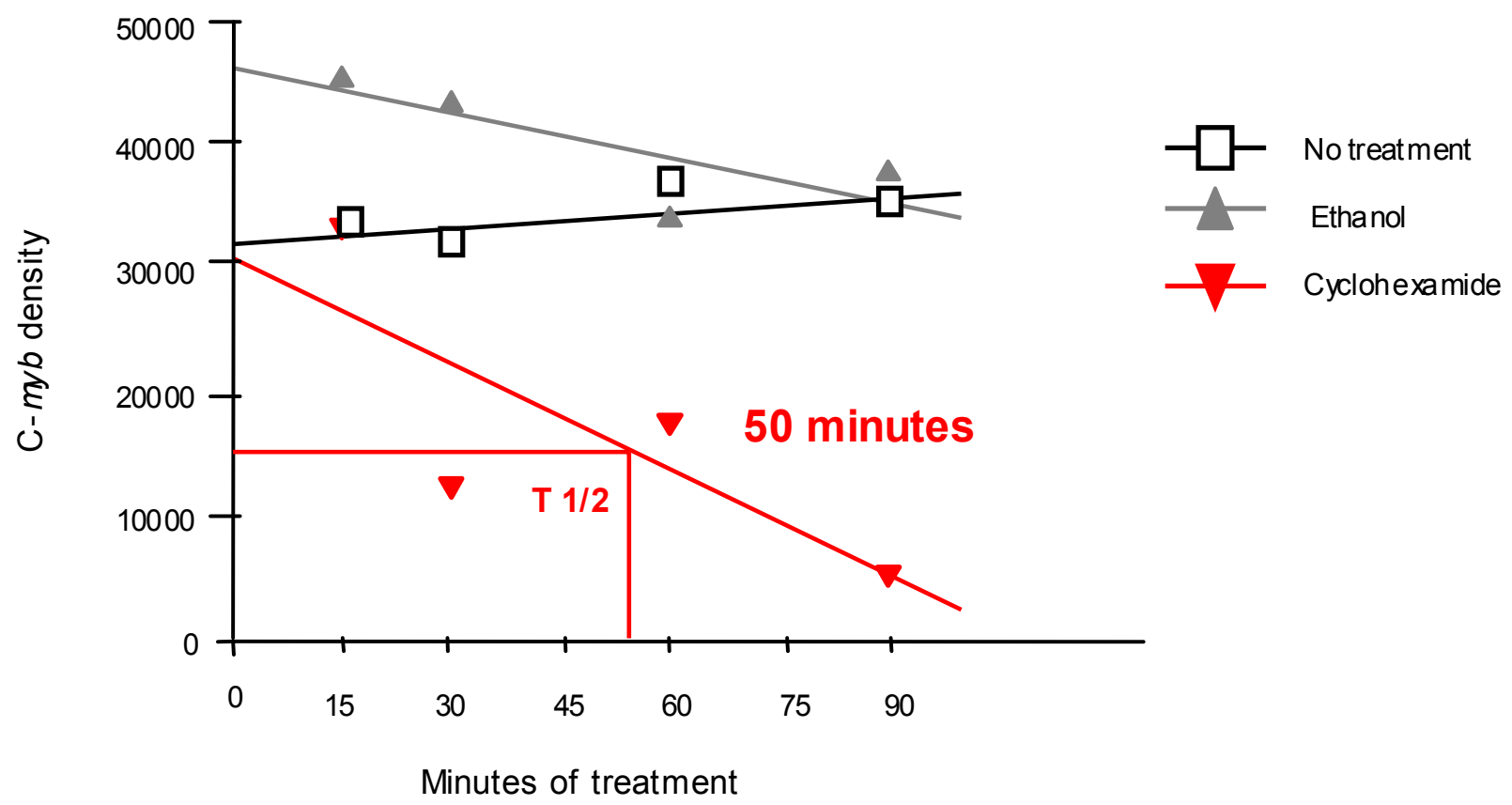

Figure 3. Half-life of C-myb Protein in Pro-B Cells. C1.92 pro-B cell lines were expanded on S10 stromal cells for 24 hours. Pro-B cell lines were treated with $10 \mu \mathrm{g} / \mathrm{ml}$ of ethanol $(\boldsymbol{\Delta}), 10 \mu \mathrm{g} / \mathrm{ml}$ of cyclohexamide $(\boldsymbol{\nabla})$, or left untreated $(\square)$. Data shown is one of five replicate experiments. 
Stromal cell regulation of c-myb. It is well documented that stromal cells regulate gene expression in developing $B$ lineage cells. We determined whether stromal cells regulated the expression of the proto-oncogene c-myb in IL-7 dependent pro-B cells. C1.92 cells were cultured for $0,2,4$, or 6 hours in cell culture medium and IL-7 in the absence of stromal cells. At each time point, RNA was isolated and amplified for c-myb and GAPDH in an RT-PCR reaction. Within 6 hours, c-myb mRNA had decreased to $50 \%$ of control levels (Fig $4 a$ ). To determine whether C-myb protein was also decreased, C1.92 cells were cultured for 8 hours in cell culture media and IL-7 with no stromal cell support. After 8 hours, cells were labeled with a C-myb specific FITC tagged antibody and analyzed by FACS analysis. Within 8 hours, C-myb protein had decreased by $50 \%$ in pro-B cells grown without stromal cell influence (Fig 4b). This was also confirmed by Western Blot analysis.

Stromal cell adhesion contacts maintain c-myb expression. Stromal cells provide both adhesion contacts and cytokine support that are necessary for B lymphopoiesis. Previous data indicated that stromal cells are necessary for maintenance of c-myb expression; however it was necessary to determine if stromal cell cytokines or actual adhesion interactions with stromal cells were responsible for maintaining c-myb levels in pro-B cells. C1.92 cells were cultured directly on a confluent stromal cell layer (control, Fig $5 \mathrm{a}$ and Fig $5 \mathrm{~b}$ ) or separated from the stromal cell layer by a cellulose transwell membrane (transwell, Fig 5a and 5b). C1.92 cells were exposed to soluble factors released by stromal cells, but prevented from physical interaction with stromal cells in transwell cultures. This dissected the influence of released soluble factors from membrane bound proteins. As shown in Figure 5, pro-B cells separated from the stromal cell layer via a transwell had a significant decrease in c-myb mRNA as well as C-myb protein within 24 hours. This indicates that stromal cell adhesion contacts are primarily responsible for maintenance of C-myb in developing B lineage cells. 


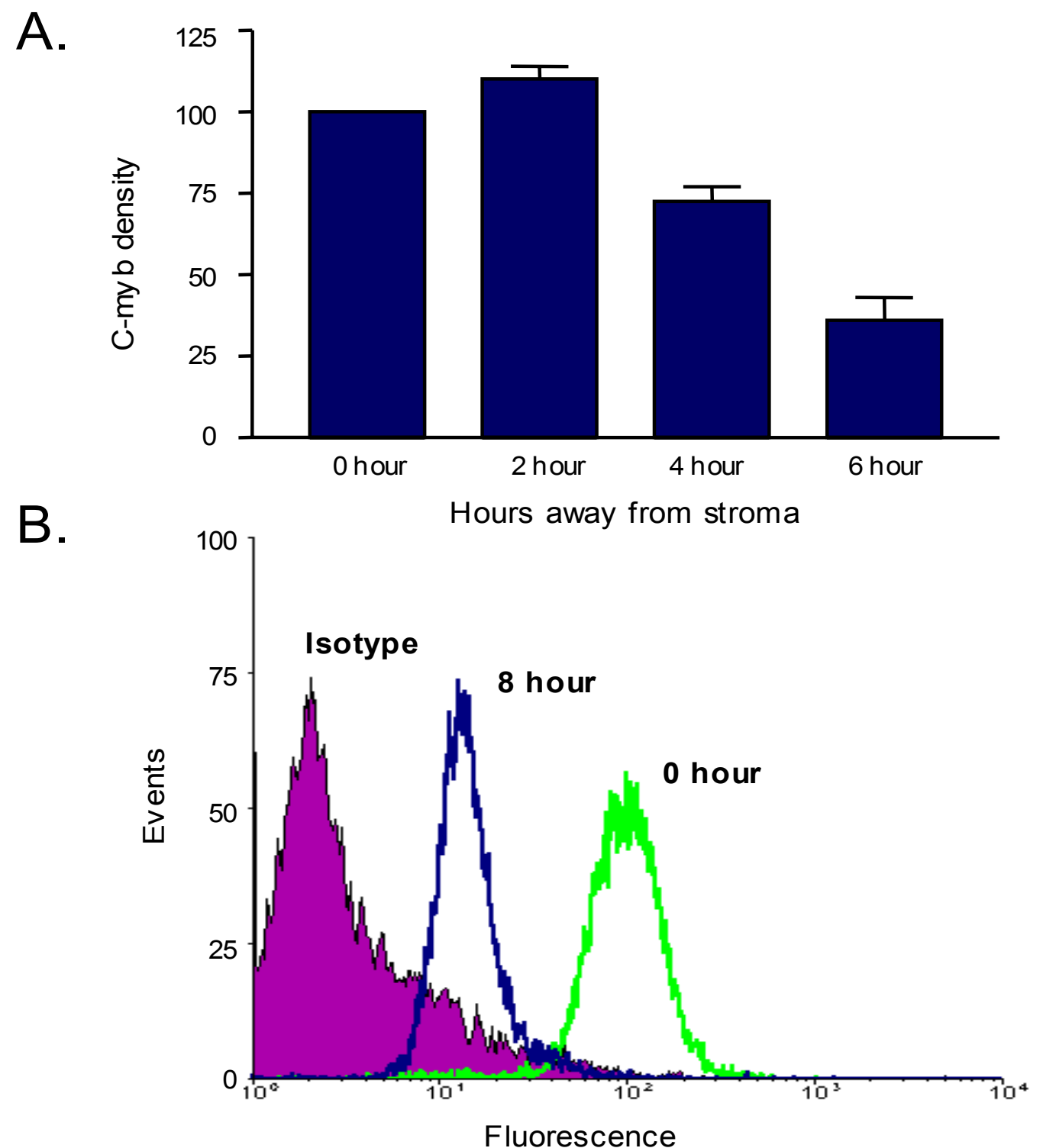

Figure 4. Stromal Cells Regulate C-myb Expression. (A) C1.92 cells were cultured for $0,2,4$, or 6 hours in cell culture medium and IL-7 in the absence of stromal cells. C1.92 cells were harvested and RNA isolated. RNA for c-myb and GAPDH was then amplified by RT-PCR. C-myb mRNA was normalized to GAPDH expression using a Stratagene Eagle Eye. C-myb mRNA was decreased by $50 \%$ within 6 hours. (B) C1.92 cells were cultured in the absence of stromal cells for 8 hours. After 8 hours, C1.92 cells were stained with a C-myb specific antibody to determine intracellular protein expression. 
A.
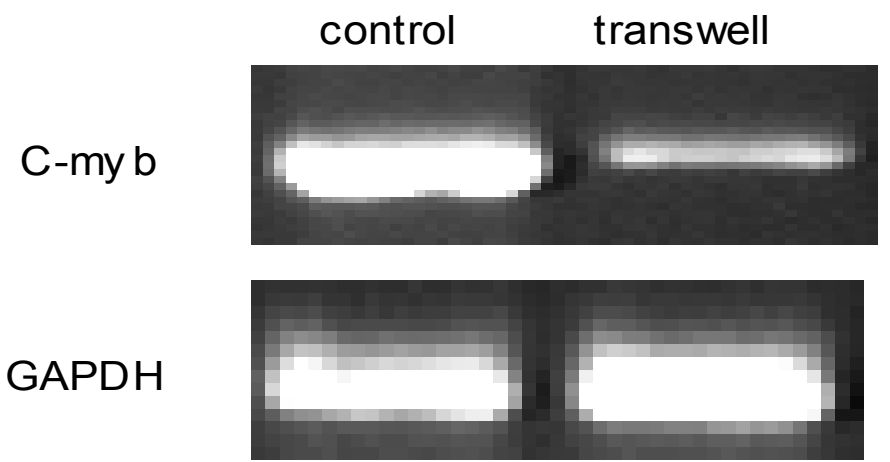

B.

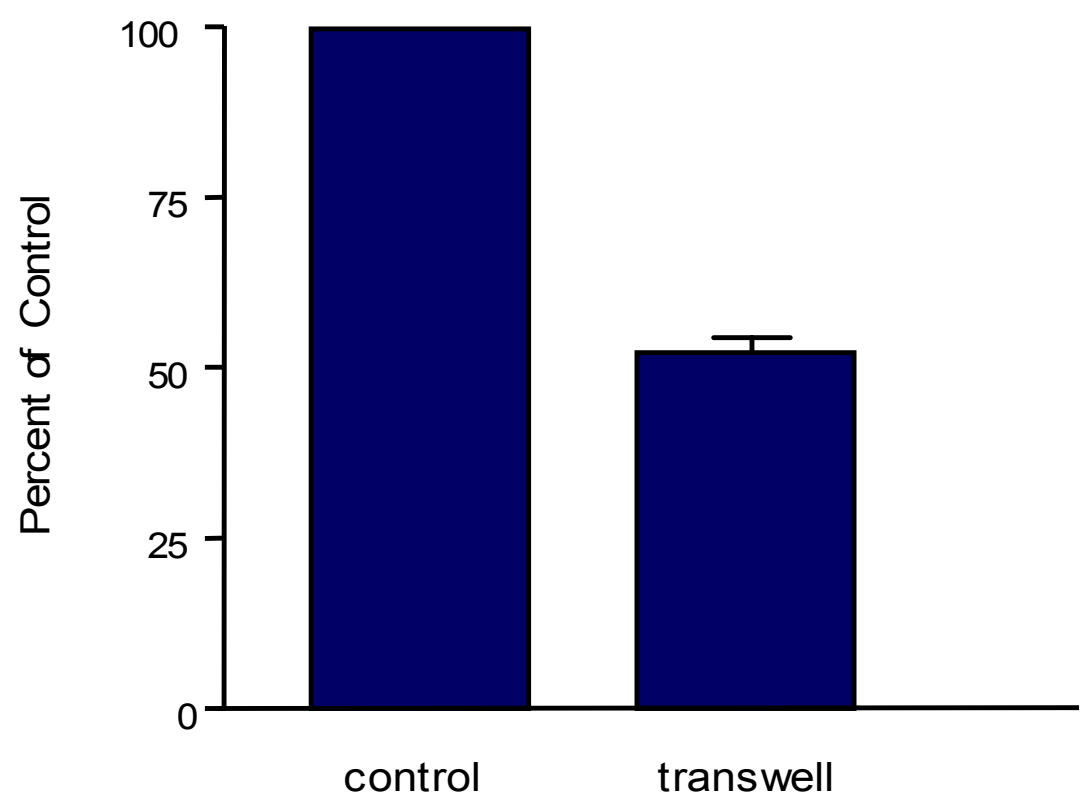

Figure 5. Stromal Cells Regulate C-myb Expression via Adhesion Contacts. (A) C1.92 cells were cultured for 24 hours directly in contact with stromal cells or separated from stromal cells in the same culture well by use of a transwell. Cells were harvested and total RNA isolated. RNA for c-myb and GAPDH was amplified by RT-PCR reaction. After 24 hours c-myb mRNA levels were decreased by approximately $80 \%$. (B) C-myb protein levels were also analyzed by Western Blotting. 
Decreased C-myb is associated with impaired proliferative capacity. It is well documented that decreases in c-myb correlate with inhibition of proliferation in myeloid cells. In order to determine whether the decrease in c-myb levels observed when pro-B cells were cultured in transwells correlated with decreased pro-B cell proliferation, tritiated thymidine uptake was assayed. Pro-B cells grown in direct contact with stromal cells (control, Fig 6) exhibited a proliferative response after exposure to IL-7. In contrast, pro-B cells that had decreased c-myb levels due to loss of stromal cell contact showed a significant impairment in the ability to respond to IL-7 (transwell, Fig 6).

Impaired proliferative capacity was due to a block in cell cycle. We wanted to determine if the observed inhibition of proliferation was due to alterations in pro-B cell cycle. Normally, approximately $65 \%$ of pro-B cells in culture with stromal cell support are in the $G_{0} / G_{1}$ phase of the cell cycle with $30 \%$ in the $G_{2} / M$ phase and $5 \%$ in the $S$ phase. However, after 24 hours of culture with a transwell, $\mathrm{C} 1.92$ cells exhibited a failure to exit the $G_{0} / G_{1}$ phase of the cell cycle. Greater than $95 \%$ of the cells were in the $G_{0} / G_{1}$ phase of the cell cycle with only $3 \%$ in the $G_{2} / M$ phase and less than $2 \%$ in the $S$ phase (Fig 7). These data indicate that impairment in cell cycle, associated with a decrease in c-myb expression levels, is the result of altered cell cycle kinetics.

Loss of c-myb expression correlated with Ig heavy chain gene rearrangement. Exit from the cell cycle in developing $B$ lineage cells is often accompanied by differentiation into a more mature cell. To investigate the possibility that pro-B cells with down regulated c-myb levels were differentiating, Ig heavy chain gene rearrangement status was evaluated. C1.92 cells are early pro-B cells, thus they have not yet rearranged either the D-J or V-DJ loci and they remain in germline configuration while in culture with direct stromal cell contact (control, Fig 8). However, when C1.92 cells are cultured in a transwell for 24 hours, D-J rearrangement of the Ig heavy chain gene occurs as indicated by the loss of an amplicon (transwell, Fig 8). V-DJ rearrangement does not occur, and this loci is retained in germline configuration. These data indicate that loss of c-myb, which occurs when $\mathrm{C} 1.92$ cells are cultured without direct stromal cell support, is accompanied by genotypic maturation. 


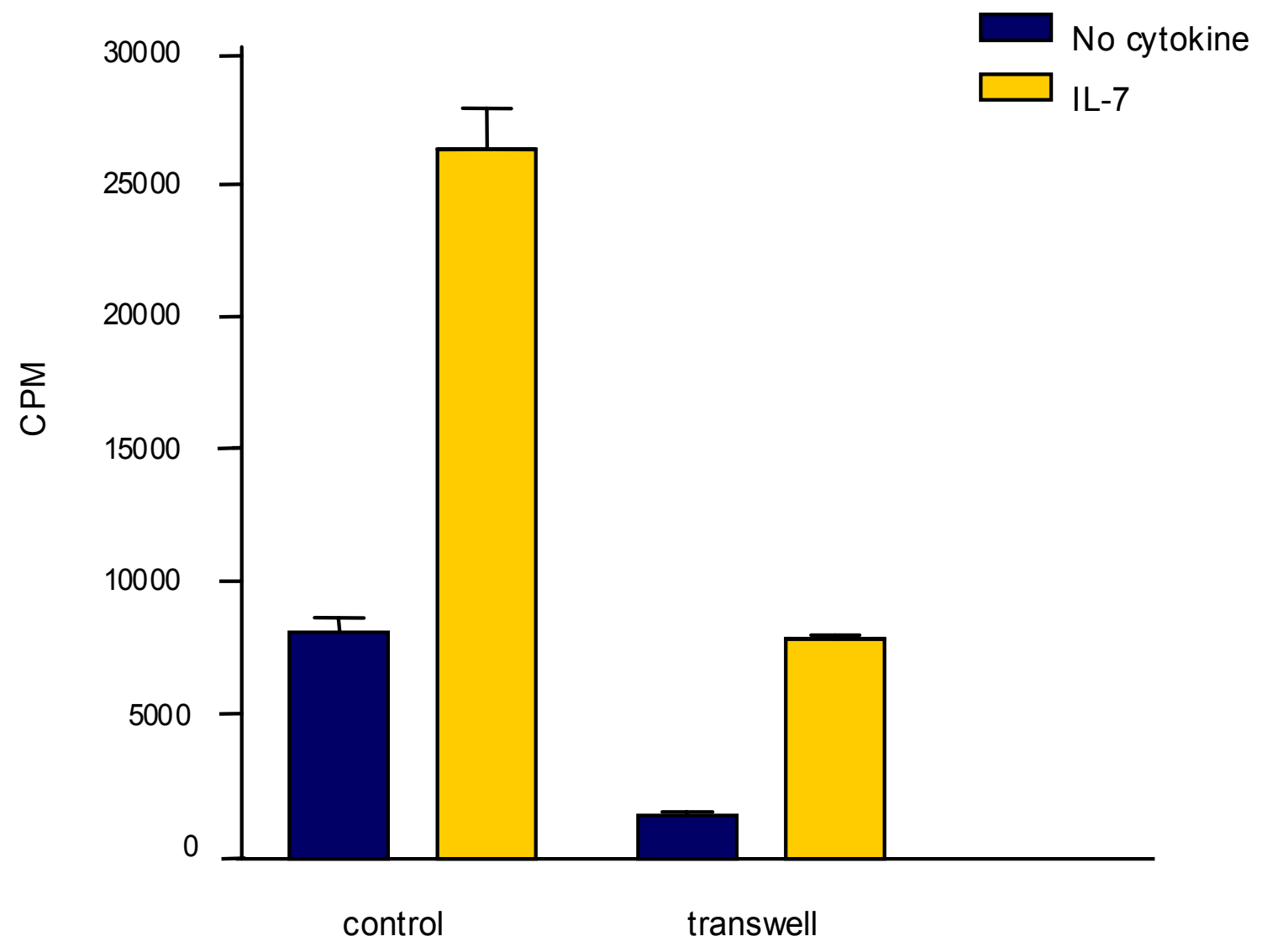

Figure 6. Proliferative Response of Pro-B Cells. C1.92 cells were cultured directly in the presence of stromal cells or separated from direct stromal cell contact via a transwell for 24 hours. After culture, $10^{5}$ live $\mathrm{C} 1.92$ cells were plated into 96 well plates with $\mathrm{S} 10$ stromal cells for 18 hours. The cytokine IL-7 (50 U/ml) was added where indicated. After 18 hours, $1 \mu \mathrm{Ci}$ of ${ }^{3} \mathrm{H}-\mathrm{TdR}$ was added to each well. Cells were harvested 6 hours later. Quantitation of incorporated $1 \mu \mathrm{Ci}$ of ${ }^{3} \mathrm{H}-\mathrm{TdR}$ is presented as counts per minute (CPM) +/- SEM for 3 replicate cultures. 


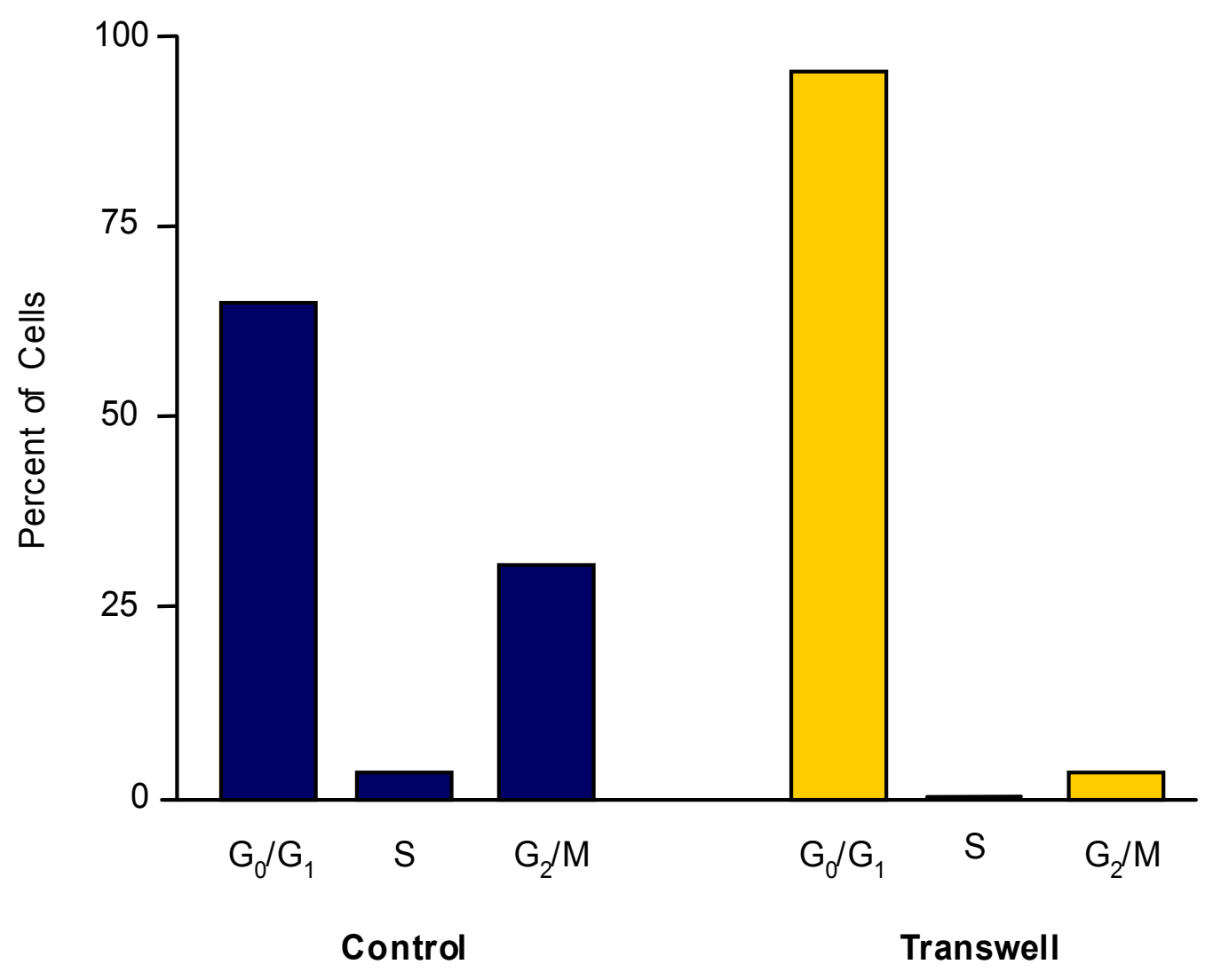

Figure 7. Altered Cell Cycle Kinetics. C1.92 cells were cultured for 24 hours with direct stromal cell contact or separated from stromal cell adhesion contacts by a transwell membrane. After 24 hours, cells were harvested and stained with propidium iodide (PI). To determine DNA content, $\mathrm{PI}$ incorporation was measured using FACS analysis and ModFit software. Data for one of 3 replicate experiments is shown. 

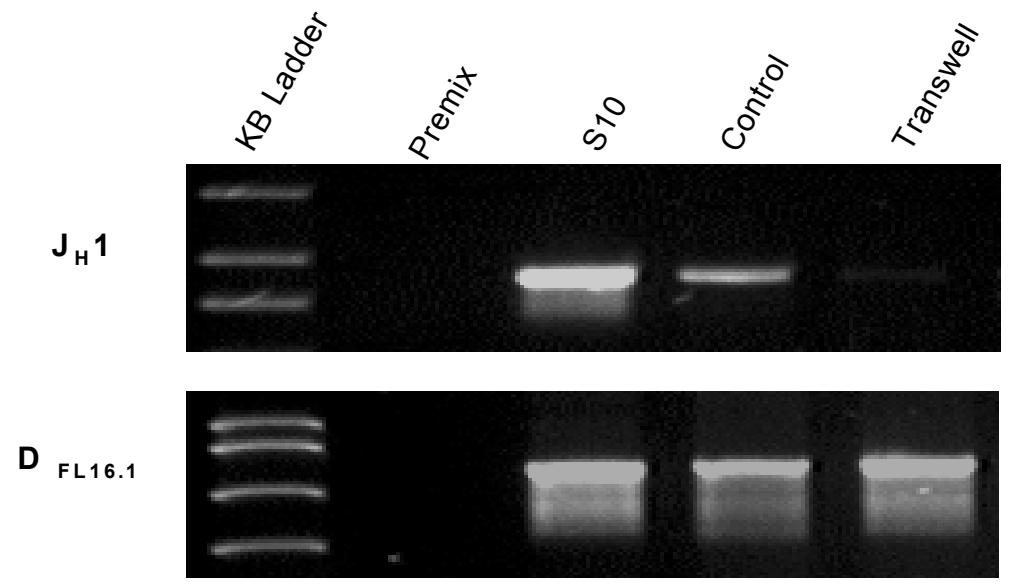

G APDH

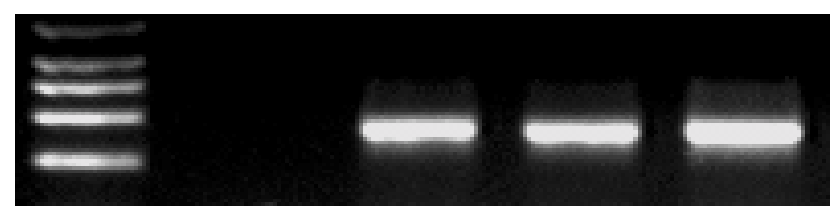

Figure 8. Down Regulation of C-myb is Associated with Pro-B Cell Differentiation. C1.92 cells were cultured in direct contact with stromal cells or separated from stromal cell contact via a transwell for 24 hours. DNA was isolated from $10^{6}$ pro-B cells. RTPCR amplification was performed using primers designed to detect gene rearrangement, as well as GAPDH primers to check template integrity. 


\section{DISCUSSION}

Early pro-B cell development is dependent on the hematopoietic microenvironment found in the bone marrow (Dorshkind, 1990). This niche provides regulatory signals that are critical for $B$ lymphopoiesis. Fibroblastic stromal cells within the bone marrow microenvironment supply a vast majority of these regulatory signals through cell adhesion contacts and cytokine stimulation. B cell progenitors must express and/or repress various genes during their maturation process. Failure to tightly regulate gene expression can halt B cell development, leading to hematopoietic defects. It is known that the regulation of some early lymphoid genes is intrinsic to the developing cell, while other genes are regulated by the stromal cell microenvironment. However, the mechanism regulating many other genes expressed by developing lymphocytes is completely unknown. One gene highly expressed in early hematopoietic cells is the proto-oncogene c-myb (Lipsick, 1996). The aims of this work are to determine if early pro-B cells express c-myb and to determine if the hematopoietic microenvironment is involved in regulating $\mathrm{c}-m y b$ expression in developing $\mathrm{B}$ lymphocytes. Data presented here demonstrate that c-myb is expressed in an IL-7, stromal cell dependent pro-B cell line and suggest that expression of c-myb is regulated by stromal cell adhesion contacts.

This report is not the first to demonstrate the important relationship between stromal cells and developing B lymphocytes. Many stromal cell derived cytokines are known to impact the expansion of $B$ cell progenitors. The stromal cell secreted cytokine IL-7, in conjunction with stromal cell derived IGF-1 and FIt3 ligand, are the major proliferative stimuli provided to early developing B cells (Gibson, 1993). Stromal cell derived factor-1 (SDF-1) is another mediator constitutively expressed by bone marrow derived stromal cells that stimulates the proliferation of $B$ cell progenitors. The majority of mutant mice harboring a targeted disruption in the SDF-1 gene expire in utero at day 18.5 of embryogenesis, and mutants that survived had significantly decreased numbers of pro-B and pre-B cells (Nagasawa, 1996). Stromal cell derived Flt-3 ligand and IGF-1 not only affect early B cell expansion, but they also have important roles in B lineage differentiation (Dorshkind, 1990 and Ray, 1996). In addition 
to releasing cytokines that aid in B cell expansion and maturation, stromal cells are involved in providing survival signals as well. Expression of both pro- and anti-apoptotic genes in developing $B$ lymphocytes is regulated by stromal cells, including $b c l-2$ and bax (Gibson, 1996). Stem cell factor (kit ligand) is produced by stromal cells and serves as a ligand for the tyrosine kinase receptor c-kit expressed on hematopoietic cells. The importance of this stromal cell/B cell interaction was evident when murine models deficient in c-kit or kit ligand resulted in prenatal lethality between days 13 and 15 of gestation due to loss of fetal liver hematopoiesis (Russel, 1979). Although many of the regulatory signals and stromal cell/B cell interactions have been reported, the full complement of genes that stromal cells may regulate, and the specific mechanisms by which stromal cells exert this regulation, are largely unknown.

Although c-myb has been shown to be critical in the development of erythroid and myeloid precursors, less work has been done on the role of c-myb in the normal development of lymphocytes. Because the loss of c-myb results in embryonic lethality, it is difficult to investigate the regulation of c-myb in developing B lymphocytes. This problem was circumvented in studies of erythroid and myeloid cells using an in vitro cell model. We have developed a cloned fetal liver pro-B cell line that is dependent on stromal cells and IL-7 for continued survival and proliferation (Gibson, 1993). This population of pro-B cells continues to proliferate in culture in the presence of stromal cells and IL-7, but does not differentiate. Westin et al previously demonstrated high expression levels of the proto-oncogene c-myb hold myeloid cells in a proliferative state and inhibit differentiation. Using Western Blot and RT-PCR, we determined that high levels of mRNA and protein for the proto-oncogene c-myb characterize $\mathrm{C} 1.92$ cells. Therefore, we have developed an in vitro model that will be useful to study the regulation of c-myb in an IL-7, stromal cell dependent pro-B ell line.

The half-life of c-myb mRNA and protein has not yet been reported for developing $B$ lineage cells. In order to investigate c-myb regulation, it was necessary to determine the degradation kinetics of c-myb mRNA and protein in pro-B cells. Our experiments with actinomycin $D$ and cyclohexamide revealed a long half-life for c-myb mRNA (11hours) with a much shorter half-life for C-myb protein (less than 1 hour). Although not reported in the literature, the half life of c-myb in pro-myelocytes is 
approximately 1 hour for both the mRNA and the protein (Westin, personal communication). While the protein half-life for c-myb in pro-B cells is similar to that reported for myeloid cells, the mRNA half-life of c-myb is much longer in pro-B cells than in pro-myelocytes. These data give us a time frame within which we can conduct further experiments at biologically relevant times.

Because $\mathrm{C} 1.92$ are continuously grown in the presence of stromal cells, and stromal cells have previously been shown to regulate other genes involved in the proliferation and differentiation of B lymphocytes, we hypothesized that the hematopoietic microenvironment is able to regulate the expression of c-myb in pro-B cells. In the present report, we show that c-myb is down regulated when $\mathrm{C} 1.92$ cells are grown in culture media alone without stromal cell support. Removal of pro-B cells from stromal cells and IL-7 for only 6 hours resulted in c-myb mRNA levels that were less than $50 \%$ of control levels. Immunofluorescent staining for intracellular C-myb protein supported mRNA data, revealing a decrease in protein levels within 8 hours after removal from S10 and IL-7. Western blots were also performed to determine C-myb protein levels. These studies confirmed observations made from immunohistochemistry data; C1.92 cells removed from S10 and IL-7 for 24 hours showed decrease levels of Cmyb protein, to almost undetectable levels. These data are particularly interesting because stromal cell regulation of c-myb expression has not been considered previously. These data are the first to suggest that c-myb expression, like the expression of many other pro-B cell genes, is under the control of stromal cells. This indicates that stromal cells are necessary to maintain the expression of c-myb in developing $B$ lineage cells.

It is known, however, that stromal cells provide both cytokine support and cell adhesion contacts to immature $B$ cells. We utilized a transwell culture system to determine if stromal cell cytokines (such as IL-7, IGF-1, SDF-1, or KL) or stromal cell adhesion contacts (such as VCAM-1, CD44, fibronectin, or hyaluronate) are responsible for the maintenance of c-myb expression. The transwell culture system prohibits stromal cell/pro-B cell contact, but still allows pro-B cell exposure to stromal cells cytokines. We determined that stromal cell adhesion contacts are largely responsible for high levels of c-myb expression in pro-B cells. At 24 hours, c-myb mRNA and 
protein expression decreased in pro-B cells that did not have direct stromal cell interaction. However, c-myb expression was not completely ablated. This indicates that stromal cell contacts are largely responsible for c-myb expression in pro-B cells, but not solely responsible. Extending the experiments to 48 hours may reveal a complete loss of c-myb, but the cell viability of transwell cultures begins to decrease after 24 hours in culture therefore complicating data analysis. It remains possible that that both stromal cell adhesion contacts and stromal cell cytokines regulate c-myb expression.

We also determined that the down-regulation of c-myb expression following culture in the transwell system correlated with alterations in the proliferative response of C1.92 cells. C1.92 cells cultured in the transwell for 24 hours exhibited a loss of responsive to their major proliferative stimulus, IL-7. In addition, there were a greater number of pro-B cells in the $G_{0} / G_{1}$ phase of the cell cycle and correspondingly fewer cells in the $G_{2} / M$ and $S$ phases of the cell cycle. This was due either to a slower rate of progression through the cell cycle or an inability to exit the $G_{0} / G_{1}$ phase. The decrease of c-myb mRNA and protein in pro-B cells corresponds with alterations in proliferative capacity and cell cycle progression.

The finding that pro-B cells exited the cell cycle when c-myb levels decreased was intriguing. The observed inhibition of proliferation and cell cycle suggest two possible fates for $\mathrm{C} 1.92$ cells. Pro-B cells may be exiting the cell cycle in preparation for apoptosis. However, this idea is not supported by our experimental data. Following culture transwells separated from stromal cells, the viability of $\mathrm{C} 1.92$ cells is not different from that of control cells. In addition, propidium iodide analysis did not reveal increases in C1.92 cells with less than 2N DNA, indicative of cell death (data not shown). These data indicate that, after 24 hours of culture in transwells, C1.92 cells are not initiating significant apoptosis. The second possibility is that the pro-B cells exit cell cycle prior to differentiation. In normal B lineage development, pro-B cell differentiation into pre-B cells is accompanied by a corresponding decrease in cell cycle progression. In addition, this maturation is also accompanied by rearrangement of the immunoglobulin (Ig) heavy chain gene. As pro-B cells become immature B cells, they must generate B cell receptors. This is accomplished through systematic rearrangements of the Ig heavy chain gene, commencing with rearrangement of the D-J loci followed by rearrangement 
of the V-DJ loci. Ig gene rearrangements were evaluated using PCR amplification of germline Ig heavy chain gene sequence. PCR analysis of the intervening sequences between the $D$ and $J$ and $V$ and $D$ segments of the Ig heavy chain gene revealed that gene rearrangement is occurring at the D-J loci after transwell culture as shown in figure 8. These data suggest an association between the down regulation of c-myb and pro-B cell maturation.

Taken together, these data provide the basis for expanding the role that stromal cells play in $B$ lymphopoiesis. As early immature cells, pro-B cells require contact with stromal cells for their continued survival, proliferation, and differentiation. Along with several other events described above, this stromal cell contact maintains a high level of $\mathrm{c}-m y b$ expression in pro-B cells. As pro-B cells mature to express Ig (pre-B cells), they lose dependence on stromal cell contact. This loss of stromal cell influence is accompanied by a decrease in c-myb expression, a corresponding decrease in proliferation, an inhibition of progression through the cell cycle, and rearrangement of the D-J loci of the heavy chain gene indicative of maturation. This suggests that c-myb expression may be one of the many ways that stromal cells guide immature $B$ cells through maturation and differentiation. 


\section{REFERENCES}

Bidenkapp H, Borgmeyer U, Sippel AE, Klempnauer KH: Viral myb oncogene encodes a sequence specific DNA binding activity. Nature 335:835, 1988

Billips LG, Petitte D, Dorshkind K, Narayanan R, Chiu C-P, Landreth KS: Differential roles of stromal cells, interleukin-7, and kit-ligand in regulation of B lymphopoiesis. Blood 79:109, 1992

Collins, LS and Dorshkind, K: A stromal cell line from myeloid long-term bone marrow cultures can support myelopoiesis and B lymphopoiesis. J Immunol 138: 1082-1087, 1987

Cumano A, Godin I: Pluripotent hematopoietic stem cell development during embryogenesis. Curr Opin Immunol 13:166, 2001

Dorshkind K: Regulation of hemopoiesis by bone marrow stromal cells and their products. Annu Rev Immunol 8:111, 1990

Gewirtz AM, Calabretta B: A c-myb antisense oligodeoxynucleotide inhibits normal human hematopoiesis in vitro. Science 242:1303, 1988

Gibson LF, Piktel D, Landreth KS: Insulin-like growth factor-1 potentiates expansion of interleukin-7 dependent pro-B cells. Blood 82:3005, 1993

Gibson LF, Piktel D, Narayanan R, Nunez G, Landreth KS: Stromal cells regulate bcl-2 and bax expression in pro-B cells. Exp Hemat 24:628, 1996 
Godin I, Garcia-Porrero JA, Dieterlen-Lievre F, Cumano A: Stem cell emergence and hematopoietic activity are incompatible in mouse intraembryonic sites. J Exp Med 190:43, 1999

Hardy RR, Carmack CE, Shinton SA, Kemp JD, Hayadawa K: Resolution and Characterization of Pro-B and Pre-Pro-B Cell Stages in Normal Mouse Bone Marrow. J Exp Med 173:1213, 1991

Johnson A, Dorshkind K: Stromal cells in myeloid and lymphoid long-term bone marrow cultures can support multiple hemopoietic lineages and modulate their production of hemopoietic growth factors. Blood 68:1348, 1986

Kincade PW, Lee G, Pietrangeli CE, Hayashi S-I, Gimble JM: Cells and molecules that regulate B lymphopoiesis in bone marrow. Annu Rev Immunol 7:111, 1989

Lee G, Namen AE, Gillis S, Ellingsworth LR, Kincade PW: Normal B cell precursors responsive to recombinant murine IL-7 and inhibition of IL-7 activity by transforming growth factor-beta. J Immunol 142:3875, 1989

Lipsick JS: One billion years of Myb. Oncogene 13:223, 1996

Micklem HS, Ford CE, Evans EP, Gray J: Interrelationships of myeloid and lymphoid cells: studies with chromosome-marked cells transplanted into lethally irradiated mice. Proc R Soc Lond B Biol Sci 165:78, 1966

Mucenski ML, McLain K, Kier AB, Swerdlow SH, Schreiner CM, Miller TA, Pietryga DW, Scott WJ, Potter SS: A functional c-myb gene is required for normal murine fetal hepatic hematopoiesis. Cell 65:677, 1991 
Moore MA, Metalf D: Ontogeny of the haemopoietic system: yolk sac origin of in vivo and in vitro colony forming cells in the developing mouse embryo. $\mathrm{Br} \mathrm{J}$ Haematol 18:279, 1970

Nagasawa T, Hirota S, Tachibana K, Takakura N, Nishikawa S, Kitamura Y, Yoshida $\mathrm{N}$, Kikutani $\mathrm{H}$, Kishimoto $\mathrm{T}$ : Defects of B-cell lymphopoiesis and bone-marrow myelopoiesis in mice lacking the CXC chemokine PBSF/SDF-1. Nature 382:635, 1996

Ray R, Paige C, Furlonger C, Lyman S, Rottapel R: Flt3 ligand supports the differentiation of early $B$ cell progenitors in the presence of interleukin-11 and interleukin-7. Eur J Immunol 26:1504, 1996

Russel, ES: Hereditary anemias of the mouse: a review for geneticists. Adv. Genet. 20:357, 1979

Sabin FR: Bone marrow. Physiol Rev 8:191, 1928

Sudo T, Ito M, Ogawa Y, lizuka M, Kodama H, Kunisada T, Hayashi S, Ogawa M, Sakai K, Nishikawa S, Nishikawa S-I: Interleukin 7 production and function in stromal cell-dependent B cell development. J Exp Med 170:333, 1989

Tavassoli M: Studies on hemopoietic microenvironments. Exp Hematol 3:213, 1975

Westin EH, Gallo RC, Arya SK, Eva A, Souza LM, Baluda MA, Aaronson SA, WongStaal F: Differential expression of the amv gene in human hematopoietic cells. PNAS 79:2194, 1982 
Witte PL, Robinson M, Henley A, Low MG, Stiers DL, Perkins S, Fleischman RA, Kincade PW: Relationships between B-lineage lymphocytes and stromal cells in long-term bone marrow cultures. Eur J Immunol 17:1473, 1987

Yancopoulos GC, Alt FW: Regulation of the assembly and expression of variableregion genes. Ann Rev Immunol 4:339, 1986 


\section{Chapter 3}

C-myb Regulates Proliferation and Differentiation of Murine Pro-B Cells 


\begin{abstract}
The expansion and maturation of a finite quantity of pluripotient stem cells into differentiated progeny is termed hematopoiesis. Pluripotent stem cells divide and mature into all blood cell types. Typically, stem cells are relatively unresponsive to cytokine influence because their proliferation and differentiation must be restrained in order to prevent stem cell depeletion. The stem cell compartment must maintain stable numbers of highly proliferative progenitor cells and must produce progeny capable of maturation into end effector cells. The molecular events that regulate cell fate determinations in hematopoietic cells are largely uncharacterized. One protein family important in regulating cell fate decisions is the myb family of proteins. In particular, cmyb has been shown to be critical in the development of erythroid and myeloid precursors. Much of the erythroid and myeloid work has been accomplished using an in vitro cell model since in vivo mutations of c-myb result in embryonic lethality. Less work, however, has been done on the role of c-myb in the normal development of lymphocytes due to the lack of an appropriate model of B cell development. Studies in this report describe development of a system in which c-myb expression in pro-B cells can be manipulated while pro-B cells remain in co-culture with stromal cells. In addition, this work determines that $c-m y b$ is an intracellular regulator of proliferation and differentiation in early B cell progenitors, but does not impact their cell survival. These data clearly establish the role of c-myb in the development of stromal-cell dependent pro-B cells.
\end{abstract}




\section{INTRODUCTION}

Hematopoiesis is the process by which a limited number of multipotient stem cells mature and expand to form differentiated progeny. The majority of stem cells are quiescent and relatively unresponsive to cytokine influence. The proliferation and differentiation of stem cells is tightly regulated in order to prevent exhaustion of the stem cell compartment. The function of the stem cell compartment is two-fold: maintenance of stable numbers of multipotent progenitor cells and differentiating into mature effector cells having a finite lifespan (Till and McCulloch, 1961; Metcalf and Moore, 1971). In order for stem cells to mature into effector cells, they must enter the cell cycle after extrinsic stimulation by cytokines (Bradford, 1997). After entering the cell cycle, the stem cell progresses through a highly proliferative, cytokine responsive progenitor cell stage. Progenitor cells undergo a sequence of genetic expression and repression that affects self-renewal and lineage specific differentiation. Molecular mechanisms that regulate self-renewal and differentiation of developing hematopoietic cells have not been well defined.

One family of proteins known to modulate lineage specific events in hematopoiesis is the Myb family of proteins. Myb family members are DNA binding proteins that play critical roles in cell fate determinations and maintenance of differentiation status in many developmental systems (Gewirtz and Calabretta, 1988; Clarke MF, 1988; Patel G, 1993; Mucenski ML, 1991). Myb family members have been highly conserved throughout evolution, and have been found in most every organism studied. Three related Myb gene family members have been identified in vertebrates; these include A-myb, B-myb, and C-myb. In particular, the proto-oncogene c-myb is essential for definitive hematopoiesis in murine models (Mucenski, 1991). The c-myb proto-oncogene encodes a $75 \mathrm{kDa}$ nuclear protein that binds to a consensus sequence of DNA [(T/C)AAC (T/G)G ] (Gonda, 1983, Westin, 1982 and Bidenkapp, 1988). C-myb is expressed at high levels in immature, highly proliferative hematopoietic cells, but levels of C-myb decrease as immature cells differentiate into more mature progeny (Westin, 1982; Gonda and Metcalf, 1984; Craig and Bloch, 1984; Sheiness and Gardinier, 1984). C-myb facilitates self-renewal of pro-myelocytes by impeding exit 
from, and maintaining these cells in, cell cycle. Overexpression of c-myb or failure to downregulate c-myb during development is thought to lead to myelocytic leukemia. These data suggest that downregulation of $c-m y b$ is required for terminal differentiation of myeloid cells. However, the role of c-myb in developing B lineage cells has not been investigated.

B lymphocyte development occurs in the bone marrow, and is characterized by progressive rearrangement and expression of immunoglobulin heavy and light chain genes (Yancopoulos, 1986). Newly formed B lymphocytes are a population of rapidly renewed cells in the bone marrow of mammals (Landreth, 1981). The steady state production of $B$ lymphocytes depends on lineage specific gene expression, alternative lineage gene repression, and a cascade of regulatory cytokines. Considerable progress has been made in defining both intracellular and extracellular signals that regulate the development of B lymphocytes. However, many other events regulating B lymphocyte development are poorly understood. In particular, the role of the proto-oncogene cmyb, which is expressed in highly proliferative, early pro-B cells, is not clearly defined. The function of c-myb is well defined in myeloid cell development, and progress is being made in determining myb's role in T cell development (Allen, 1999, Westin, 1982, Mucenski, 1991, Gewirtz and Calabretta, 1988). However, the role of c-myb in B lymphocyte development is virtually unknown. B lymphocyte development is a complicated system to investigate because early B lymphocytes do not develop independently. Instead, they develop in conjunction with non-hematopoietic stromal cells located in the bone marrow.

Previous data from this lab demonstrated that stromal cells regulate c-myb expression in pro-B cells. In this manuscript, we further delineate the role of c-myb in the survival, proliferation, and differentiation of pro-B cells. Our studies aimed to determine whether c-myb is an intracellular regulator of survival, differentiation, and/or proliferation in pro-B cells. Downregulation of c-myb in C1.92 pro-B cells resulted in genotypic maturation, progressive immunoglobulin gene rearrangements, and impaired proliferative capacity. However, c-myb downregulation in pro-B cells did not directly impact cell survival. Taken together, these data demonstrate that proliferation and 
differentiation of pro-B cells depends on expression and regulation of c-myb whereas pro-B cell survival is c-myb independent.

\section{MATERIALS AND METHODS}

Cell Lines and Cytokines. A panel of pro-B cell lines was derived from normal Balb/C mice. Fetal livers were removed from murine embryos at day 14 of gestation. Fetal livers were dispersed into single cell suspension and the non-adherent cells were passaged in the presence of a cloned bone marrow stromal cell line, $\mathrm{S} 10$, and $50 \mathrm{U} / \mathrm{mL}$ of recombinant murine interleukin-7 (IL-7). The fetal liver cells were then cloned at limiting dilution in the presence of S10 and IL-7. One of the resulting clones, C1.92, is utilized in these studies. C1.92 cells are maintained in $\alpha$-modification of Eagle's medium ( $\alpha$-MEM) supplemented with $5 \%$ fetal calf serum (Summit), $1 \%$ penicillin/streptomycin, $1 \% \mathrm{I}$-glutamine, and $0.1 \%$ 2-Mercaptoethanol in the presence of S10 and 50U/mL of IL-7. S10 stromal cells were a generous gift from Dr. Kenneth Dorshkind (University of California). Isolation and biological characteristics of S10 have been previously described in detail (Johnson, 1986). S10 cells were maintained in $\alpha$ MEM media supplemented as described above and grown to confluence in $75 \mathrm{~cm}^{2}$ flasks. They were passaged weekly by trypsinization (0.25\%, GIBCO).

Downregulation of C-myb. C-myb expression was abrogated using two methods. Non-specific downregulation was accomplished using DMSO (dimethylsulphoxide). DMSO was added directly to culture conditions at varying concentrations including $0.5 \%, 0.75 \%, 1.0 \%, 1.25 \%$ and $1.5 \%$. Cultures were treated for varying times: 2 hours, 6 hours, 12 hours, 24 hours, 48 hours, 72 hours, 96 hours, and 144 hours. Specific Cmyb downregulation was accomplished by using antisense oligonucleotides complementary to the start site of the c-myb mRNA sequence. Antisense oligonucleotides (5'-GTTGAGTGGGGCGCCCATCATCGC-3' with phosphorothioated backbone) (Biosource International and Integrated DNA Technologies, Inc.) were added to pro-B cell cultures at a concentration of $14 \mu \mathrm{M}$ for 60 hours. As a control, scrambled oligonucleotides (5'-CGGTCCTCACGGTAGCAGGTGTCG-3' with phosphorothioated backbone) were also added to pro-B cell cultures. Scrambled oligonucleotides 
contained the same $A / T$ and $G / C$ content as antisense oligos. PBS was also added to cultures as a control since antisense and scrambled oligonucleotides were reconstituted in PBS.

Cell Counts and Viability assay. After treatment with DMSO or oligonucleotides, C1.92 cells were removed from culture, diluted with an equal volume of $0.4 \%$ trypan blue (Sigma), and counted in a hemacytometer. Both total cells and viable cells in culture were calculated from hemacytometer counts.

RNA Isolation. After culture with DMSO or oligonucleotides, $2 \times 10^{6} \mathrm{C} 1.92$ cells were harvested, washed with PBS, and frozen in liquid nitrogen. Total RNA was extracted using the SNAP RNA isolation kit (Invitrogen). After isolation, RNA was quantitated using a spectrophotometer and quartz cuvettes. $0.1 \mu \mathrm{g}$ of total RNA was amplified simultaneously for c-myb and GAPDH using a one-step RT-PCR reaction (Qiagen). 0.1 $\mu \mathrm{g}$ of RNA was combined with 1x Qiagen OneStep RT-PCR Buffer, $400 \mu \mathrm{M}$ of each dNTP, $0.5 \mu \mathrm{g}$ c-myb sense primer, $0.5 \mu \mathrm{g}$ c-myb antisense primer, $1 \mu \mathrm{g}$ GAPDH sense primer, $1 \mu \mathrm{g}$ GAPDH antisense primer, $2 \mu$ l Qiagen OneStep RT-PCR Enzyme Mix, 5 units RNase inhibitor, and water to a total volume of $50 \mu$ l. C-myb specific primers used were: (sense primer) 5'-GAGCTTGTCCAGAAATATGGTCCGAAG-3' and (antisense primer) 5'-GGCTGCCGCAGCCGGCTGAGGGAC-3' (Biosource International). GAPDH amplification was used as a control for template integrity and normalization of data utilizing the following primers: (sense primer) 5'TGAAGGTCGGTGTGAACGGATTTGG-3' and (antisense primer) 5'ACGACATACTCAGCACCGGCCTCAC-3' (Biosource International). RT-PCR amplifications were performed in a GeneAmp PCR System 9700 (Perkin Elmer Applied BioSystems). Reverse transcription was carried out at $50^{\circ} \mathrm{C}$ for 30 minutes. DNA polymerase was activated by heating for 15 minutes at $95^{\circ} \mathrm{C}$. Amplification was performed for 30 cycles with denaturation at $94^{\circ} \mathrm{C}$ for 30 seconds, annealing at $60^{\circ} \mathrm{C}$ for 1 minute, and extension for 1 minute at $72^{\circ} \mathrm{C}$ with an additional 10 minute, $72^{\circ} \mathrm{C}$ extension added to the final cycle. PCR products were separated on $2 \%$ ethidium bromide stained gels and visualized using Eagle Eye (Stratagene).

Protein Analysis. To evaluate the influence of DMSO or antisense oligonucleotides on C-myb protein levels, C1.92 cells were maintained in normal culture conditions (in 
the presence of S10 and IL-7) or in cultures to which $14 \mu \mathrm{M}$ antisense oligonucleotides or varying concentrations of DMSO were added. Protein was isolated from $1 \times 10^{6}$ pro-B cells in Laemmli's buffer and separated on $8 \%$ denaturing polyacrylamide gels. Gels were transferred to PVDF membrane and blocked for 30 minutes in PBS with 5\% dry milk. Blots were than probed with a primary monoclonal mouse C-myb antibody (Clone 1.1, Upstate Biotechnology, $1 \mu \mathrm{g} / \mathrm{ml}$ ) or monoclonal mouse GAPDH (glucose-aldehydephosphate dehydrogenase) antibody (Research Diagnostics, $0.5 \mu \mathrm{g} / \mathrm{ml}$ ) in PBS with $3 \%$ milk overnight at $4^{\circ} \mathrm{C}$. Blots were then washed with one change of water and probed with a goat $\alpha$-mouse Ig-HRP as the second antibody for 2 hours at room temperature. Blots were washed with one quick wash of water, one 15 minute wash of TBS with $0.1 \%$ Tween, and then 5 vigorous washes in water at room temperature for one minute. ECL plus (Amersham) was used as a chemiluminescent reagent and then blots exposed to Kodak X-OMAT film. Densitometry analysis was done using Eagle Eye Software.

Cell Depletion. G10 Sephadex was used to deplete adherent stromal cells from pro-B cell suspensions. Sterile G10 columns were prepared as described by Kincade et al (1981). Sterile $10 \mathrm{ml}$ syringe barrels were plugged with glass wool, autoclaved, and filled with $8 \mathrm{mls}$ of sterile pre-swollen G10 Sephadex. Columns were washed with sterile PBS and equilibrated with $20 \mathrm{mls}$ warm media. Two mls of media containing $5 \times 10^{6} \mathrm{C} 1.92$ cells were applied to each column. Columns were incubated at room temp for 30 minutes. Cells were then washed from columns with $30 \mathrm{mls}$ of warm media.

DNA Isolation and Ig gene rearrangment status. DNA was isolated from $1 \times 10^{6}$ C1.92 cells using the Easy-DNA isolation kit (Invitrogen). DNA was RNAse treated to remove contaminating RNA and resuspended in $100 \mathrm{ml}$ of Tris-EDTA (pH 8). 500 ngs of DNA were used in an RT-PCR reaction (Promega) to determine immunoglobulin (Ig) gene rearrangement status. The Ig heavy chain is assembled from a variable (V) region, a diversity (D) region, a joining $(\mathrm{J})$ region, as well as a constant region. These loci are separated from one another in the germline by intervening sequences and are joined together upon B cell differentiation. Ig heavy chain gene rearrangement status was determined using primer sets that are complementary to the intervening sequence between the $V$ and $D$ section of the heavy chain gene (using primers $D_{F L 16.1} ; 1227$ bp amplicon) and between the $\mathrm{D}$ and $\mathrm{J}$ section of the heavy chain gene (using primers $\mathrm{JH}_{1}$; 
472 bp amplicon). The sequence of primer sets was as follows: $D_{\mathrm{FL} 16.1}$ (sense primer) 5'-GCCTGGGGAGTCACTCAGCAGC-3';

(antisense primer) - 5'-GTGTGGAAAGCTGTGTATCCCC-3' and

$\mathrm{JH}_{1}$ (sense primer) - 5'- CCCGGACAGAGCAGGCAGGTGG-3' and (antisense primer) -5'-GGTCCCTGCGCCCCAGACA-3'. Amplification was performed for 35 cycles with denaturation at $95^{\circ} \mathrm{C}$ for 1 minute, annealing at $58^{\circ} \mathrm{C}$ for 3 minutes, and extension for 4 minutes at $72^{\circ} \mathrm{C}$ with an additional 15 minute extension added to the final cycle. Loss of a $D_{F L 16.1}$ or a $\mathrm{JH}_{1}$ amplicon was indicative of gene rearrangement. DNA from identically prepared $\mathrm{S} 10$ was used to confirm germline configuration.

GAPDH ((sense primer)5'-TGAAGGTCGGTGTGAACGGATTTGG-3' (antisense primer) 5'-ACGACATACTCAGCACCGGCCTCAC-3')) amplification was used as a control for template integrity and normalization of data. PCR products were separated on $2 \%$ ethidium bromide stained gels and visualized using Eagle Eye (Stratagene).

Proliferation assay. Following culture with DMSO or oligonucleotides, $1 \times 10^{5}$ viable C1.92 cells were allocated in 96 well plates coated with S10 and $200 \mu \mathrm{l}$ of $\alpha$-MEM media. Cells were cultured over night for 18 hours, and then pulsed with $1 \mu \mathrm{Ci}{ }^{3} \mathrm{H}$ TdR/well. After 6 more hours of culture, cells were harvested onto glass wool fiber strips with an automated cell harvester. Radioactive incorporation was determined by liquid scintillation counting in an aqueous fluor (Biosafe-II). Each treatment was repeated in triplicate.

Cell Cycle Analysis. C1.92 cells were cultured with DMSO or oligonucleotides as previously described. $1 \times 10^{6}$ cells were fixed in $70 \% \mathrm{EtOH}$ (at $-20^{\circ} \mathrm{C}$ ) and treated with $20 \mu \mathrm{g}$ RNase A (Sigma) at $37^{\circ} \mathrm{C}$ for 30 minutes. Cells were then stained with $50 \mu \mathrm{g} / \mathrm{mL}$ propidium iodide (PI) (Sigma) to evaluate DNA content. PI stained cells were evaluated using a flow cytometer (FACScan; Becton Dickinson) and analyzed using ModFit Software.

Fluorescent Staining. For surface Ig, flt-3, BP-1, HSA (CD24), and CD43 staining, $10^{6}$ C1.92 cells were harvested after being cultured with PBS, scrambled oligonuclotide, or antisense olignucleotide for 0 or 60 hours. Cells were washed with ice-cold PBS containing $0.1 \%$ heat inactivated fetal bovine serum (PBS/FBS). Cells were aspirated to dryness, resuspended in $25 \mu \mathrm{l}$ of PBS and stained with $1 \mu \mathrm{g} / \mathrm{ml}$ FITC conjugated 
primary antibody (or a corresponding isotype) for 30 minutes at $4^{\circ} \mathrm{C}$. Cells were then washed twice with PBS/FBS and resuspended in $500 \mathrm{ml}$ of PBS and $500 \mathrm{ml}$ of paraformaldehyde buffer (2\%). Samples were analyzed using a flow cytometer (FACScan; Becton Dickinson) and WinMidi software.

\section{RESULTS}

Effect of DMSO on C-myb Expression in Pro-B Cells. DMSO treatment (Collins, 1978; Westin, 1982) was utilized to downregulate C-myb levels in pro-B cells while allowing them to remain in the presence of stromal cells. C1.92 cells were cultured with several different concentrations of DMSO to determine optimal concentrations for c-myb downregulation. C1.92 cells were cultured with $0 \%, 0.5 \%, 0.75 \%, 1.0 \%, 1.25 \%$, and 1.5\% DMSO for 2 hours, 6 hours, 12 hours, 24 hours, 48 hours, 72 hours, 96 hours, and 144 hours. A dose dependent response to DMSO was observed. C-myb protein levels were not altered after 24 hours of culture with the lowest concentrations of DMSO. However, 24 hours of culture with the highest DMSO concentration (1.5\%) resulted in undetectable C-myb protein expression in pro-B cells. In order to avoid any toxicity to pro-B cell cultures, $\mathrm{C} 1.92$ cells were treated with moderate levels of DMSO and evaluated at 48,72 , and 96 hours post treatment. After 72 hours of culture, C.192 treated with $0.5 \%$ DMSO had a $15 \%$ reduction in C-myb protein while pro-B cells treated with $1.0 \%$ DMSO had a $50 \%$ reduction in C-myb expression. Within 96 hours Cmyb protein expression was almost undetectable in cultures treated with $1.0 \%$ DMSO, but was still present in pro-B cells cultured with 0.5\% DMSO (figure 1).

DMSO Treatment Does Not Decrease Cell Viability. After treatment with DMSO, cell viabilities were assessed using trypan blue exclusion. C1.92 cells were cultured with moderate concentrations of DMSO, $0.5 \%$ and $1.0 \%$ DMSO, for 48,72 , and 96 hours. As discussed above, there was a decrease in C-myb protein in $\mathrm{C} 1.92$ cells treated with 1.0\% DMSO within 72 hours and levels were almost undetectable by 96 hours. However, there was no change in viabilities of treated or untreated pro-B cells (figure 2). 


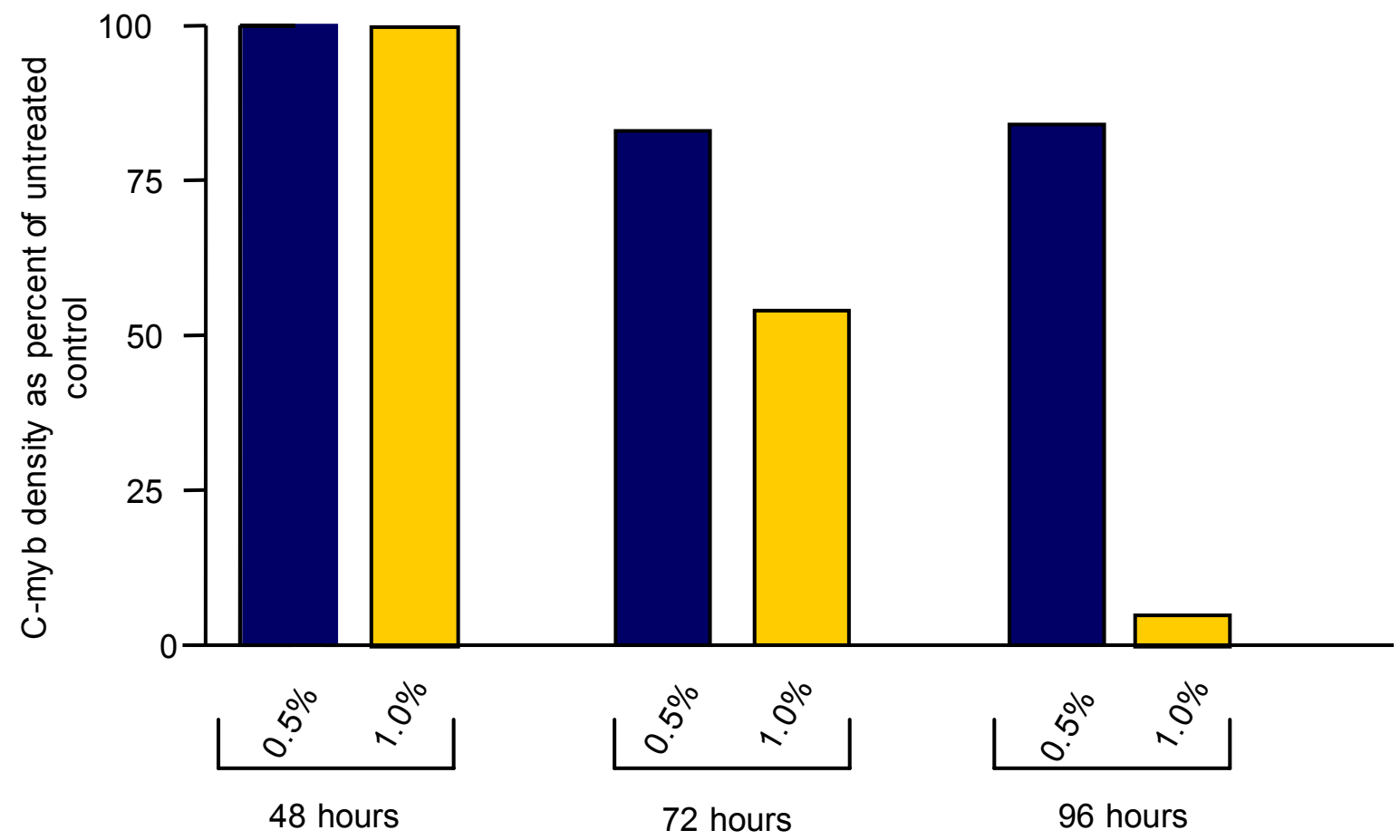

Figure 1. Effect of DMSO on C-myb Expression in Pro-B Cells. C1.92 cells were treated with culture medium alone, medium containing $0.5 \%$ DMSO, or medium containing $1.0 \%$ DMSO for 48,72 , or 96 hours. $10^{6}$ live $\mathrm{C} 1.92$ cells were harvested and C-myb protein levels were determined by Western Blot analysis. Data is shown as Cmyb protein density as a percentage of untreated controls. Data is representative of 3 replicate experiments. 
A.

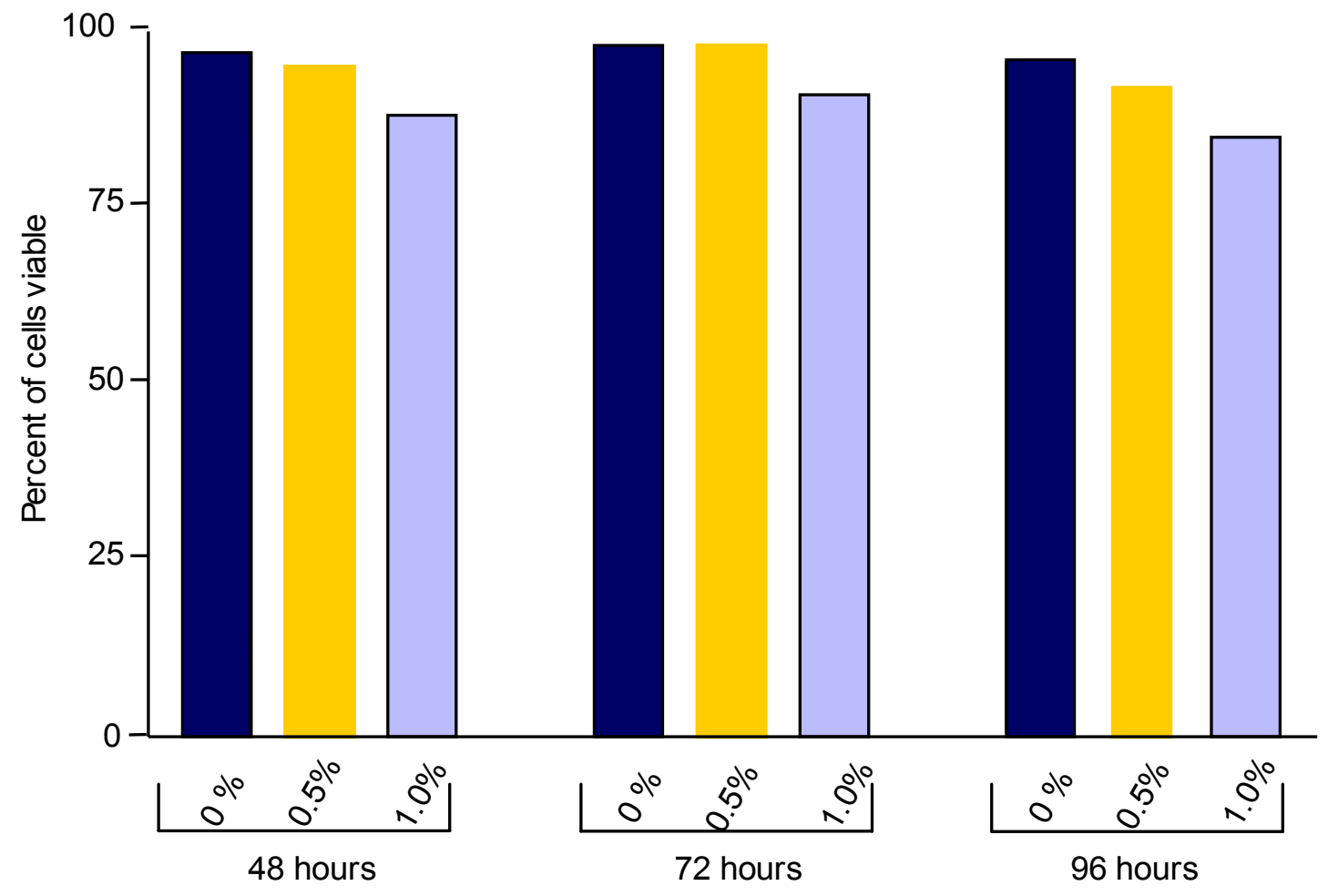

Figure 2. DMSO Treatment Does Not Decrease Cell Viability. C1.92 cells were treated with culture medium alone, medium containing 0.5\% DMSO, or medium containing $1.0 \%$ DMSO for 48,72 , or 96 hours. Cell viability of both treatment groups was then determined using trypan blue exclusion. Data presented is one of 3 replicate experiments. 
Non-Specific Inhibition of C-myb Results in Decreased Pr-B Cell Expansion in Culture. After treatment with DMSO, C1.92 cells were enumerated to assess total number of cells in culture. C1.92 cells left untreated or treated with $0.5 \%$ DMSO expanded in culture over the experimental timecourse. However, as shown in figure 3 , C1.92 cells with downregulated C-myb expression (by treatment with 1.0\% DMSO) expanded less in culture.

Downregulation of C-myb is Associated with Ig Gene Rearrangement. C-myb downregulation has been associated with the maturation and differentiation of myeloid cells. In order to determine if $\mathrm{C}-m y b$ was involved with progression through the $\mathrm{B}$ lineage pathway, gene rearrangement status of the Ig heavy chain gene in C1.92 cells was evaluated. Prior to any treatment regime, C1.92 cells have both the D-J and V-DJ segments of the Ig heavy chain gene in germline configuration (figure 4, 0 hour), and they remain germline throughout the entire culture period. C1.92 cells were cultured with $1.25 \%$ DMSO for 24 or 48 hours. After treatment, C1.92 cells were removed from culture and depleted of any adherent stromal cell contamination. This was to ensure that S10 DNA, which is in germline configuration, would not contaminate C1.92 DNA. After culture for 24 hours, pro-B cells cultured with $1.25 \%$ DMSO rearranged genes at the D-J loci. Within 48 hours, genes at both the D-J and V-DJ loci were rearranged (figure 4, 1.25\% DMSO). Gene rearrangement also occurred in $\mathrm{C} 1.92$ cells treated with $1.0 \%$ DMSO, however 144 hours of culture with DMSO was necessary to induce gene rearrangement. In untreated control cultures, gene rearrangement was not observed. As a control, GAPDH expression was evaluated. GAPDH was unchanged in all treatment groups. This indicates that genotypic maturation occurs after C-myb downregulation in pro-B cells. 
A.

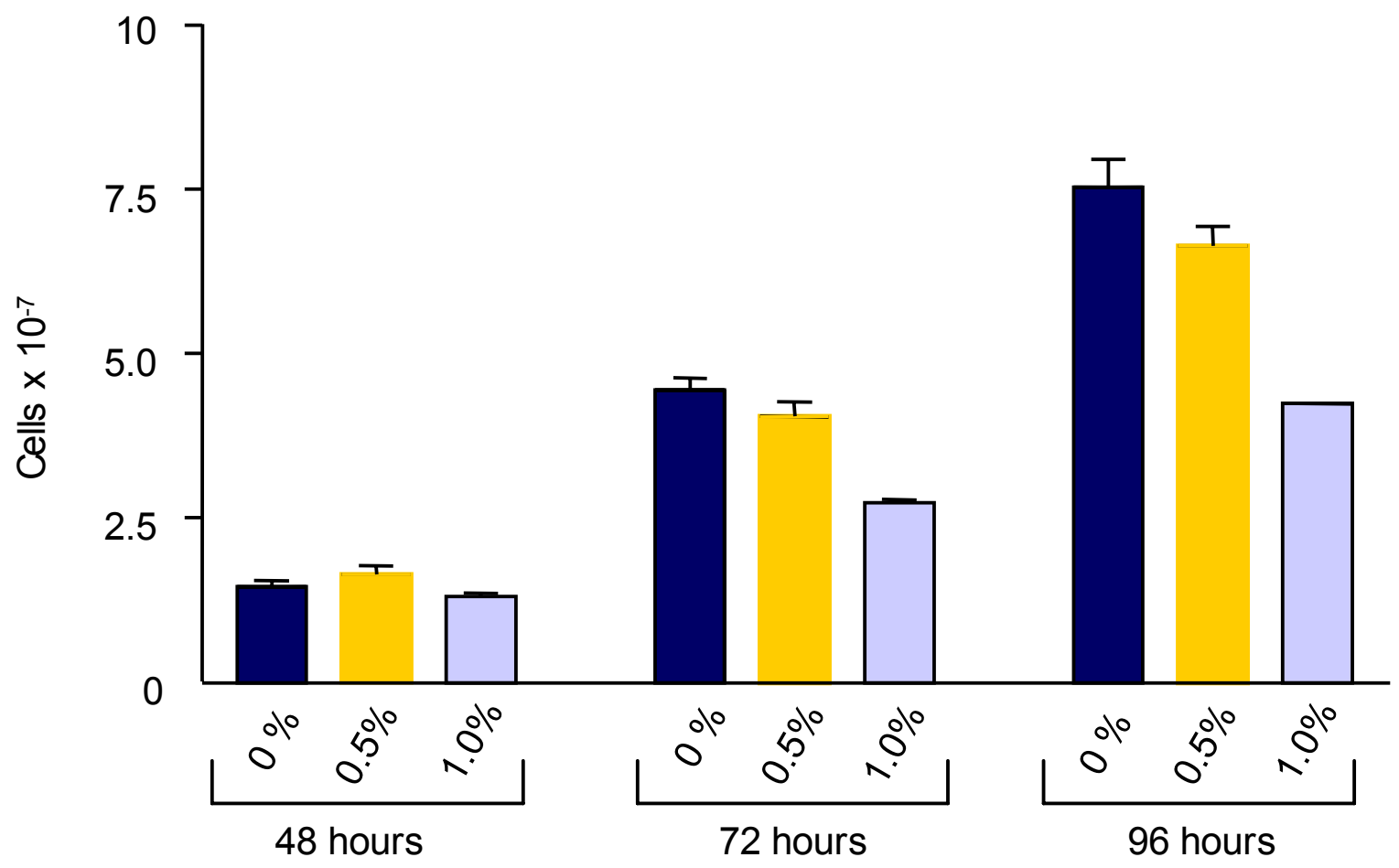

Figure 3. Inhibition of C-myb Results in Decreased Pro-B Cell Expansion in Culture. C1.92 cells were cultured for 48, 72, or 96 hours in tissue culture media alone, in media containing $0.5 \%$ DMSO, or in media containing 1.0\% DMSO. Cell recovery and cell viability were determined. Data shown is mean and SEM of 3 replicate experiments. 


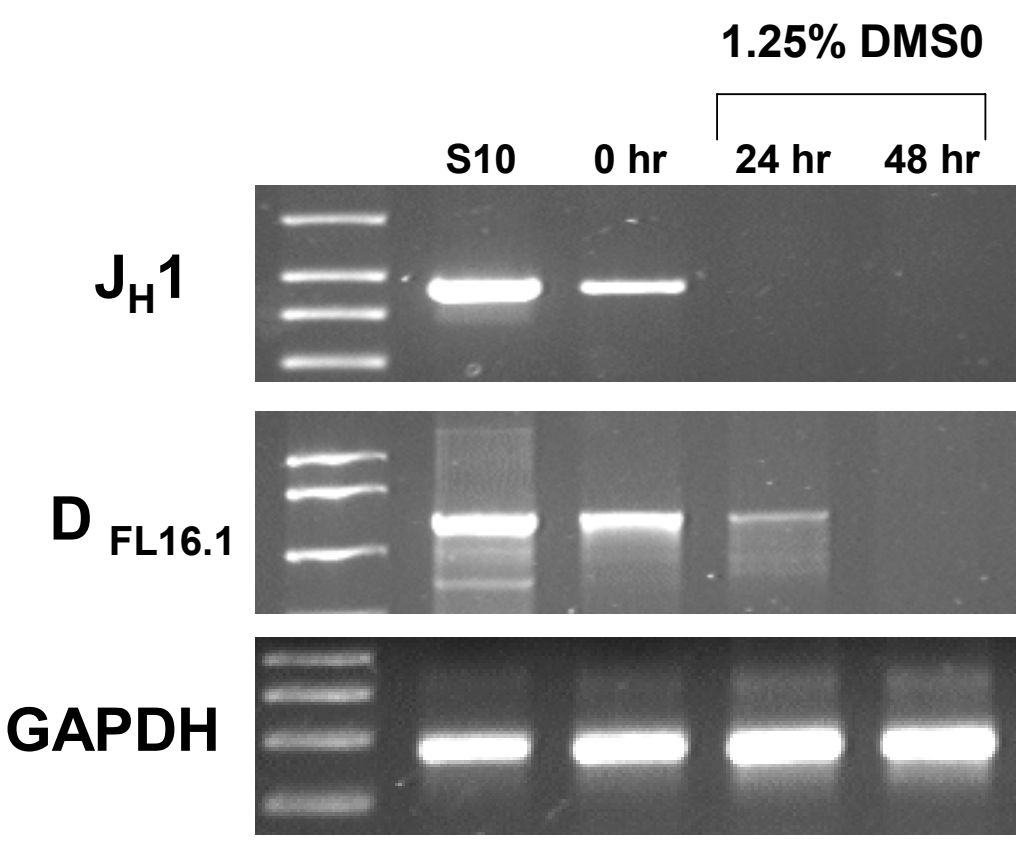

Figure 4. Downregulation of C-myb is Associated with Pro-B Cell Differentiation. C1.92 cells were treated with cell culture medium alone or medium containing $1.25 \%$ DMSO for 24 or 48 hours. DNA was isolated from $10^{6}$ pro-B cells. RT-PCR amplification was performed using primers designed to detect gene rearrangement, as well as GAPDH primers to check template integrity. Data from one of 3 replicate experiments is shown. 


\section{$1.5 \%$ DMSO treated}

C1.92 Pro-B Cell S10 Stromal Cell S10 Stromal Cell

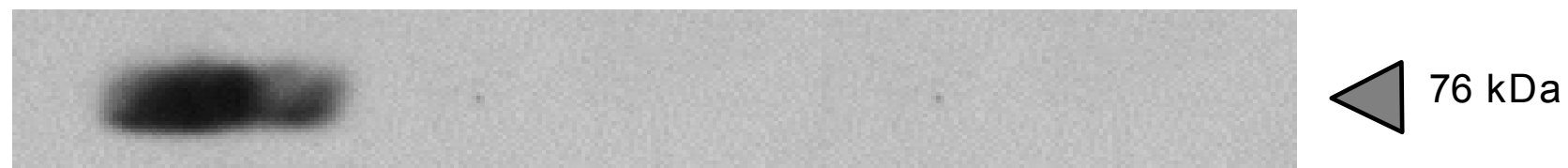

Figure 5. Stromal Cell C-myb Levels Are Not Altered By DMSO Treatment. Nonconfluent flasks of S10 stromal cells were treated with $1.5 \%$ DMSO for 48 hours. After 48 hours of DMSO treatment, C-myb protein expression was examined by western blot analysis. Data from one of 3 experiments is presented. 


\section{C-myb Downregulation Results in Cell Surface Expression of Immunoglobulin but}

Not in Other Phenotypic Changes. In addition to genotypic alterations, B cell maturation is accompanied by several phenotypic alterations. After immunoglobulin heavy chain gene rearrangement, surface Ig expression is an indicator of progression through the B lineage pathway. Under normal culture conditions, C1.92 cells do not express cell surface immunoglobulin; C1.92 cells are CD43 ${ }^{\text {hi }}, C D 24^{\mathrm{lo}}, \mathrm{CD} 45 \mathrm{R}^{\mathrm{lo}}, \mathrm{ftt}-3^{\mathrm{lo}}$, and sig. C1.92 cells treated with $0.5 \%$ DMSO remained slg-. However, pro-B cells treated with $1.0 \%$ DMSO that exhibited downregulation of C-myb had an increase in the expression of surface immunoglobulin (slg) as detected by fluorescent staining. In addition to surface Ig expression, alterations in several other cell surface molecules have been correlated with stages in B cell development. These changes include increased expression of flt-3, CD24 (Heat Stable Antigen), BP-1, and CD45R. C1.92 cells treated with $0.5 \%$ and $1.0 \%$ DMSO exhibited no alterations in these cell surface molecules. No changes in BP-1, CD24, CD45R, or flt-3 were observed after 96 hours of treatment with $1.0 \%$. These data indicate that downregulation of C-myb results in rearrangement of immunoglobulin heavy chain genes, expression of immunoglobulin on the cell surface, and pro-B cell maturation, but not in changes of other cell surface molecules.

Stromal Cell Alterations Following DMSO Treatment. Several changes were observed in C1.92 cells after treatment with DMSO. However, since they are grown in co-culture with stromal cells, it was necessary to ensure that DMSO was not also affecting stromal cell characteristics. Therefore S10 stromal cells were also treated with media containing 1.5\% DMSO, the highest concentration used for any of these experiments, for 48 hours. S10 stromal cells do not normally express C-myb mRNA or protein. Culture with DMSO for 48 hours did not induce C-myb expression (figure 5). In addition, the cytokine profile of S10 stromal cells was examined after culture with $1.5 \%$ DMSO for 48 hours. RT-PCR showed little to no changes in stromal cell expression levels of IGF-1 or IL-7 (figures 6 and 7). Although there appears to be a slight increase in IL-7 mRNA following DMSO treatment, a proliferation assay showed no increase in functional IL-7 protein. PCR of DNA from DMSO treated stromal cells revealed that the 
Ig genes of stromal cells remained in germline configuration (figure 8). These data indicate that DMSO treatment alters c-myb expression and Ig gene rearrangement status in pro-B cells but not in stromal cells. And, stromal cells treated with DMSO neither have alterations of B cell specific cytokines (IL-7 and IGF-1) nor do they exhibit an impaired ability to support pro-B cells in culture. Therefore, the effects of DMSO in the pro-B cell/stromal cell culture are specific to B cell progenitors.

\section{Regulation of C-myb Expression in Pro-B Cells Using Antisense}

Oligonucleotides. Although DMSO treatment was effective at downregulating C-myb in pro-B cells, the mechanism by which this is accomplished is non-specific. In order to specifically downregulate C-myb expression in pro-B cells, antisense oligonucleotides were utilized. Antisense oligonucleotides were cultured with pro-B cells for 60 hours. As controls, pro-B cells were also cultured with a scrambled sequence of oligonucleotides. The scrambled oligos had the same $\mathrm{G} / \mathrm{C}$ and $\mathrm{A} / \mathrm{T}$ content as did antisense oligos, however the nucleotides were in random order. This was used to ensure that any effects observed were due to specificity of antisense oligonucleotides and not due to non-specific oligonucleotide effects. In addition, cultures were also treated with PBS since this served as the solvent for reconstituting antisense and scrambled designed complimentary to the start site of the c-myb mRNA. Pro-B cells were cultured with stromal cells and $14 \mu \mathrm{m}$ oligos. After 60 hours of treatment C-myb protein was significantly decreased in cultures treated with antisense oligonucleotides but was unchanged in scrambled or PBS treated cultures (figure 9). 

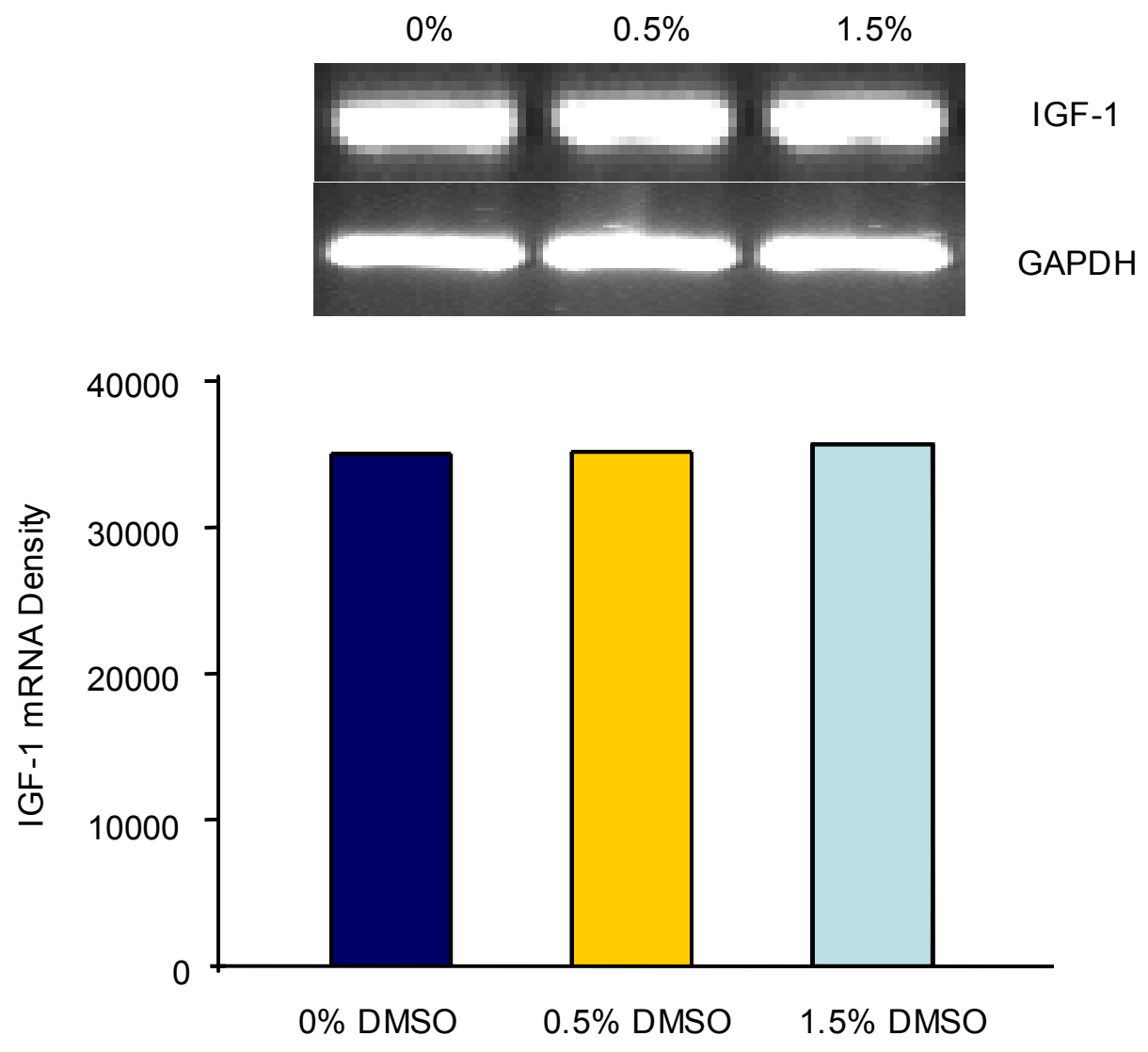

Stroma Treatment

Figure 6. DMSO Treatment of Stromal Cells Does Not Alter IGF-I Expression. S10 stromal cells were treated with DMSO for 48 hours. RNA was isolated from treated cells and RT-PCR was performed. GAPDH was amplified as an internal control. Data from one of three experiments is shown. 


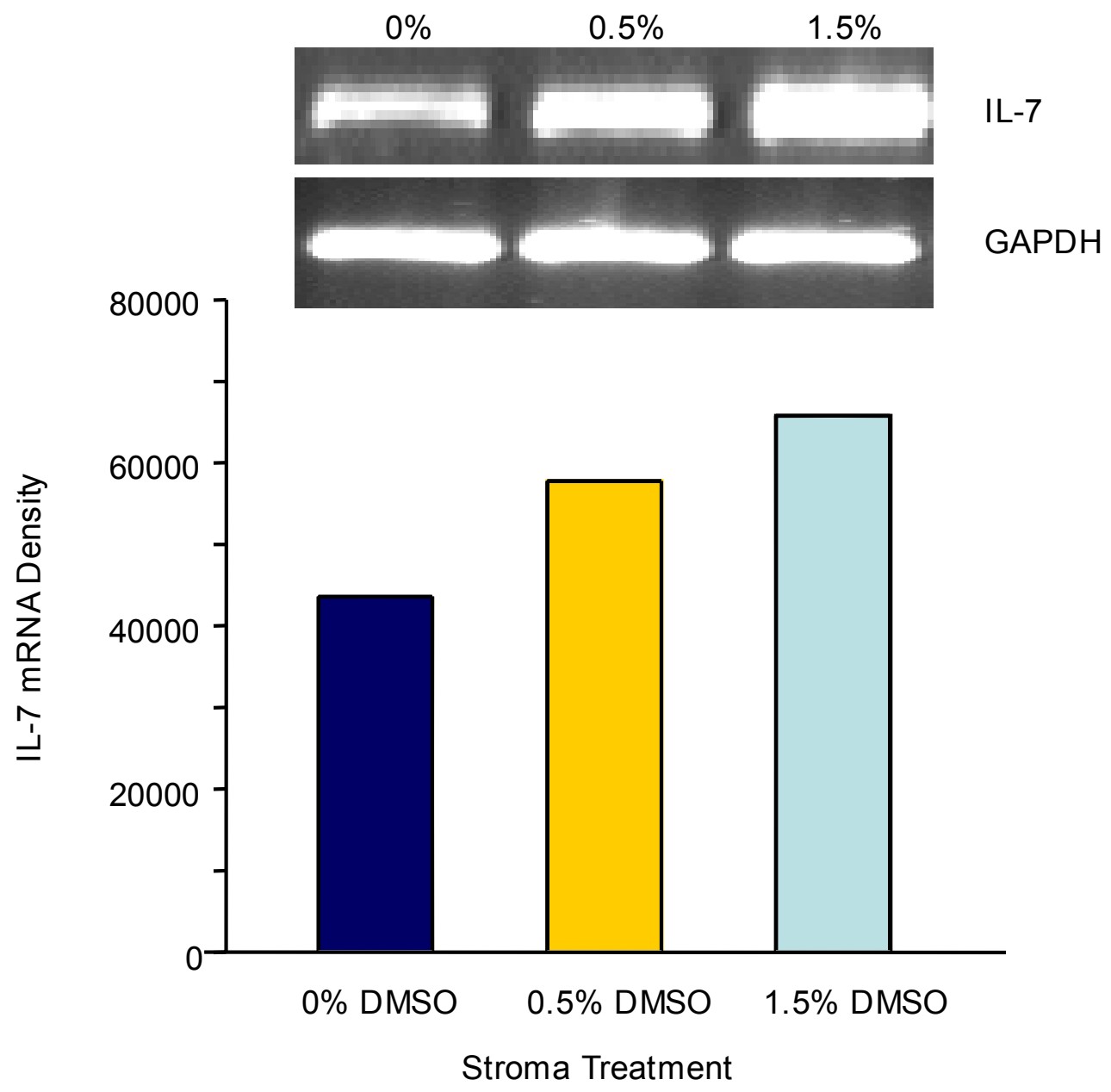

Figure 7. DMSO Treatment of Stromal Cells Does Not Alter IL-7 Expression. S10 stromal cells were treated with DMSO for 48 hours. RNA was isolated from treated cells and RT-PCR was performed. GAPDH was also amplified as an internal control. Data from one of three experiments is pictured. 

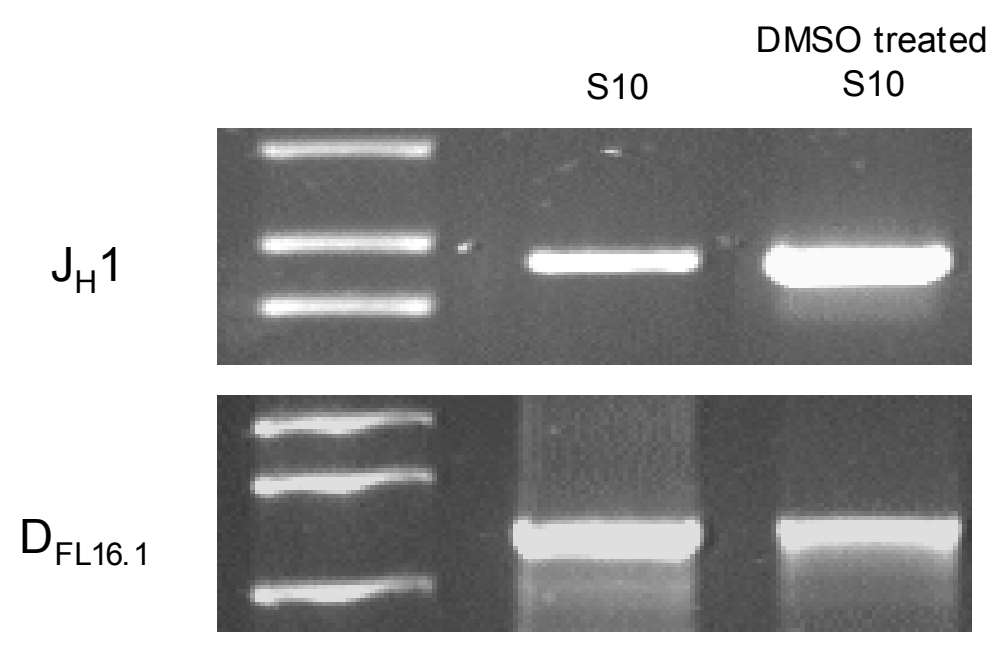

Figure 8. Stromal Cell Ig Gene Rearrangement Status is Not Altered by DMSO Treatment. Non-confluent flasks of S10 stromal cells were treated with 1.5\% DMSO for 48 hours. After 48 hours of DMSO treatment, DNA was isolated from stromal cells and PCR amplified to detect gene rearrangement status. 


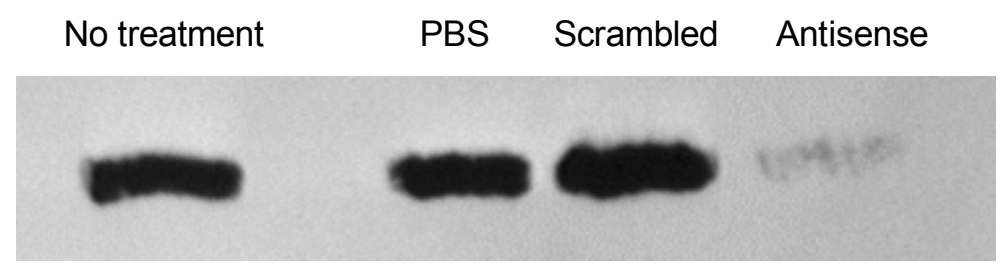

Figure 9. Regulation of C-myb Expression in Pro-B Cells Using Antisense Oligonucleotides. C1.92 cells were grown in medium with S10 and IL-7 for 24 hours. $14 \mu \mathrm{M}$ c-myb scrambled oligonucleotides, $14 \mu \mathrm{M}$ c-myb antisense oligonucleotides, or saline solvent were then added to the culture for 60 hours. After 60 hours, $10^{6}$ live cells were collected and C-myb protein analyzed by Western Blot. Data shown is one of 5 representative experiments. 
Antisense Oligonucleotide Treatment Does Not Decrease Cell Viability. As with DMSO, the viability of C1.92 cells after treatment with oligonucleotides was examined using trypan blue exclusion. Downregulation of C-myb by culture with antisense oligonucleotides resulted in no changes in cell survival. These data indicated that proB cell survival was not altered by specific decreases in C-myb expression (figure 10).

\section{Specific Inhibition of C-myb Results Decreased Pro-B Cell Expansion in Culture.} After treatment with oligonucleotides, $\mathrm{C} 1.92$ cells were enumerated to assess total number of cells in culture. C1.92 cells treated with PBS or treated with scrambled oligonucleotides expanded in culture over the experimental timecourse. However, as shown in figure 11, C1.92 cells with downregulated C-myb expression (by treatment with antisense oligonucleotides) expanded less in culture.

Inhibition of C-myb Results in a Decreased Response to IL-7. Since C-myb downregulation by antisense oligonucleotides inhibited pro-B cell expansion, the ability of C1.92 cells to respond IL-7, their major proliferative stimulus, was evaluated. C1.92 cells were treated either with PBS, scrambled oligonucleotides, or antisense oligonucleotides for 60 hours. After 60 hours of treatment cells were washed and plated in S10 coated-96 well plates, with or without IL-7 as indicated in figure 12. Pro-B cells treated with PBS or scrambled oligonucleotides proliferated in response to IL-7 exposure. However, pro-B cells treated with antisense oligonucleotides nucleotides exhibited a decreased proliferative response following IL-7 exposure (figure 12, antisense). 


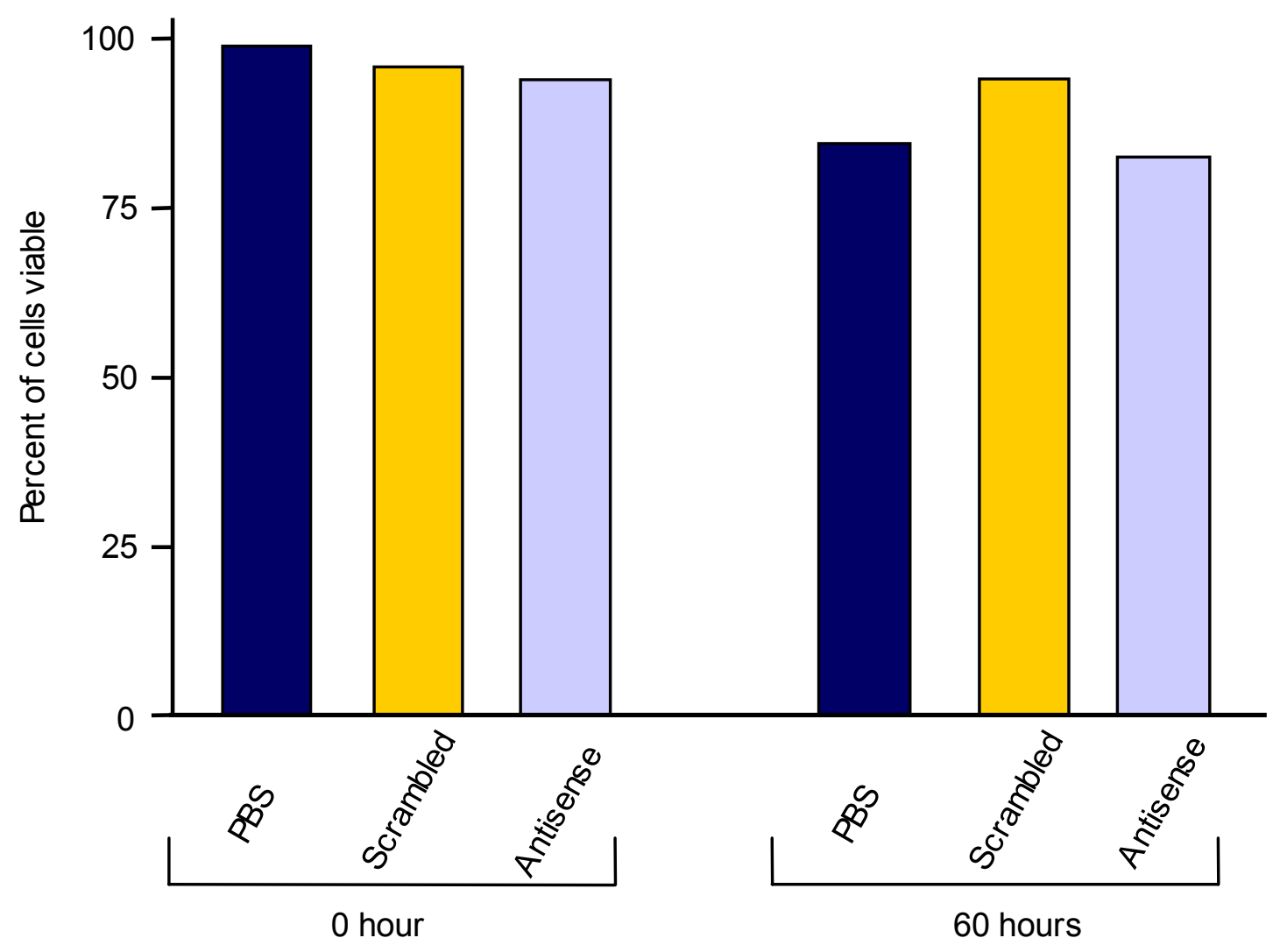

Figure 10. Antisense Oligonucleotide Treatment Does Not Decrease Cell Viability. C1.92 cells were cultured for 60 hours in media alone or in media containing PBS, $14 \mu \mathrm{M}$ c-myb scrambled oligonucleotides, or $14 \mu \mathrm{M}$ c-myb antisense oligonucleotides. Cell viability of both treatment groups was then determined using trypan blue exclusion. Data shown is representative of 5 experiments. 


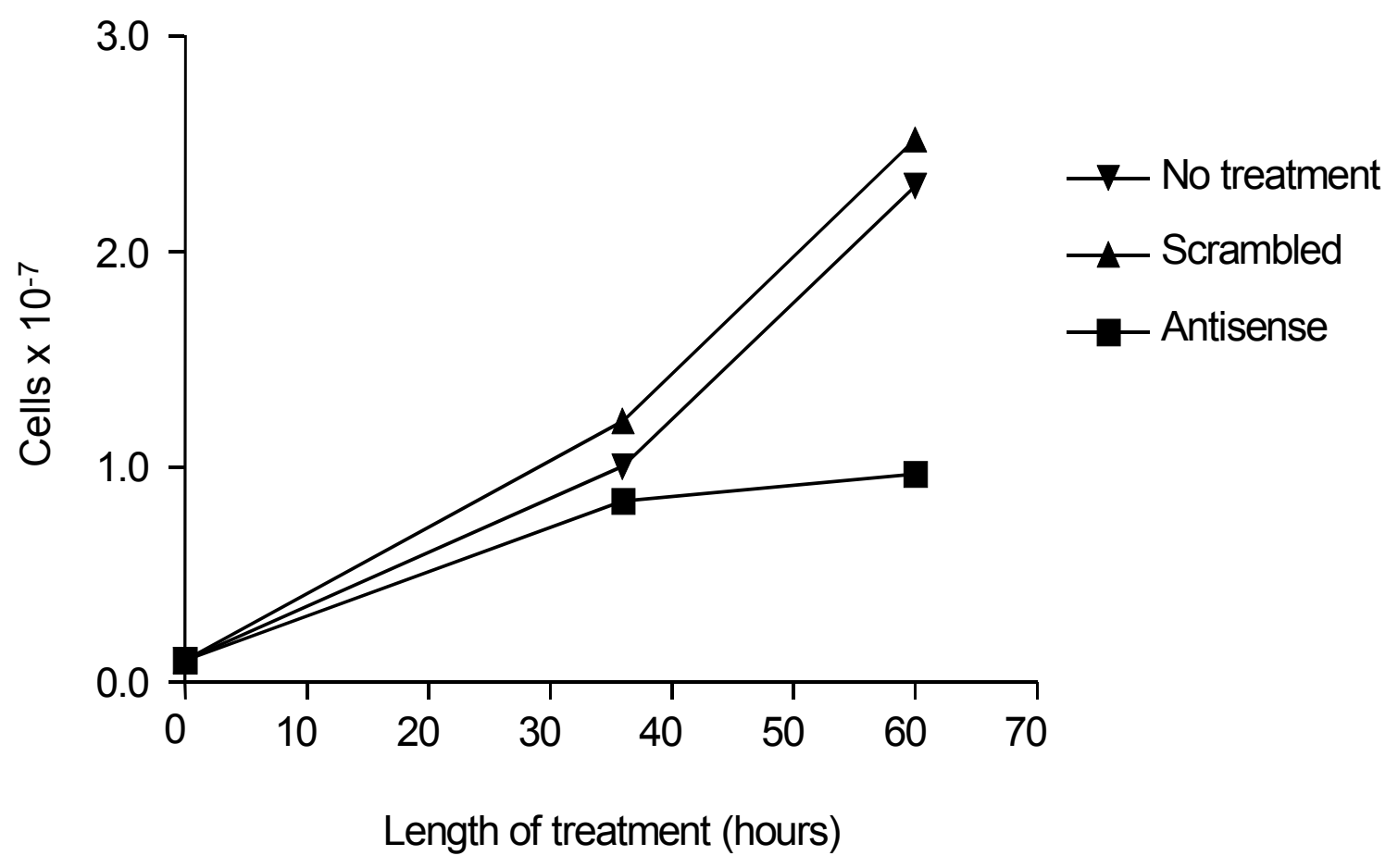

Figure 11. Inhibition of C-myb Results in Decreased Pro-B Cell Expression in Culture. C1.92 cells were cultured for 60 hours in tissue culture medium alone or in medium containing PBS, $14 \mu \mathrm{M}$ c-myb scrambled oligonucleotides, or $14 \mu \mathrm{M}$ c-myb antisense oligonucleotides. Cell recovery and cell viability was determined. Data is presented as one of 5 experiments. 


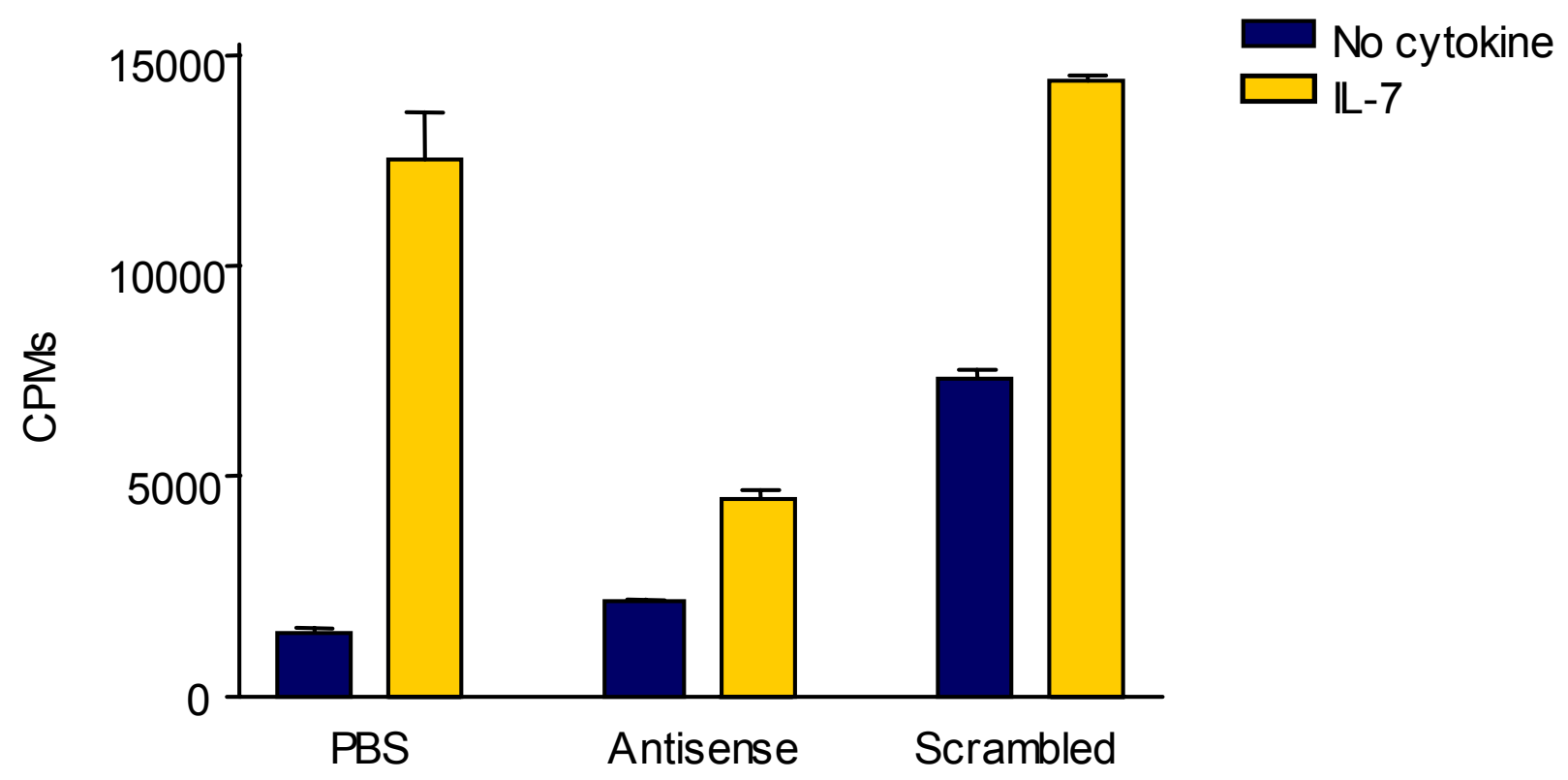

Figure 12. Inhibition of C-myb Results in a Decreased Response to IL-7. C1.92 cells were cultured for 60 hours in tissue culture medium containing PBS, $14 \mu \mathrm{M}$ c-myb scrambled oligonucleotides, or $14 \mu \mathrm{M} c-m y b$ antisense oligonucleotides. Cell recovery and cell viability was determined. After treatment, $10^{5} \mathrm{C} 1.92$ cells were cultured on S10 with or without IL-7 for 18 hours in 96 well plates. Cells were pulsed with tritiated thymidine following an 18 hour exposure to IL-7. Data is presented as mean and SEM of 3 replicate wells. Experiments were conducted a minimum of 3 times. 


\section{DISCUSSION}

Although c-myb has been shown to be critical in the development of erythroid and myeloid precursors, less work has been done on the role of c-myb in the normal development of lymphocytes. Because c-myb deletion in vivo results in embryonic lethality, it is difficult to investigate c-myb regulation in developing B lymphocytes. Much of the erythroid and myeloid work has been accomplished using an in vitro cell model. Therefore, an appropriate model of B cell development must be utilized to determine the role of c-myb in B lymphopoiesis. The aim of this work was to develop a system in which c-myb expression in pro-B cells could be downregulated while they remain in coculture with stromal cells. In addition, this work will determine whether c-myb is an intracellular regulator of survival, proliferation, and/or differentiation in early $B$ cell progenitors. This project demonstrates that the addition of DMSO or antisense oligonucleotides to pro-B cell cultures results in c-myb downregulation, even in the presence of stromal cells. These data also clearly establish the role of c-myb in the proliferation and differentiation of stromal-cell dependent pro-B cells.

Expression and regulation of the proto-oncogene c-myb are critical events in the maturation of myeloid lineage cells. Myeloid differentiation has primarily been studied using tumor cell models comprised of cells blocked in a specific hematopoietic differentiation state. The HL-60 tumor cell line has been an in vitro model widely utilized to dissect the processes involved in myeloid cell development. HL-60 cells are a human leukemic cell line established from the peripheral blood leukocytes of a patient with acute promyelocytic leukemia. HL-60 cells are primarily promyelocytes arrested in an immature proliferative state. Previous data from Collins et al had demonstrated that addition of DMSO to HL-60 cell cultures would induce terminal differentiation of the promyelocytes into mature neutrophils and monocytes (Collins, 1977). The mechanism responsible for inducing maturation was unknown. In 1982, Westin et al further investigated the differentiation of $\mathrm{HL}-60$ cells and discovered that the maturation of promyelocytes correlated with a significant decline in c-myb expression. This finding laid the foundation to further expand the role of c-myb in myeloid cell development. 
In 1988, Clark et al demonstrated that constitutive expression of exogenously introduced c-myb inhibited erythroid differentiation in a murine erythroleukemia cell line (Clark, 1988). McClinton and collaborators further expanded Clarke's findings. They investigated the effects of ectopic C-myb over expression at different times during differentiation using a Friend virus-infected MEL cell line. The MEL cell line is an early erythroid precursor model that can be induced to differentiate into mature erythroid cells using chemical inducers, including erythropoietin and DMSO. During early and late stages of MEL cell differentiation, c-myb mRNA is biphasically downregulated. (Kirsch,1986 and Ramsay, 1986). McClinton et al introduced an inducible metallothionein promoter driven c-myb gene into MEL cells and expressed c-myb during different phases of differentiation. Expression of c-myb during the early phase of differentiation did not have an affect on MEL cell maturation, indicating that early downregulation of c-myb is not necessary for differentiation. However, if c-myb was continuously expressed during the entire induction phase, differentiation was completely blocked indicating that late down-regulation of c-myb is critical for terminal differentiation of MEL cells (McClinton, 1990). Recently, in 2001, Chen and Bender demonstrated that MEL cells could be induced to differentiate into a more mature cell by introducing an inducible dominant interfering myb allele (MEnT). Introduction of MEnT in MEL cells resulted in the cessation of proliferation and initiation of differentiation without chemical induction. These experiments demonstrate that c-myb downregulation alone (in MEL cells) is sufficient to induce terminal differentiation (Chen and Bender, 2001). Taken together these data supported a critical role for c-myb in myeloid and erythroid hematopoiesis: down regulation of c-myb is required for terminal differentiation of myeloid and erythroid cells.

We previously developed a cloned fetal liver pro-B cell line that is dependent on stromal cells and IL-7 for continued survival and proliferation (Gibson, 1996). This cloned pro-B cell line, termed C1.92, remains dependent on the presence of stromal cells for survival and proliferation, does not form tumors, and reconstitutes B lymphocytes in severe combined immunodeficient (SCID) mice. However, studies of the pro-B cell clone show it is characterized by rapid and continuous proliferation. We noted this continuously growing pro-B cell line was characterized by unusually high 
levels of c-myb expression. Culture of C1.92 pro-B cells without stromal cells resulted in decreased c-myb expression. However, C1.92 cells are dependent on stromal cell adhesion contacts for survival signals. Due to decreased cell viability, culture without stromal cells is not the best way to investigate the role of c-myb in B cell development. Previous work by Westin indicated that c-myb in myeloid cells could be non-specifically downregulated after culture with DMSO. Although the mechanism by which DMSO decreases c-myb expression is not known, it is nevertheless an effective method to alter c-myb levels. To determine if this would work with pro-B cells, C1.92 cells were cocultured with S10 stromal cells and exogenously added IL-7. DMSO was then added to pro-B cell cultures at varying concentrations. C1.92 cells exhibited a dose-response decrease in C-myb expression after treatment with DMSO. C-myb protein expression was only slightly altered after 48 hours of culture with $0.5 \%$ DMSO but was undetectable in pro-B cells cultured with $1.25 \%$ or $1.5 \%$ DMSO. This approach allowed us to downregulate $\mathrm{C}-m y b$ expression in pro-B cells while allowing them to remain in coculture with stromal cells. However, since this is a co-culture system, it was necessary to ensure that DMSO treatment was not altering stromal cells. S10 stromal cells do not express mRNA or protein for c-myb and they retain Ig heavy chain genes in germline configuration. After treatment with 1.5\% DMSO for 48 hours, S10 stromal cells still do not express c-myb mRNA or protein and their Ig heavy chain genes remain in germline configuration. In addition, the cytokine profile of stromal cells was examined after DMSO treatment. It has been previously reported in the literature that DMSO treatment causes alterations of IL-6 message. It was necessary to determine if DMSO was altering other cytokines produced by stromal cells that may influence B cell development. In particular, IGF-1 and IL-7 messages were examined because of their importance in pro-B cell proliferation and differentiation. Again, S10 stromal cells were treated with $1.5 \%$ DMSO for 48 hours, and IGF-1 and IL-7 message were amplified by RT-PCR. No significant differences in IGF-1 or IL-7 mRNA levels were seen in untreated S10 stromal cells compared with those treated with DMSO. In addition, stromal cells treated with DMSO were still able to support pro-B cell cultures. Pretreatment of S10 with DMSO did not alter the cell viability or c-myb levels of pro-B cells in the co-culture. Therefore, DMSO treatment of pro-B cell/stromal cell cultures resulted 
in significant decreases in C-myb expression in pro-B cells but did not result in significant alterations of the stromal cell feeder layer.

Although DMSO treatment was found to be an effective method to downregulate c-myb expression, it suffers because it is non-specific. In 1988, Gewirtz and Calabretta first reported the use of c-myb antisense oligonucleotides to specifically downregulate cmyb expression (Gewirtz and Calabretta, 1988). In the current work, antisense oligonucleotides complimentary to the start site of the c-myb mRNA were used. Antisense oligo were added to cultures of pro-B cells and stromal cells at $14 \mu \mathrm{m}$ for 60 hours. After 60 hours of treatment, there was a significant decrease in C-myb protein as determined by Western Blot. Therefore, a model system has been developed in which C-myb expression in IL-7, stromal cell dependent pro-B cells can be downregulated both specifically by antisense oligonucleotides and non-specifically by DMSO addition. This in vitro system allows us to examine the importance of c-myb in B lymphoid development.

We determined whether c-myb regulated survival, proliferation, and/or differentiation of developing $B$ lineage cells. When c-myb was downregulated by moderate doses of DMSO $(1.0 \%)$ or by antisense oligonucleotides, there was no change in viability of treated cells. C-myb remained at undetectable levels in pro-B cells, yet they continued to survive. These data suggested that pro-B cell survival is Cmyb independent.

Although the pro-B cells continued to survive while c-myb was downregulated, we observed a marked impairment in the ability of pro-B cells to expand in culture. Enumerating total cells in culture after treatment with DMSO revealed that there were $25 \%$ fewer cells in the cultures containing 1.0\% DMSO than were present in untreated cultures. In cultures treated with antisense oligonucleotides, there was a $50 \%$ reduction in the number of cells recovered after 60 hours of treatment. Since cell viabilities were not decreased, the decreased number of cells in culture was not due to cell death. For that reason, the proliferative potential of pro-B cells with decreased c-myb levels was evaluated. Pro-B cells proliferate in response to the stromal cell derived cytokine IL-7. C1.92 cells were cultured with stromal cells, exogenous IL-7, and tritiated thymidine for 24 hours. Thymidine uptake was used as an indicator of the proliferative potential of 
C1.92 cells. C1.92 cells with decreased c-myb levels displayed an inability to proliferate in response to stromal cells and IL-7. Therefore, pro-B cells with downregulated c-myb failed to expand in culture and were unable to proliferate in response to IL-7. This indicates that c-myb expression in pro-B cells is necessary for maintenance of the progenitor cell population.

The $B$ cell progenitor stage is the main proliferative compartment of developing $B$ lineage cells. As pro-B cells mature into pre-B cells, they loose some of their proliferative ability. Since pro-B cells with decreased C-myb levels had a decreased proliferation rate, but continued to survive in culture, we wanted to determine if C1.92 cells differentiated into pre-B cells. Ig gene rearrangement gene status of $\mathrm{C} 1.92$ cells was evaluated. C1.92 cells are early pro-B cells that retain both the D-J and the V-DJ loci of their Ig heavy chain gene in germline configuration. Maturation into late pro-B cells or early pre-B cells would be indicated by rearrangement of the D-J and V-DJ loci. This can be detected using PCR primers complimentary to the intervening regions between the $\mathrm{V}, \mathrm{D}$, and $\mathrm{J}$ segments. If Ig genes are unrearranged, the intervening sequences between the $\mathrm{V}, \mathrm{D}$, and $\mathrm{J}$ will be amplifiable by PCR. However, once rearrangement occurs, the intervening sequences are excised out and will no longer be detectable by PCR. C1.92 cells were treated with $1.25 \%$ DMSO for 24 or 48 hours. $1.25 \%$ DMSO was used because treatment with this concentration resulted in undetectable C-myb protein within 48 hours. 24 hours after culture with DMSO, C1.92 pro-B cells had rearranged the D-J segment of the Ig heavy chain gene; within 48 hours V-DJ rearrangement had occurred. These data indicate that downregulation of C-myb is necessary for pro-B cell genotypic differentiation. However, there are also phenotypic changes that correlate with B cell maturation stages. Loss of CD43 and an increase in flt-3, BP-1, HSA, and slg are indicative of B cell maturation. However, C1.92 cells treated with DMSO or antisense oligonucleotides did not exhibit any change in these markers. Therefore, although genotypic maturation is regulated by C-myb expression, phenotypic maturation is C-myb independent. Genotypic maturation usually correlates with phenotypic changes. However, these data indicate that genotypic and phenotypic maturation are correlative, not causative, and that C-myb regulates one aspect of maturation but not the other. 
Taken together, these data establish c-myb as an intracellular regulator of proliferation and genotypic differentiation in IL-7, stromal cell dependent pro-B cells but not as a regulator of survival. As early immature cells, pro-B cells require contact with stromal cells for their continued survival, proliferation, and differentiation. These data suggest that pro-B cells receive survival signals directly from stromal cells. However, the proliferation and differentiation of pro-B cells are regulated through stromal cell control of the proto-oncogene c-myb. We previously demonstrated that stromal cell contact maintains a high level of c-myb expression in pro-B cells. As pro-B cells mature into pre-B cells, they lose their dependence on stromal cells. So, as pro-B cells detach from stromal cells, there is a decrease in c-myb expression. This decrease in c-myb expression causes a decreased responsiveness to IL-7 and cessation of proliferation. Following a decrease in proliferative potential, genotypic maturation of pro-B cells into pre-B cells occurs. Therefore, stromal cells coordinate progression through the $B$ lineage pathway by regulating c-myb expression. 


\section{REFERENCES}

Allen RD, Bender TP, Siu G: c-Myb is essential for early T cell development. Genes and Dev 13:1073, 1999

Bidenkapp H, Borgmeyer U, Sippel AE, Klempnauer KH: Viral myb oncogene encodes a sequence specific DNA binding activity. Nature 335:835, 1988

Bradford GB, Williams B, Rossi R, Bertoncello I: Quiescence, cycling, and turnover in the primitive hematopoietic stem cell compartment. Exp Hematol 25:445, 1997

Chen J, Bender TP: A novel system to identify myb target promoters in friend murine erythroleukemia cells. Blood Cell Mol Disease 27:429, 2001

Clarke MF, Kukowska-Latallo JF, Westin E, Smith M, Prochownik EU: Constitutive expression of a c-myb cDNA blocks friend murine erythroleukemia cell differentiation. Mol Cell Biol 8:884, 1988

Collins SJ, Gallo RC, Gallagher RE: Continuous growth and differentiation of human myeloid leukaemic cells in suspension culture. Nature 27:347, 1977

Collins SJ, Ruscetti FW, Gallagher RE, Gallo RC: Terminal differentiation of human promyelocytic leukemia cells induced by dimethyl sulfoxide and other polar compounds. PNAS 75:2458, 1978

Craig RW, and Bloch A: Early decline in c-myb oncogene expression in the differentiation of human myeloblastic leukemia (ML-1) cells induced with 12-Otetradecanoylphorbol-13-acetate. Cancer Res 44:442, 1984

Gewirtz AM, Calabretta B: A c-myb antisense oligodeoxynucleotide inhibits normal human hematopoiesis in vitro. Science 242: 1303, 1988 
Gibson LF, Piktel D, Landreth KS: Insulin-like growth factor-1 potentiates expansion of interleukin-7-dependent pro-B cells. Blood 82:3005, 1993

Gonda TJ, Bishop JM: Structure and transcription of the cellular homolog (c-myb) of the avian myeloblastosis virus transforming gene (v-myb). J Virol 46:212, 1983

Gonda TJ, Metcalf D: Expression of myb, myc, and fos proto-oncogenes during the differentiation of a murine myeloid leukaemia. Nature 310:249, 1984

Johnson A, Dorshkind K: Stromal cells in myeloid and lymphoid long-term bone marrow cultures can support multiple hemopoietic lineages and modulate their production of hemopoietic growth factors. Blood 68:1348, 1986

Kincade, PW, Lee G, Paige CJ, Scheid MP: Cellular interactions affecting the maturation of B lymphocyte precursors in vitro. J Immunol 127:255, 1981

Kirsch IR, Bertness V, Silver J, Hollis GF: Regulated expression of the c-myb and cmyc oncogenes during erythroid differentiation. J Cell Biochem 32:11, 1986

Landreth KS, Rosse C, Clagett J: Myelogenous production and maturation of B lymphocytes in the mouse. J Immunol 127:126, 1981

McClinton D, Stafford J, Brents L, Bender TP, Duehl WM: Differentiation of mouse erythroleukemia cells is blocked by late up-regulation of a c-myb transgene. Mol Cell Biol 10:705, 1990

Metcalf D, Moore MA: Factors modifying stem cell proliferation of myelomonocytic leukemic cells in vitro and in vivo. J Natl Cancer Inst 44:801, 1970 
Mucenski ML, McLain K, Kier AB, Swerdlow SH, Schereiner CM, Miller TA, Pietryga DW, Scott WJ, Potter SS: A functional c-myb gene is required for normal murine fetal hepatic hematopoiesis. Cell 65:677, 1991

Patel G, Dreider B, Rovera G, Reddy P: v-myb blocks granulocyte colony-stimulating factor-induced myeloid differentiation but not proliferation. Mol Cell Biol 13:2269, 1993

Ramsay RG, Ikeda K, Rifkind RA, Marks PA: Changes in gene expression associated with induced differentiation of erythroleukemia: protooncogenes, globin genes, and cell division. PNAS 83:6849, 1986

Sheiness D, Gardinier M: Expression of a proto-oncogene (proto-myb) in hematopoietic tissues of mice. Mol Cell Biol 4:1206, 1984.

Till JE, McCulloch EA: A direct measurement of the radiation sensitivity of normal mouse bone marrow cells. Radiation Res 14:213, 1961

Westin EH, Gallo RC, Arya SK, Eva A, Souza LM, Baluda MA, Aaronson SA, WongStaal F: Differential expression of the amv gene in human hematopoietic cells. PNAS 79:2194, 1982

Yancopoulos GD, Alt FW: Regulation of the assembly and expression of variableregion genes. Annu Rev Immunol 4:339, 1986 
Chapter 4

Loss of A-myb and C-myb Differentially Impact B Lymphopoiesis in Murine Fetal Liver 


\begin{abstract}
The differentiation of hematopoietic stem cells into B lymphocytes occurs in a hierarchal fashion during which stem cells develop first into lineage committed progenitor cells and then into precursor cells having decreased proliferative potential and increased lineage commitment. To dissect the molecular events regulating this process, in vivo deletion of specific genes can be utilized. This technique has been used to delete many target genes, including the DNA binding proteins a- and c-myb. In vivo deletion of c-myb results in embryonic lethality due to a complete failure of fetal liver erythropoiesis. Embryonic inactivation of the a-myb gene results in spermatogenesis and breast development defects. However, the effect of embryonic myb deletion on $B$ lymphopoiesis has not been described. To better understand the biological function of a- and c-myb in B lymphopoiesis, we have utilized the available myb knockout mice. Homozygous c-myb mutant mice display complete failure of $\mathrm{B}$ lymphopoiesis in the fetal liver of day 13.5 mice. However, homozygous a-myb mutant mice appear to have no defects in B lymphopoiesis. These results suggest that embryonic expression of c-myb is critical for embryonic B cell development while a-myb expression is not required.
\end{abstract}




\section{INTRODUCTION}

The c-myb proto-oncogene, the cellular homolog of the v-myb gene, is expressed in highly proliferative, immature progenitor cells of the myeloid, erythroid, and lymphoid lineages (Klempnauer,1982). Transcription levels of c-myb are dramatically reduced as progenitor cells differentiate into more mature cells (Westin et al, 1982, Gonda and Metcalf 1984). C-myb expression is found in embryonic stem cells and neural tissues of embryonic, fetal, and adult brain (Dyson 1989, Thiele 1988). Fibroblasts and $T$ lymphocytes express c-myb transiently during cellular proliferation (Stern and Smith, 1986, Thompson, 1986, Lipsick and Boyle, 1987). Over-expression of c-myb has been associated with leukemias and neoplasms. Human neuroectodermal and hematopoietic malignancies, as well as carcinomas of lung, colon, and breast, have all been reported to express c-myb (Alitalo, 1984; Griffin and Baylin, 1985; Thiele, 1987; Salmon 1984; Slamon 1986; Torelli, 1987). The expression pattern of the c-myb gene suggested a role for c-myb in hematopoiesis and developmental processes. The development of a mouse model with a homozygous mutant c-myb gene confirmed these data (Mucenski, 1991).

To better define the normal biological function of c-myb, Mucenski et al generated a mouse model heterozygous for a mutated c-myb gene. Mice heterozygous for mutant c-myb appeared phenotypically normal after birth. However, no c-myb null animals were present postnatally, suggesting that the c-myb mutation was lethal. In utero examinations of animals, at day 13 of gestation, revealed that homozygous null embryos were indistinguishable from c-myb wildtype embryos. They were present in appropriate numbers and had developed brains, kidneys, lungs, hearts, and limb buds. However, by day 15, mutant mice were pale in color, severely anemic, and expired in utero. At days 12.5-13.5 of gestation, hematocrit levels in wild type and mutant mice were $35 \%$. By day 15.5, there was a 10 -fold decrease in hematocrits of c-myb null mice. Null mice had hematocrit levels of $5 \%$ whereas wild-type animals had $40 \%$. At this time in embryogenesis, the site of erythropoiesis moves from the AGM region into the fetal liver. Erythrocytes derived from the AGM can be morphologically differentiated from fetal liver derived erythrocytes; erythrocytes from the AGM region remain 
nucleated and are larger than those from the fetal liver. Examination of peripheral blood at day 12 revealed normal numbers of nucleated erythrocytes, indicating that early intraembryonic erythropoiesis in the AGM was normal. However, there was a significant defect in fetal hepatic erythropoiesis. Animals exhibited a complete loss of erythropoiesis in the fetal liver. This indicates that c-myb mutant mice are unable to switch the site of fetal erythropoiesis from the AGM region to the liver (Mucenski, 1991). These observations clearly establish that $c-m y b$ is responsible for the maintenance of myelo and erythropoiesis. Although c-myb has been shown to be critical in the development of erythroid and myeloid precursors, less work has been done on the role of c-myb in the normal development of lymphocytes.

C-myb is closely related to another member of the Myb gene family, a-myb. Unlike c-myb, a-myb is expressed in a tissue-specific fashion. The A-myb protein is primarily found in breast epithelial cells of pregnant mice and in male germ cells. A-myb has also been detected in ovaries, brain, and germinal center B cells (Mettus et al, 1994, Trauth et al, 1994). DeRocco et al showed in 1997 that mice over expressing the A-myb protein develop hyperplasia of the spleen and lymph nodes. These mice exhibited increased DNA synthesis and a polyclonally expanded B cell population (DeRocco et al, 1997). Development of a homozygous null mutant mouse deficient in A-myb protein further clarified the role of a-myb. Mice homozygous for a germline mutation in the a-myb gene are present postnatally and appear normal at birth. However, during the first weeks of life, the pups lagged behind in growth appearing small, wrinkled, and hunched. At 4 months of life, however, the mutant pups were identical to normal littermates in body size. Male mice with a-myb gene mice were sterile due to a block in spermatogenesis. Female a-myb mutant mice were not sterile and delivered offspring sired by wild-type or heterozygous males. However, pups born to a-myb null mothers failed to thrive because the mutant mother mice exhibit abnormal mammary function and are unable to nurse pups. Taken together, these data suggest that a-myb may serve as a mediator of proliferation in certain cell types, particularly in spermatocytes and mammary epithelial cells (Toscani et al, 1997).

Although the literature describes anatomic defects associated with myb mutant mice, B lymphopoiesis in these animals has not yet been described. This work utilizes 
the currently available myb knockout models to explore B lymphocyte development. This work demonstrates that loss of c-myb completely ablates B lymphopoiesis while loss of a-myb does not impact B lymphoid development. C-myb is critical for fetal development of $\mathrm{B}$ cells whereas a-myb is dispensable.

\section{METHODS AND MATERIALS}

Mice. C-myb mutant mice were obtained from Dr. Michael Mucenski at Children's Hospital Research Foundation in Cincinnati, OH. Generation of c-myb mutant mice has been described in detail (Mucenski et al, 1991). Briefly, a vector was constructed with a neomycin resistance gene inserted in opposite transcriptional orientation into the sixth c-myb exon. The construct was introduced, by electroporation, into stem cells and cells containing the construct were identified by G418 selection. Embryonic stem cells with the construct were implanted into pseudopregnant female mice. The altered c-myb allele was passed to progeny animals and the affect of the alteration was examined. Cmyb mice were housed in the West Virginia Office for Laboratory Animal Resources.

A-myb mutant mice were obtained from Dr. Premkumar Reddy at Fels Institute for Cancer Research and Molecular Biology, Temple University, Philadelphia PA. Generation of a-myb mutant mice has been described in detail (Toscani et al, 1997). Briefly, a targeting vector was designed in which the neomycin resistance gene was inserted into exon 4 of the a-myb gene. The vector was electroporated into ES cells. Cells containing the disrupted a-myb gene were selected by $\mathrm{G} 418$ and verified by Southern Blot analysis. Clones bearing a disrupted a-myb gene were used to generate a-myb ${ }^{-/-}$mice. A-myb mice were housed at the West Virginia University vivarium.

Fetal liver preparation. Day 13.5 fetal livers were removed from wild type, heterozygous mutant, or homozygous null mice. They were made into single cell suspensions after several passages through a 23-gauge needle. White blood cells were then enumerated and underlayed with $1.5 \mathrm{ml}$ fetal bovine serum to remove any remaining tissues from suspension. Cells were collected in a new tube and enumerated a second time. 
Colony-forming assays. Recombinant interleukin-7 (rlL-7) -induced colony formation was measured using culture of fetal liver cell suspensions in methylcellulose. Methylcellulose, with no additives, was diluted 1:1 using $1 \mathrm{x}$ Iscoves medium containing $30 \%$ fetal calf serum, $2 \%$ l-glutamine, $2 \%$ penicillin/streptomycin, and $0.2 \% 2$ mercaptoethanol. Triplicate $1 \mathrm{ml}$ cultures were prepared in $35 \mathrm{~mm}$ culture dishes with $2.5 \times 10^{5}$ fetal liver cells per culture and $50 \mathrm{U} / \mathrm{ml} \mathrm{rlL}-7$. Control cultures with rlL-7 were also examined. GM-CSF (granulocyte macrophage colony stimulating factor) induced colony formation was also measured in methylcellulose, prepared as described above. Triplicate $1 \mathrm{ml}$ cultures were prepared in $35 \mathrm{~mm}$ culture dishes with $1 \times 10^{5}$ fetal liver cells per culture and $50 \mathrm{U} / \mathrm{ml}$ GM-CSF. Both CFU-IL-7 and CFU-GM-CSF colonies were counted using a dissecting microscope after 7 days incubation at $37^{\circ} \mathrm{C}$ in $5 \% \mathrm{CO}_{2}$. Colonies from CFU-IL-7 and CFU-GM were isolated and cytospin slide preparations were made. Slides were stained with Jenner-Giemsa stain and morphology was examined to ensure that colonies were pure.

Gender determination. Chromosomal DNA was isolated from embryos using the Easy-DNA isolation kit (Invitrogen). DNA was RNase treated to remove contaminating RNA and resuspended in $100 \mathrm{ml}$ of Tris-EDTA (pH 8). The DNA sequence of the Sry gene, which is $Y$ chomosome specific in the mouse, was amplified using PCR. The primers used for PCR were 5'-AAGCGCCCCATGAATGCATT-3' and 5'TCCCAGCTGCTTGCTGATCT-3' and the expected size of the amplified fragment was 105 nucleotides (Han et al, 1993).

Pro-B cell assay. S10 stromal cells were split into 96 well plates in $50 \mathrm{ml} \alpha$-MEM media the day prior to the experiment. On the day of the experiment, fetal liver cells were seeded onto stromal cell layers at 50,100 , or 200 cells per well with $50 \mathrm{U} / \mathrm{ml}$ of rIL-7 and $125 \mathrm{ml} \alpha-M E M$ media. IL-7 was added to pro-B cell cultures after 2 days of culture. Pro-B cell cultures were incubated at $37^{\circ} \mathrm{C}$ in $5 \% \mathrm{CO}_{2}$ for 5 days. At 5 days, wells were examined and those with expanded pro-B cell colonies were counted as positive.

Proliferation assay. $2.5 \times 10^{5}$ fetal liver cells were allocated in 96 well plates coated with $\mathrm{S} 10$ and $200 \mu \mathrm{l}$ of $\alpha$-MEM media. Where indicated, IL-7 $(50 \mathrm{U} / \mathrm{ml})$ was added to the cultures. Cells were cultured over night for 18 hours, and then pulsed with $1 \mu \mathrm{Ci}{ }^{3} \mathrm{H}$ - 
TdR/well. After 6 more hours of culture, cells were harvested onto glass wool fiber strips with an automated cell harvester (Cambridge Instruments, Boston, MA). Radioactive incorporation was determined by liquid scintillation counting in an aqueous fluor (Biosafe-II; Research Products International). Each treatment was repeated in triplicate.

Genotyping of animals. To identify wild-type, heterozygous, and homozygous mutant c-myb mice, PCR was utilized. Chromosomal DNA was isolated from embryos or tail clippings using the Easy-DNA isolation kit (Invitrogen). DNA was RNase treated to remove contaminating RNA and resuspended in $100 \mathrm{ml}$ of Tris-EDTA (pH 8). PCR was performed with primers complimentary to sequences in c-myb exon 6 that flanked the inserted neomycin resistance gene. C-myb primer sequences were as follows: (sense) 5'-GCAAGGTGGAACAGGAAGGCTACC-3' and 5'GTGCTTCGgCGATGTGgTAATAGG-3' (Biosource International, CA). Primers were diluted from lyophilized solution to $1 \mu \mathrm{g} / \mu \mathrm{l}$ in autoclaved water. Reaction mixtures of $25 \mu \mathrm{l}$ were used. PCR mixtures were: $25 \mu \mathrm{l}$ Stratagene Optiprime Buffer \#8, $5 \mu \mathrm{l} \mathrm{60 \%}$ sucrose, $1 \mu \mathrm{l} 10 \mathrm{mM}$ (each) dNTP, $0.5 \mu \mathrm{l}$ Stratagene Master Mix, $0.2 \mu \mathrm{l}$ c-myb sense primer, $0.2 \mu \mathrm{l} \mathrm{c-myb}$ antisense primer, $1.0 \mu \mathrm{l} 25 \mathrm{mM} \mathrm{MgCl}_{2}, 0.5 \mu \mathrm{l}$ Promega Taq, $250 \mathrm{ng}$ genomic DNA, and water to $25 \mu \mathrm{l}$. Initially, the reaction mixture was activated with a hot start for 2 minutes at $95^{\circ} \mathrm{C}$. Then, amplification was performed for 35 cycles with denaturation at $95^{\circ} \mathrm{C}$ for 30 seconds, annealing at $65^{\circ} \mathrm{C}$ for 30 seconds, and extension for 2 minutes at $72^{\circ} \mathrm{C}$ with an additional 10 minute extension added to the final cycle. PCR amplifications were performed in a GeneAmp PCR System 9700 (Perkin Elmer Applied BioSystems). PCR products were resolved on a $2 \%$ agarose gel to identify amplified bands. Expected band sizes were 200 bp (wild-type c-myb gene) or 1548 bp (mutated c-myb gene).

To identify wild-type, heterozygous, and homozygous mutant a-myb mice, PCR was also utilized. 2 sets of PCR primers were utilized to genotype a-myb animals. Amyb PCR primers were complimentary to sequences in a-myb exon 4 and they flanked the inserted neomycin resistance gene. In addition, neo primers were used that were complimentary to the inserted neomycin resistance cassette. A-myb and Neo primers were obtained from Biosource International and diluted to $1 \mu \mathrm{g} / \mu \mathrm{l}$ in autoclaved water. 
A-myb primer sequences were (sense) 5'-GTATACTTAAATTTGGGCTAATTT-3' and (antisense) 5'-TAAATTTTTTCAAAAGAATATGAA-3'. Amplification was performed for 35 cycles with denaturation at $94^{\circ} \mathrm{C}$ for 1 minute, annealing at $55^{\circ} \mathrm{C}$ for 2 minutes, and extension for 3 minutes at $72^{\circ} \mathrm{C}$ with an additional 15 minute extension added to the final cycle in a Perkin Elmer 480 DNA Cycler. The a-myb PCR reaction included $4 \mu \mathrm{l}$ Promega $\mathrm{MgCl}_{2}, 5 \mu \mathrm{l} 10 \mathrm{x}$ Promega Buffer, $5 \mu \mathrm{lNTP}, 1 \mu \mathrm{l}$ sense a-myb primer, $1 \mu \mathrm{l}$ antisense a-myb primer, $1 \mu$ l Promega Taq, $250 \mathrm{ng}$ DNA, and autoclaved water to $50 \mu \mathrm{l}$. The expected a-myb amplicon size was 200 bp (a-myb wildtype).

Neo primer sequences were:

(sense) 5'-GATGGATTGCACGCAGGTTCTCCGG-3' and (antisense) 5'ATGGGCAGGTAGCCGGATCAAGCGT -3'. The neo PCR reaction included $4 \mu \mathrm{l}$ Promega $\mathrm{MgCl}_{2}, 5 \mu \mathrm{l} 10 \times$ Promega Buffer, $5 \mu \mathrm{ldNTP}, 1 \mu \mathrm{l}$ sense neo primer, $1 \mu \mathrm{l}$ antisense neo primer, $1 \mu \mathrm{l}$ Promega Taq, $250 \mathrm{ng}$ DNA, and autoclaved water to $50 \mu \mathrm{l}$. PCR amplifications were performed in a GeneAmp PCR System 9700 (Perkin Elmer Applied BioSystems). Amplification was initiated with a $94^{\circ} \mathrm{C}$ hot start for 3 minutes. Amplification was then performed for 28 cycles with denaturation at $94^{\circ} \mathrm{C}$ for 30 seconds, annealing at $60^{\circ} \mathrm{C}$ for 1 minute, and extension for 30 seconds at $72^{\circ} \mathrm{C}$. PCR amplifications were performed in a GeneAmp PCR System 9700 (Perkin Elmer Applied BioSystems). PCR products were separated on $2 \%$ ethidium bromide stained gels and visualized using Eagle Eye (Stratagene). Expected neo amplicon size was $385 \mathrm{bp}$.

All DNA samples were evaluated for template integrity using PCR amplification of GAPDH. GAPDH primers were also obtained from Biosource International and diluted with autoclaved water to $1 \mu \mathrm{g} / \mu \mathrm{l}$. GAPDH primers sequences were: (sense) 5'TGAAGGTCGGTGTGAACGGATTTGG-3' and (antisense) 5'-ACGACATACTCAGCACCGGCCTCAC-3'. Reaction conditions were as described above for neo primers. 


\section{RESULTS}

PCR Strategy to Detect Targeted C-myb Allele. C-myb null mice were generated by breeding heterozygous animals. In order to construct appropriate breeding pairs, it was necessary to genotype parental animals. Genotyping was done by PCR amplification of genomic DNA acquired from adult tail clippings. Mating of heterozygous male and female mice will result in wild-type, heterozygous, and homozygous null embryos in each pregnancy. In these experiments, embryos from pregnant heterozygous females were examined at day 13.5, before c-myb null embryos expired in utero. At day 13.5, there is little phenotypic difference between wild-type, heterozygous, and c-myb null animals. Therefore, genotypic analysis was also needed to determine which embryos were c-myb knockout animals. In order to genotype c-myb animals, a PCR strategy developed by Mucenski et al was utilized. We used one set of primers which were complimentary to sequences in exon 6 of the c-myb gene. Additionally, these primers flanked the $1348 \mathrm{~kb}$ neomycin cassette inserted to inactivate the c-myb gene (see figure 1). PCR amplification of genomic DNA from embryos or tail cuttings revealed the presence of either one or two bands. Wild-type animals had only one $200 \mathrm{~kb}$ band amplified indicating the neomycin gene was not present in exon 6 of the c-myb gene. Heterozygous animals had 2 amplicons following PCR, a $200 \mathrm{~kb}$ band and a $1548 \mathrm{~kb}$ band. This indicated that both the wild-type c-myb gene and the inactivated c-myb gene were present. C-myb null animals also exhibited only one band, a $1548 \mathrm{~kb}$ band.

Absence of the $200 \mathrm{~kb}$ band indicated that no native c-myb gene was present in the DNA, only c-myb with the neo insertion was present. This PCR strategy provided a method to distinguish c-myb null mice from wild type and heterozygous animals. It also provided a way to distinguish wild-type from heterozygous animals for breeding purposes. 


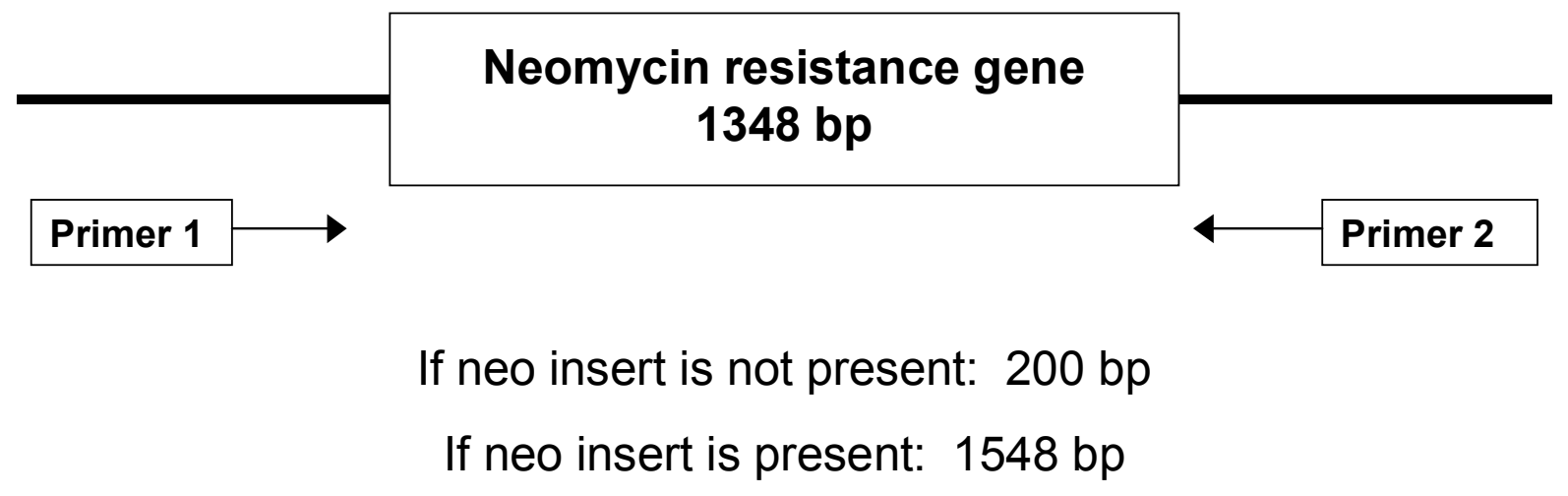

Figure 1. PCR Strategy to Detect Targeted C-myb Allele. Primers were designed to flank an inserted neomycin resistance cassette in the c-myb gene. Differential bands can be used to distinguish wild-type, heterozygous, and homozygous null animals. Wildtype animals had only one $200 \mathrm{~kb}$ band. Heterozygous animals had 2 amplicons following PCR, a $200 \mathrm{~kb}$ band and a $1548 \mathrm{~kb}$ band indicating both wild-type c-myb and inactivated c-myb were present. C-myb null animals also exhibited only one band, a $1548 \mathrm{~kb}$ band. 


\section{CFU-GM Progenitor Cells are Present but Drastically Decreased in C-myb}

Knockout Mice. In their original description of the c-myb null mouse, Mucenski et al had reported an $88 \%$ decrease in the number of progenitor cells capable of forming GM colonies in methylcellulose from c-myb null livers as compared to wild type livers. This experiment was repeated in the current report to ensure that this experimental system was similar to the one described by Mucenski. Culture of $1 \times 10^{5}$ live fetal liver cells from wild-type, heterozygous, or homozygous null mice in methylcellulose resulted in a significant decrease in CFU-GM progenitors obtained from the c-myb null mice as compared to wild-type or heterozygous animals. As reported by Mucenski, there was no CFU-GM difference between wild-type and heterozygous animals while there was greater than an $80 \%$ decrease in c-myb null CFU-GM progenitors (Figure 2). This indicates that, as previously reported, myelopoiesis is severely impaired in mutant cmyb animals.

Often, deletion of a single gene or protein has differential effects on males and females. As c-myb embryos were harvested, they were genotyped using PCR. In all experiments, the difference between males and females was examined. No difference between male and female mice was observed in any experiment conducted. Therefore, all data presented includes both male and female embryos.

Cellular Composition of C-myb Fetal Livers. Mucenski et al reported a significant reduction in the total number of cells found in c-myb null fetal livers as compared to wild-type fetal livers. C-myb knockout mice examined in the current report had approximately $3 \times 10^{6}$ white blood cells per fetal liver while c-myb wild-type mice had approximately $16 \times 10^{6}$ white blood cells on day 13.5 (Table 1). However, Mucenski et al did not determine the number of lymphocytes present in the fetal livers of c-myb mice. Examination of fetal livers at day 13.5 post-coitus indicated that $22 \%$ of fetal liver cells in the wild-type mice were lymphocytes. $2.3 \%$ of wild-type fetal liver cells were $\mathrm{B} 220^{+}$ while $0.5 \%$ were IL-7R . In contrast, only $0.1 \%$ of the c-myb knockout fetal liver cells were lymphocytes, $0.6 \%$ were $\mathrm{B}_{22} \mathrm{O}^{+}$, and $0.01 \%$ were IL-7R positive. In the wild-type animals, $12 \%$ of the cells that fell within the lymphocyte gate were B220+ cells. This 
number was significantly increased in the c-myb null animal; $67 \%$ of the lymphocytes were $\mathrm{B} 220+$. This indicates that c-myb knockout mice not only have a severe impairment in myelopoiesis, but there is also a marked defect in $\mathrm{B}$ lymphopoiesis.

\section{Mutations in C-myb Ablate Clonable, IL-7 Responsive Pro-B Cell Potential.}

Although the number of lymphocytes is decreased in c-myb null fetal livers, there were $\mathrm{B}_{220}{ }^{+}, \mathrm{IL}-7 \mathrm{R}^{+}$lymphocytes present. We determined whether lymphocytes present in the c-myb null fetal liver were IL-7 responsive lymphocytes. To accomplish this 96 well plates were coated with $\mathrm{S} 10$ stromal cells that have been shown to support $\mathrm{B}$ lymphocyte development. 100 fetal liver cells were plated per well, and $20 \mathrm{U} / \mathrm{ml}$ of exogenous IL-7 was added to each well. Cells were cultured for 2 days, exogenous IL7 was added again, and cells were cultured for 3 more days. After 5 days of cultures, individual wells were examined for the presence of expanded B cell progenitor colonies. Wells with 10 or more expanded cells were scored as positive. As demonstrated in Figure 3, the numbers of clonable IL-7 responsive cells in the wild-type fetal livers were not significantly different from the numbers present in the heterozygous animals. However, the c-myb null fetal livers had almost no cells that were capable of forming IL7 responsive pro-B cell colonies. In addition, the numbers of progenitor cells capable of forming IL-7 colonies in methylcellulose (CFU-IL-7) were examined. $2.5 \times 10^{5}$ fetal liver cells were plated in methylcellulose, incubated for 7 days with IL-7, and then examined. The CFU-IL-7 data paralleled those data obtained in figure 3; no IL-7 responsive colonies were obtained from c-myb null fetal livers. Finally, we tried to develop a pro-B cell line from c-myb null fetal livers similar to $\mathrm{C} 1.92$ pro-B cells that were described earlier in this work. Fetal livers were dispersed into single cell suspension and the nonadherent cells were passaged in the presence of the cloned bone marrow stromal cell line, S10, and exogenously added IL-7. Although several attempts were made, no lymphocytes from c-myb null fetal livers survived in culture long term. 


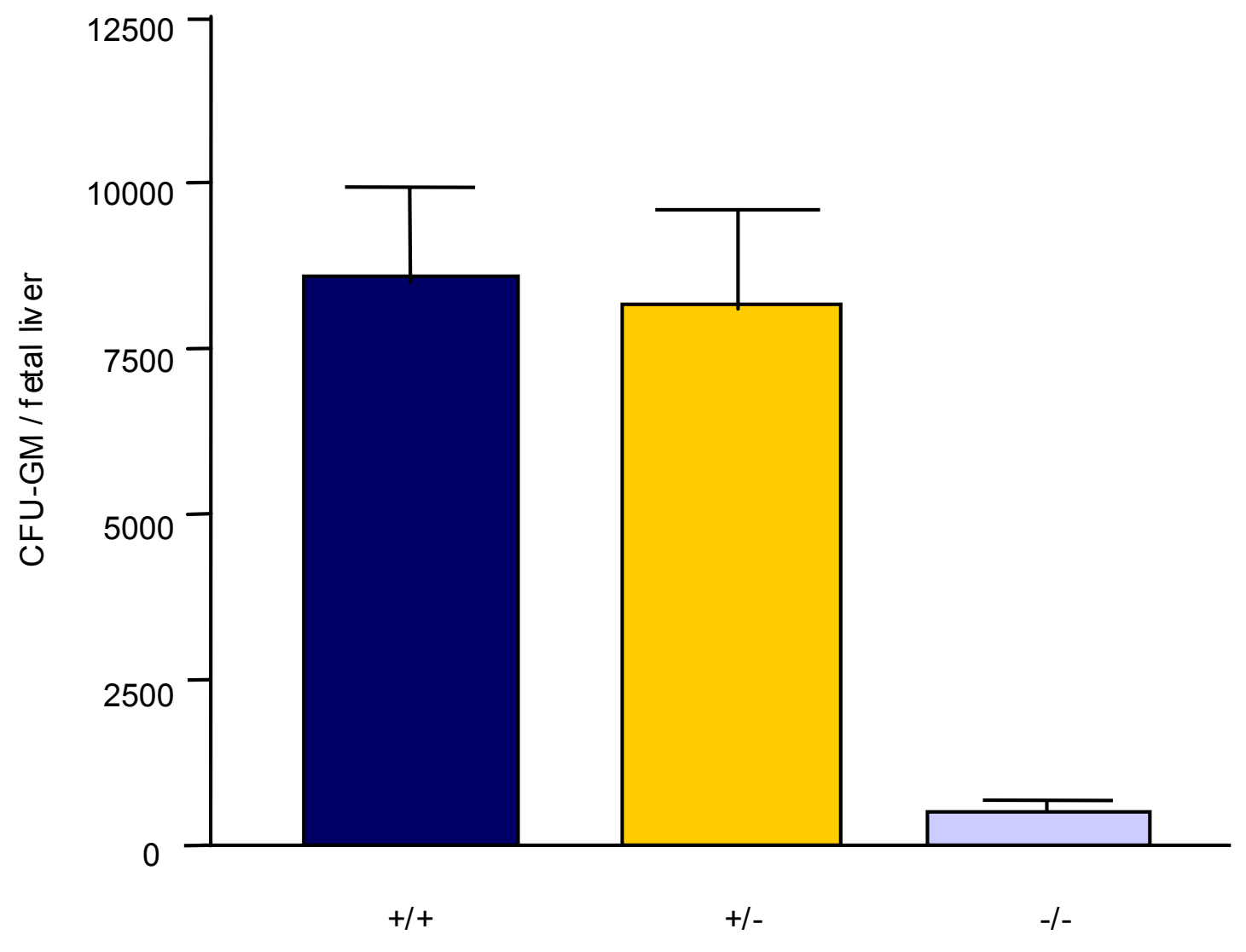

Figure 2. CFU-GM Progenitor Cells are Present but Drastically Decreased in Cmyb Knockout Mice. $10^{5}$ live fetal liver cells from wild-type, heterozygous, or homozygous null mice were plated in methylcellulose. CFU-GM colonies were enumerated after 7 days in culture. Data are presented as mean and SEM of a minimum of 3 mice per group. 


\begin{tabular}{|c|c|c|c|c|}
\hline & FL cells $\times \mathbf{1 0}^{-6}$ & Lymphocytes $\times \mathbf{1 0}^{-5}$ & B220 $^{+}$cells $\times \mathbf{1 0}^{-5}$ & IL-7R $^{+}$cells $\times \mathbf{1 0}^{-3}$ \\
\hline $\boldsymbol{+} / \boldsymbol{+}$ & $16 \pm 2.7$ & $36 \pm 5.7$ & $4.4 \pm 0.7$ & $64 \pm 12$ \\
\hline $\boldsymbol{+} /-$ & $12 \pm 2.6$ & $39 \pm 8.2$ & $6.7 \pm 2$ & $38 \pm 12$ \\
\hline$-/-$ & $3.1 \pm 0.5$ & $0.3 \pm .02$ & $0.2 \pm .03$ & $0.4 \pm 0.2$ \\
\hline
\end{tabular}

Table 1. Cellular Composition of C-myb Fetal Livers. Fetal livers were harvested from wild-type, heterozygous, and homozygous null c-myb mice. Cells were dispersed into single cell suspension and white blood cells were enumerated. Cells were stained for B220 (CD45R) and IL-7 receptor. FACS analysis was completed on stained cells. Data are presented as mean \pm SEM of a minimum of 3 animals per group. 


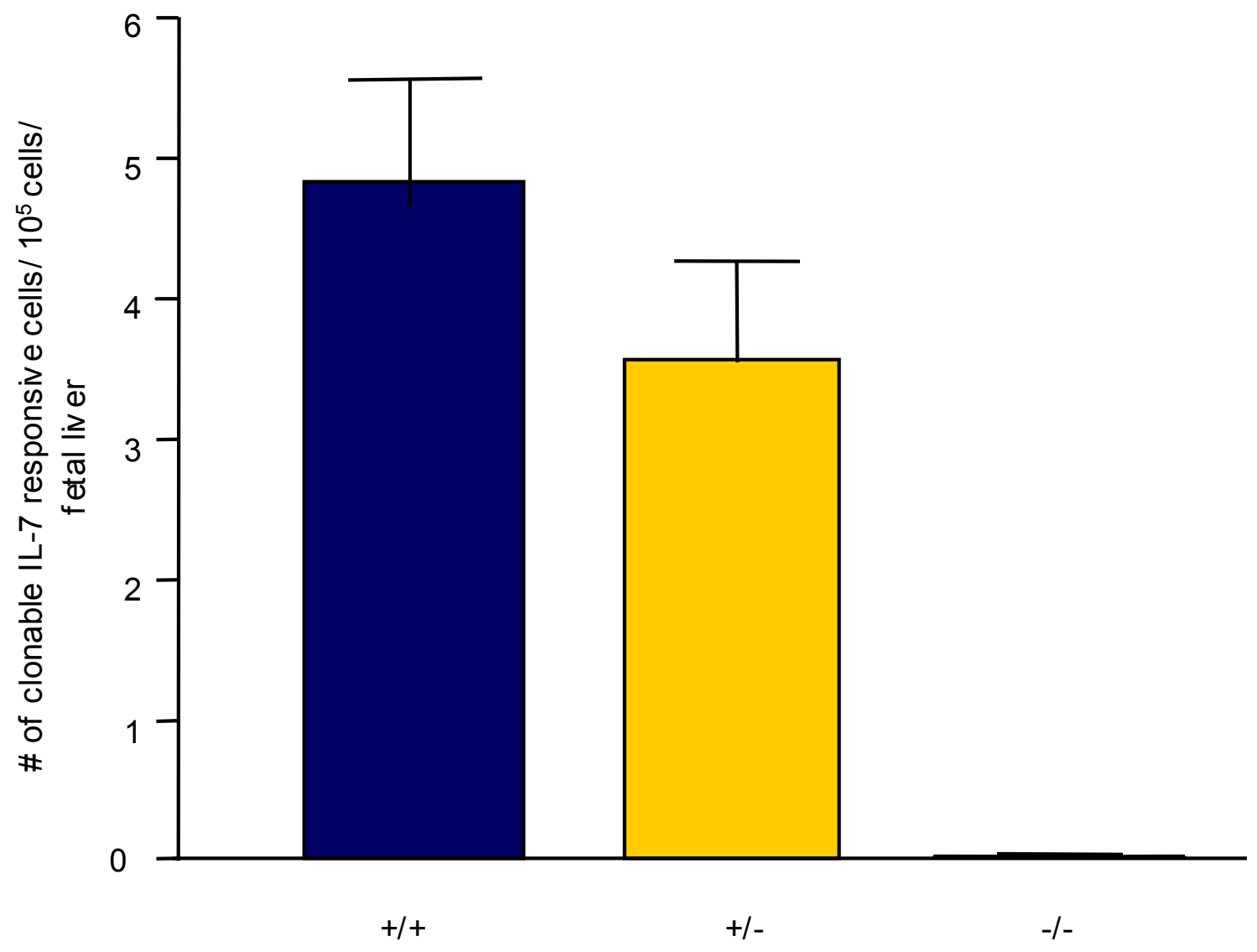

Figure 3. Mutations in C-myb Ablate Clonable, IL-7 Responsive Pro-B Cell Potential. 100 live fetal liver cells were plated into individual wells of a 96 well plate coated with stromal cells. IL-7 was added to cultures at day 0 and day 2. Plates were incubated for 5 days and then the number of IL-7 responsive pro-B cell colonies formed was determined. Data are presented as mean \pm SEM of a minimum of 3 animals per group. 
PCR Strategy to Detect Targeted A-myb Allele. From previous literature it is known that a-myb null mice do not expire in utero, but males are unable to father pups due to sterility and mothers are not able to nurse pups due to mammary gland defects. Therefore, a-myb knockout mice also were generated by breeding heterozygous animals. As with c-myb animals, it was necessary to genotype parental animals via tail cuttings to ensure that heterozygous male and female mice were bred. Although the amyb deletion is not an embryonic lethal, the deletion was also examined in embryos at day 13.5 of gestation in order to compare effects of a-myb deletion with c-myb deletion. As previously described for c-myb, embryos from pregnant heterozygous females were examined at day 13.5. At day 13.5, no phenotypic difference existed between wild-type, heterozygous, or a-myb null animals. Genotypic analysis was necessary to detect amyb null animals. To genotype a-myb animals, a PCR strategy was developed by this laboratory. As detailed in the methods, two sets of PCR primers were utilized. The first primer set was complimentary to sequences in exon 4 of the a-myb gene. These primers amplified a $200 \mathrm{~kb}$ region of the native a-myb gene. However, these primers also flanked the inserted neo cassette. These primers differed from c-myb primers because a-myb primers will not produce a detectable amplicon if the neomycin gene is inserted. This is most likely due to the high $A / T$ content of the primers, resulting in decreased primer fidelity. To detect the inserted neo cassette, we used another set of primers specific for the neomycin gene. If the neomycin gene was present, a $385 \mathrm{~kb}$ band was detected. PCR amplification of genomic DNA from embryos or tail cuttings revealed either one or two bands. Wild-type animals had only one $200 \mathrm{~kb}$ band amplified. This indicated that the neomycin gene was not present in exon 4 of the amyb gene. Heterozygous animals had 2 amplicons following PCR with both primer sets, a $200 \mathrm{~kb}$ band and a $385 \mathrm{~kb}$ band. These data indicated that both the wild-type amyb gene and the neo cassette were present. A-myb null animals also exhibited only one band, a $385 \mathrm{~kb}$ band. Absence of the $200 \mathrm{~kb}$ band indicated that no native a-myb gene was present in the DNA, only a-myb with the neo insertion was present. Like the previously described PCR method, this two-step PCR method also provided a method to distinguish a-myb null mice from wild type and heterozygous animals as well as a way to distinguish wild-type from heterozygous animals for breeding purposes. 
A.

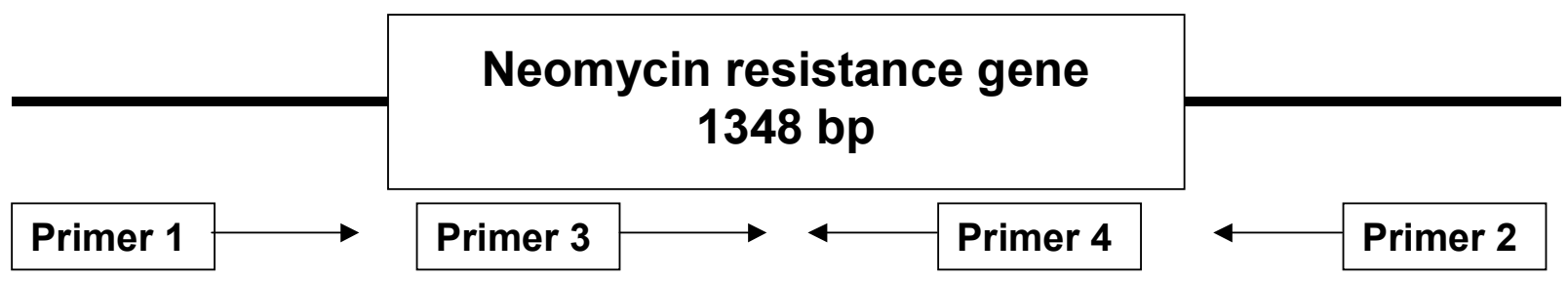

B.

If neo insert is present: $385 \mathrm{bp}$ band A-myb

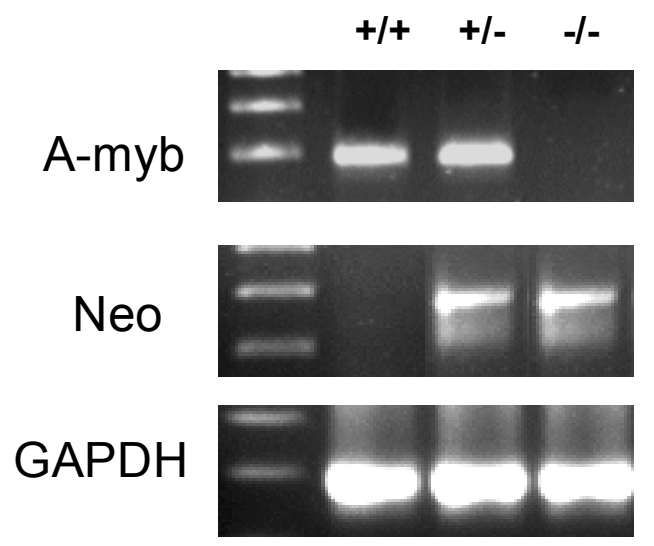

If neo insert is not present: $200 \mathrm{bp}$ band

Figure 4. PCR Strategy to Detect Targeted A-myb Allele. (A) One set of primers was complimentary to sequences in exon 4 of the a-myb gene on either side of the inserted neomycin cassette. The second set of primers was complimentary to sequences within the neomycin resistance cassette. (B) Differential band sizes can be used to distinguish wild-type, heterozygous, and homozygous null animals. Wild type animals have an amplicon using a-myb primers, but no neo amplicon. Heterozygous animals have a PCR product for both a-myb and neo. Homozygous null animals only display an amplicon after neo amplification; no a-myb amplicon is detected. 
CFU-GM Progenitor Cells Are Present in A-myb Knockout Mice. To compare the effects of the a-myb mutation with the drastic effects observed with the c-myb mutation, a-myb null mice were also examined at day 13.5 of gestation. CFU-GM potential of the a-myb knockout animal was examined. Livers were harvested from day 13.5 embyos from pregnant heterozygous a-myb females, dispersed into single cell suspension, and enumerated. Unlike the c-myb animals, there was no difference in the number of total cells in wild-type, heterozygous, or homozygous null fetal livers. On average, a-myb wild-type and heterozygous fetal livers contained $7.42 \times 10^{6}\left( \pm 9.4 \times 10^{5}\right)$ white blood cells while a-myb null fetal livers had $6.31 \times 10^{6}\left( \pm 1.2 \times 10^{6}\right)$ white blood cells. $10^{5}$ live fetal liver cells from each mouse were plated into methylcellulose with exogenous addition of GM-CSF cytokine. Cells were cultured for 7 days then the numbers of colonies formed were counted. As shown in Figure 5, no differences were observed in the number of GM progenitor cells in a-myb wild-type and heterozygous fetal livers versus a-myb null fetal livers. In addition, male and female a-myb animals were independently examined in these experiments. This was done because effects of the amyb deletion are expressed differently in males and females. Although there is a slight reduction in the number of CFU-GM colonies found in a-myb ${ }^{-1-}$ females, the difference is not statistically significant. These data indicate that, unlike mutations in the c-myb gene, mutations in the a-myb gene have no effect on GM progenitor cells found in the day 13.5 fetal liver. 


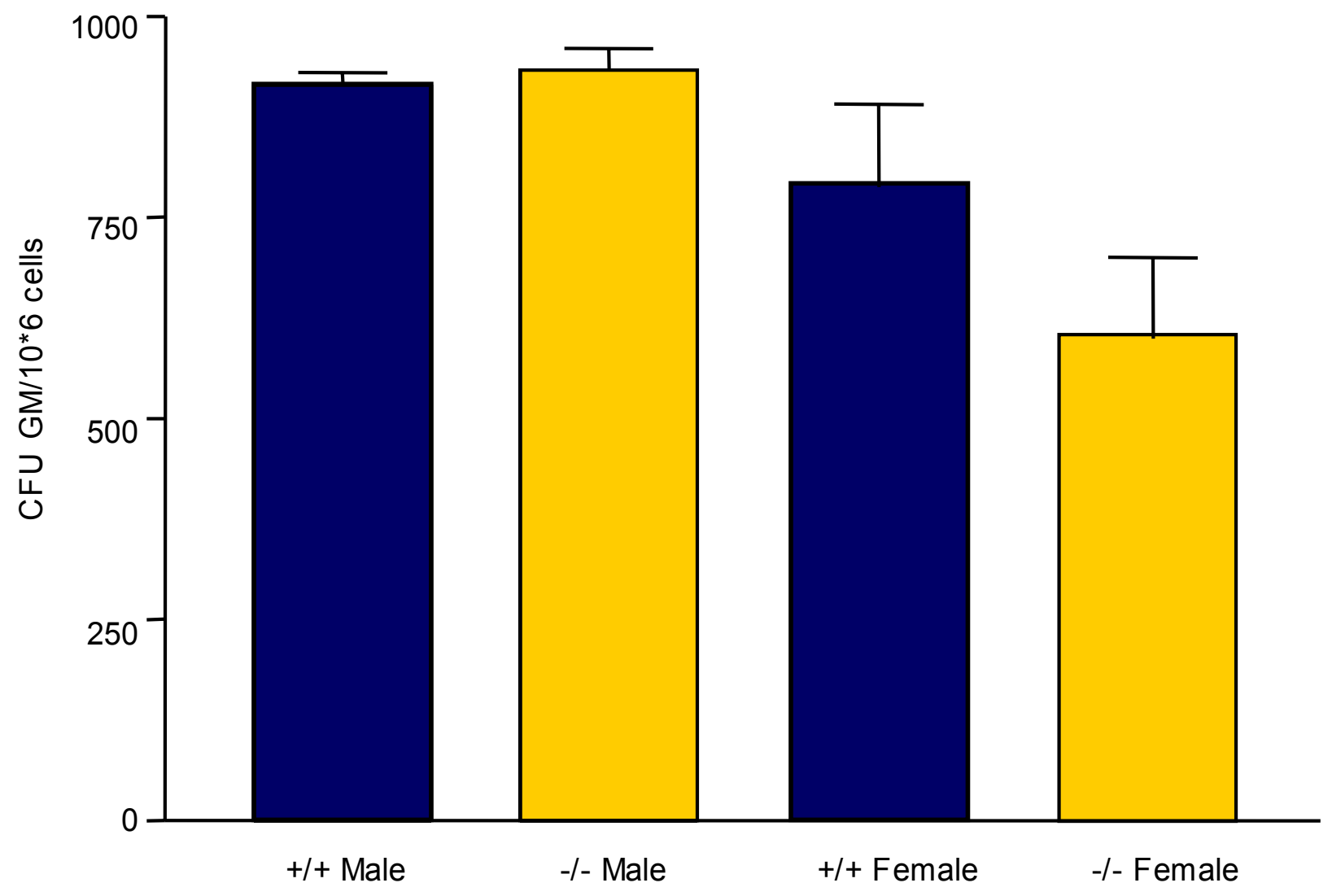

Figure 5. CFU-GM Progenitor Cells Are Present in A-myb Knockout Mice. $10^{5}$ live fetal liver cells from wild-type or homozygous null mice were plated in methylcellulose. CFU-GM colonies were enumerated after 7 days in culture. Data is presented as an average of atleast 3 animals $+/$ - SEM. 
A-myb Mutation Does Not Alter Pro-B Cell Frequency. Finally, this report examined the number of white blood cells present in a-myb null fetal livers that were clonable, IL-7 responsive lymphocytes. As described above, a pro-B cell assay was employed. 96 well plates were coated with S10 stromal cells that can support B lymphocyte development. 100 fetal liver cells were plated per well, and $20 \mathrm{U} / \mathrm{ml}$ of exogenous IL-7 was added to each well. Cells were cultured for 2 days, exogenous IL-7 was added again, and cells were cultured for 3 more days. After 5 days of cultures, individual wells were examined for presence of expanded $B$ cell progenitor colonies. Wells with 10 or more expanded cells were scored as positive. As demonstrated in Figure 6, the numbers of clonable IL-7 responsive cells in the wild-type fetal livers were not significantly different from the numbers present in homozygous null animals.

Additionally, the numbers of progenitor cells capable of forming IL-7 colonies in methylcellulose (CFU-IL-7) were examined. $2.5 \times 10^{5}$ fetal liver cells were plated in methylcellulose, incubated for 7 days with IL-7, and then examined. The CFU-IL-7 data paralleled those data obtained in figure 6; no statistically significant difference in IL-7 responsive colonies was observed between wild-type and homozygous null fetal livers. 


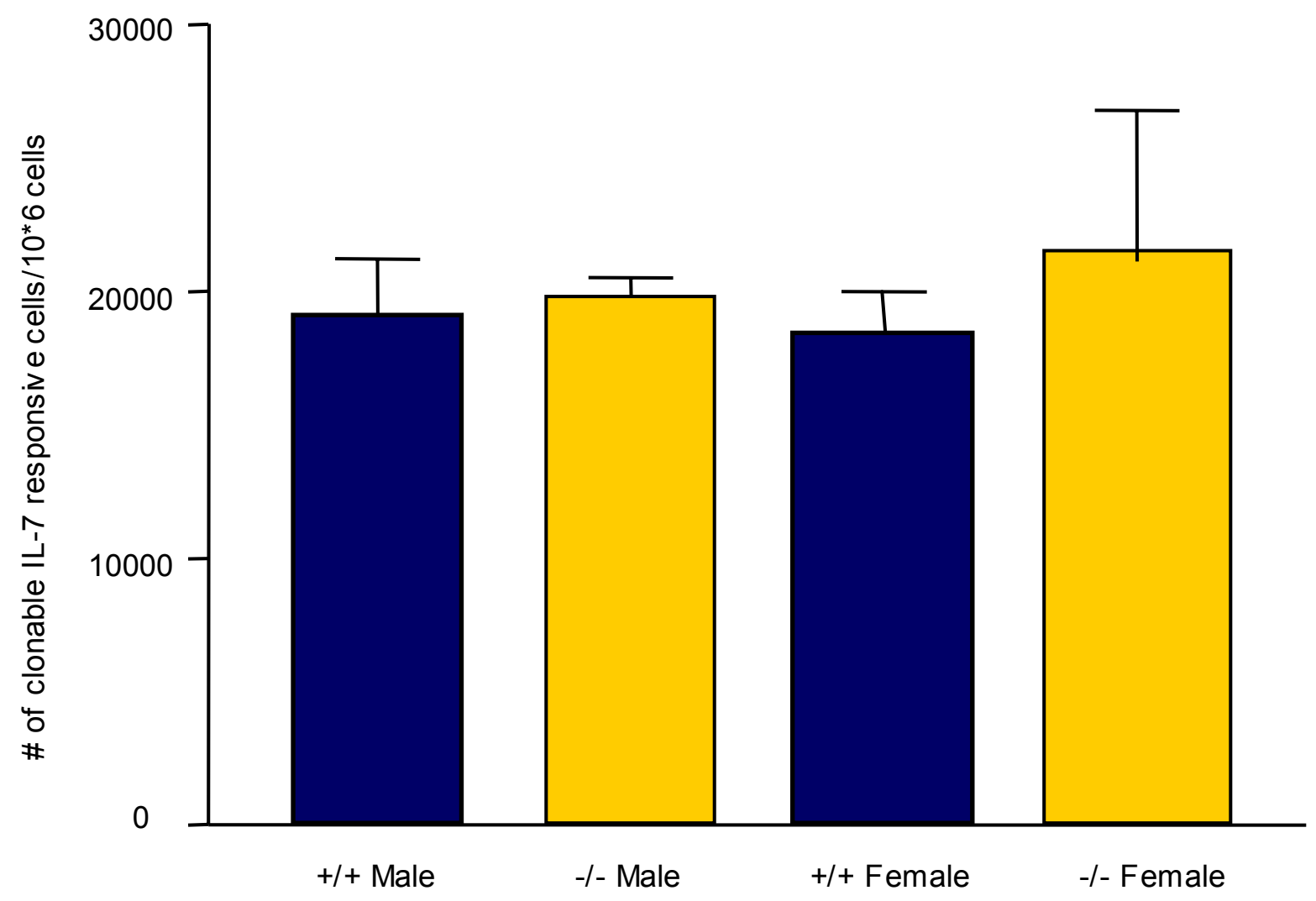

Figure 6. A-myb Mutation Does Not Alter Pro-B Cell Frequency. 100 cells from amyb wild-type or homozygous null fetal livers were plated into individual, stromal cell coated wells of 96 well plates. After incubation for 5 days with exogenously added IL-7, wells with clonable IL-7 responsive colonies were counted. Data is presented as the average of atleast 3 mice \pm SEM. 


\section{DISCUSSION}

Animal models harboring a mutation in one or more genes are valuable tools used to investigate the role specific genes play in development. Often, mutating a single gene can have deleterious effects on development. This is the case for several genes, including the proto-oncogene c-myb. Homozygous inactivation of c-myb results in embryonic lethality at days 14 to 15 of gestation due to a loss of fetal liver erythropoiesis. Other mutations, however, have less dramatic effects. This phenomenon is observed in animals harboring homozygous mutations of the a-myb gene. Inactivation of the a-myb gene results in male sterility and defects in mammary gland development, but does not prevent embryo formation. The original reports that describe the myb mutations discuss the most obvious defects associated with animals harboring the mutations. The objective of this report was to investigate an area not previously described by literature: the effect of a- and c-myb deletions on B lymphopoiesis. These data indicate that inactivation of the c-myb gene completely ablates B lymphopoiesis in the murine fetal liver while inactivation of the a-myb gene does not significantly alter fetal liver B lymphopoiesis.

In order to differentiate between wild-type, heterozygous, and homozygous null embryos, a genotyping strategy was needed. Mucenski et al had previously developed a PCR based strategy for genotyping c-myb animals, which was employed in this report. However, a PCR based strategy had not been developed for genotyping a-myb animals. We tried to mimic the PCR strategy used by Mucenski et al using one set of primers complimentary to exon 4 of a-myb that flanked the neomycin cassette. However, due to the high $\mathrm{A} / \mathrm{T}$ content of the a-myb gene, we could not design a set of primers to amplify the entire length of the neomycin cassette plus 200 bases of the a-myb gene. Therefore, a second set of primers was designed that amplified a region within the neo cassette. This required two separate PCR reactions, but allowed for detection of the native a-myb gene, the neo insert, and the a-myb gene containing a neo insert.

C-myb mutant animals expire at approximately day 15 of gestation. Therefore we analyzed embryos at day 13.5 , before the mutation was lethal. In order to compare effects of the c-myb mutation with the a-myb mutation, a-myb mice were also examined at day 13.5 of gestation. All experiments described in this report were performed on 
fetal livers from day 13.5 embryos. Fetal livers from day 13.5 c-myb null mice had significantly reduced numbers of white blood cells when compared to fetal livers of wildtype and heterozygous animals. There was a 10 fold decrease in the number of cells present in the c-myb null livers as compared to wild-type livers. However, in a-myb animals, there was no difference in the number of cells in the wild-type fetal liver versus fetal livers harboring a homozygous a-myb null mutation. These data indicate that while inactivation of the a-myb gene does not impact proliferation of fetal liver cells, inactivation of the c-myb gene leads to significant impairments in fetal liver cell expansion.

CFU-GM potential was evaluated in both a- and c-myb animals. In animals deficient for c-myb, there was greater than an $80 \%$ reduction in the number of CFU-GM progenitors as compared to wild-type animals. These data agreed with those results reported by Mucenski et al (Mucenski, 1991). In a-myb animals, however, the numbers of CFU-GM progenitors were the same in wild-type and in heterozygous null livers. In addition, CFU-GM progenitor numbers were evaluated in males and females. This was done because effects of the a-myb mutation are displayed differently in male and female animals. In males, a-myb inactivation results in sterility and spermatogenesis defects. In females, however, sterility does not result from inactive a-myb. A-myb mutant females can birth offspring but display an inability to nurse pups due to defective breast development. Although the a-myb mutation results in different phenotypes in males and females, the effects of the mutation on GM progenitor cell formation is not gender specific. Neither males nor females had altered numbers of fetal liver GM progenitor cells. These data indicate that a-myb and c-myb mutations have differential effects on GM progenitor formation. While loss of c-myb severely decreases GM progenitor potential, loss of a-myb does not alter GM progenitor cell numbers.

In order to evaluate the role a- and c-myb play in B lymphopoiesis, colony forming units in response to IL-7 were evaluated. CFU-IL-7 progenitor potential was first evaluated in c-myb deficient animals. Mice harboring a homozygous null mutation of the c-myb gene had no IL-7 colonies formed above no cytokine controls. Loss of cmyb function resulted in a complete abrogation of IL-7 progenitor cell expansion. To confirm these results, a pro-B cell assay was utilized. Plating 100 fetal liver cells from c- 
myb homozygous null mice into individual wells of a 96 well plate resulted in no clonable IL-7 responsive cells. Also, the number of fetal liver cells cultured was increased to 200 cells per well. Still, no clonable IL-7 pro-B cells were obtained from c-myb mutants. These data correlated well with CFU-IL-7 data; no IL-7 responsive pro-B cells could be cultured from c-myb null fetal livers. Therefore, while both wild-type and heterozygous fetal livers contained clonable IL-7 responsive pro-B cells, B lymphopoiesis was absent in c-myb null animals. In animals with a mutated a-myb gene, the numbers of fetal liver pro-B cells were no different than those in wild-type litter mates. In addition, there was no difference in the numbers of IL-7 responsive pro-B cells present in males or in females. These data suggest that $B$ lymphopoiesis is severely damaged in animals containing mutated c-myb genes, but is unaltered in animals with a-myb mutations.

Overall, data presented in this report demonstrate that B lymphopoiesis is almost completely ablated in animals harboring a mutant c-myb gene. Even at day 13.5, before the c-myb mutation is lethal, B lymphopoiesis is significantly altered. Taken together with the previous work presented by Mucenski et al, this suggests that c-myb is critical for development of both myeloid and lymphoid lineage cells. It is reasonable to suggest two possibilities for the observed defect in B lymphopoiesis. First, it is possible that loss of c-myb results in an intrinsic defect in early B cell progenitors that prohibits them from expanding within the fetal liver compartment. Secondly, it is possible that the microenvironment of the fetal liver is altered and is no longer permissive for lymphocyte expansion. Most likely, the defect in B lymphopoiesis is a combination of an altered microenvironment as well as progenitor cells with impaired proliferative capacity. In contrast, inactivation of the a-myb gene does not significantly impact $B$ lymphopoiesis at all. Although a-myb is expressed in different cell types than c-myb, the two display highly homologous DNA binding regions. Both a-myb and c-myb bind the same consensus DNA site on target DNA. How the two proteins exhibit differential effects is not completely understood, especially given their similar DNA binding preferences. This report indicates that, although they are highly homologous proteins, a-myb and c-myb play largely different roles in the development of B lymphopoiesis. C-myb is critical for normal development of $B$ lymphopoiesis since mice with a homozygous deletion of $\mathrm{C}$ myb have a complete loss of B cell development in the fetal live. However, a-myb is not 
essential to B cell development as evidenced by unaltered B cell development in mice with a homozygous null mutation of a-myb. Taken together these data suggest that, although a- and c-myb are closely related proteins, they do not play redundant roles in the development of B lymphocytes. 


\section{REFERENCES}

Alitalo K, Winquist R, Linn C, de la Caapelle A, Schwab M, Bishop JM: Aberrant expression of an amplified c-myb oncogene in two cell lines from a colon carcinoma. PNAS 81:4534, 1984

Dyson PJ, Poirier F, Watson RJ: Expression of C-myb in embryonal carcinoma cells and embryonal stem cells. Differentiation 42:24, 1989

Gonda TJ, Metcalf D: Expression of myb, myc, and fos proto-oncogenes during the differentiation of a murine myeloid leukaemia. Nature 310:249, 1984

Griffin CA, Baylin SB: Expression of the c-myb oncogene in human small cell ling carcinoma. Cancer Res 45:272, 1985

Klempnauer KH, Gonda TD, Bishop JM: Nucleotide sequence of the retroviral leukemia gene v-myb and its cellular progenitor c-myb: the architecture of a transduced oncogene. Cell 31:453, 1982

Lipsick JL, Boyle WJ: c-Myb protein expression is a late event during T-lymphocyte activation. Mol Cell Biol 7:3358, 1987

Mettus RV, Litvin J, Wali A, Toscani A, Latham K, Hatton K, Reddy EP: Murine Amyb: evidence for differential splicing and tissue-specific expression. Oncogene 9:3077, 1994

Mucenski ML, McLain K, Kier AB, Swerdlow SH, Schreiner CM, Miller TA, Pietryga DW, Scott WJ, Potter SS: A functional c-myb gene is required for normal murine fetal hepatic hematopoiesis. Cell 65:677, 1991 
Slamon DJ, deKernion JB, Verma IM, Cline MJ: Expression of cellular oncogenes in human malignancies. Science 224:256, 1984

Slamon KJ, Boone TC, Murdock DC, Keith DE, Press MF, Lavson RA, Souza LM: Studies of the human c-myb gene and its product in human acute leukemias. Science 233: 347, 1986

Stern JB, Smith KA: Interleukin-2 induction of T-cell G1 progression and c-myb expression. Science 233:203, 1986

Thiele CJ, McKeon C, Triche TJ, Ross RA, Reynolds CP, Israel MA: Differential proto-oncogene expression characterizes histopathologically indistinguishable tumors of the peripheral nervous system. J Clin Invest 80:804, 1987

Thiele CJ, Cohen PS, Israel MA: Regulation of c-myb expression in human neuroblastoma cells during retinoic acid induced differentiation. Mol Cell Biol 8:1677, 1988

Thompson CB, Challoner PB, Neiman PE, Groudine M: Expression of the c-myb proto-oncogene during cellular differentiation. Nature 319:374, 1986

Torelli G, Venturelli D, Colo A, Zanni C, Selleri L, Moretti L, Claabretta B, Troelli U: Expression of c-myb proto-oncogene and other cell cycle-related genes in normal and neoplastic human colonic mucosa. Cancer Res 47:5266, 1987

Toscani A, Mettus RV, Coupland R, Simpkins H, Litvin J, Orth J, Hatton KS, Reddy EP: Arrest of spermatogenesis and defective breast development in mice lacking Amyb. Nature 386:713, 1997

Trauth K, Mutschler B, Jenkins NA, Gilbert DJ, Copeland NG, Klempnauer KH: Mouse A-myb encodes a trans-activator and is expressed in mitotically active cells 
of the developing central nervous system, adult testis, and B- lymphocytes. EMBO 13:5994, 1994

Westin EH, Gallo RC, Arya SK, Eva A, Souza LM, Baluda MA, Aaronson SA, and Wong-Staal F: Differential expression of the amv gene in human hematopoietic cells. PNAS 79:2194, 1982 
Chapter 5

General Conclusions 
The overall goal of this study was to investigate the role of the proto-oncogene cmyb in B lymphopoiesis. We undertook this study because the current literature has focused on the role of c-myb in proliferation and differentiation of erythroid, myeloid, and $\mathrm{T}$ lymphoid cells, but far less is known about the role of myb in B lymphoid development. Our studies led to several novel observations: 1). C-myb is expressed at high levels in pro-B cells, 2). The half-life of c-myb mRNA is long lived in pro-B cells while the protein half-life is less than 1 hour, 3). Stromal cells regulate c-myb expression in pro-B cells, 4). C-myb is an intracellular regulator of proliferation in pro-B cells, 5). Cmyb is an intracellular regulator of differentiation in early $B$ lymphocytes, 6 ). C-myb does not regulate survival in pro-B cells, and 7). C-myb knockout animals exhibit a complete failure of fetal liver lymphopoiesis while animals deficient for a-myb do not exhibit any alterations in B cell development.

The first goal of this dissertation was to determine the normal expression patterns of $\mathrm{c}-m y b$ in developing $\mathrm{B}$ lymphocytes. Previous literature reported that late stage pro-B cells (those with D-J rearrangement of the heavy chain gene) do not express c-myb. We utilized a pro $B$ cell line which does not have Ig gene rearrangements to investigate c-myb in B lymphopoiesis. C1.92 was cloned from fetal liver. This cell line retains dependence on stromal cells and IL-7, and retains Ig heavy chain genes in germline configuration. This cell line is characterized as an early B cell progenitor line because the D-J region of the heavy chin gene remains germline and the cells continue to express CD43 along with CD45R (B220). C1.92 cells cultured with stromal cell support proliferate continuously in culture and do not differentiate. In addition, expression of Cmyb remains high throughout their life cycle. Since the $\mathrm{C} 1.92$ cell line is an early pro-B cell that still retains c-myb expression, it is a useful model to examine c-myb expression and regulation. Our data demonstrate that $\mathrm{C} 1.92$ pro-B cells express both mRNA and protein for c-myb.

C1.92 cells are similar in developmental status to the myeloid cell line HL-60. HL-60 cells are pro-myelocytes that continually proliferate in culture but do not differentiate. HL-60 cells are also characterized by high expression levels of c-myb. The $\mathrm{C} 1.92$ cell line is a model system similar to HL-60 cells, but lymphoid in nature. This provides a model of lymphocyte development which can be compared to c-myb data reported for 
myeloid cells. In order to complete assays at biologically relevant times, it was necessary to determine the degradation kinetics of c-myb in lymphoid cells. The halflife of c-myb mRNA and protein in myeloid cells is approximately one hour (E Westin, personal communication). However, when the half-life of c-myb in pro-B cells was evaluated we determined the half-life of c-myb mRNA to be long lived. Inhibition of mRNA transcription revealed the c-myb mRNA half-life to be approximately 11 hours. Conversely, the half-life of c-myb protein was short; inhibition of mRNA translation revealed the half-life of c-myb protein to be less than 1 hour. Therefore, while the halflife of c-myb protein is similar in lymphoid and myeloid cells, the half-life of c-myb protein is much longer in pro-B cells than in myeloid cells. These data establish the degradation kinetics of c-myb mRNA and protein in early pro B cells and demonstrate that c-myb is expressed continuously at high levels in an early pro-B cell model.

The second goal of this dissertation was to determine whether stromal cells regulated to expression of c-myb in pro-B cells. Developing $B$ cells within the bone marrow are dependent upon the bone marrow microenvironment for normal development. In particular, bone marrow stromal cells are known to regulate the survival, proliferation, and differentiation of developing B lymphocytes. Much of this regulation is accomplished through molecular changes in specific gene expression. One particular gene, c-myb, is known to be regulated during development in myeloid cells. Since stromal cells are important in regulating several other genes important in $B$ cell development, we wanted to investigate whether stromal cells also regulated c-myb expression in $\mathrm{C} 1.92$ cells. The data presented here demonstrate that stromal cells are also responsible for regulating c-myb in $\mathrm{C} 1.92$ cells. Culturing $\mathrm{C} 1.92$ cells in media alone, without the support of stromal cells, resulted in a decrease in both c-myb mRNA and protein within 8 hours. A decrease in c-myb mRNA was observed within 6 hours, indicating that loss of stromal cell support resulted in an active degradation of c-myb mRNA. However, it is known that stromal cells can regulate gene expression both by adhesion contacts and by producing numerous cytokines.

Our next aim was to determine whether stromal cells regulated c-myb expression through cytokine production or via adhesion contacts. Using a transwell culture system, it was determined that stromal cell adhesion contacts are largely responsible for 
maintaining c-myb expression. Although loss of stromal cell adhesion contacts did not completely ablate c-myb expression, it was significantly decreased. This indicates that although both stromal cell cytokine support and stromal cell adhesion molecules are involved in c-myb expression, stromal cell adhesion contacts are mainly responsible for the maintenance of c-myb expression in early B lymphocytes.

There are three hallmarks of the life of developing blood cells: the ability to survive, proliferate, and differentiate. Mechanisms that regulate these three fundamental events are not well understood. Our working hypothesis was that c-myb regulated proliferation and differentiation of developing $B$ linage cells in the bone marrow. Therefore, the next goal of this work was to determine if c-myb was an intracellular regulator of proliferation in developing B lymphocytes. It is well documented that c-myb regulates the proliferation and expansion of myeloid, erythroid, $\mathrm{T}$, and transformed B cells. This study investigated if proliferation in normal progenitor B cells was regulated by c-myb. Although culturing pro-B cells without stromal cells effectively downregulated c-myb, this is not the best method to use to investigate regulation of c-myb in pro-B cells because this results in initiation of apoptosis. In order to downregulate c-myb without initiating cell death in pro-B cells, treatment of cells with DMSO or antisense oligonucleotides was utilized. Treatment of pro-B cells with DMSO or antisense oligonucleotides resulted in decreased c-myb protein as detected by western blot analysis. Following cmyb downregulation by either of these treatments, pro-B cells failed to expand in culture. When cells were enumerated after c-myb downregulation, cultures treated with antisense oligonucleotides or DMSO had significantly fewer cells. When pro-B cells with downregulated c-myb levels were put into a proliferation assay, there was a significant decrease in their ability to respond to the proliferative cytokine interleukin-7. Analysis of their cell cycle profile using propidium iodide revealed that pro-B cells with decreased c-myb levels had an increased proportion of cells in the G0/G1 phase of the cell cycle with fewer numbers of cells in the $S$ and G2/M phases of the cell cycle. These data indicated that downregulation of c-myb resulted in an inhibition of proliferation by blocking cells in the G0/G1 phase of the cell cycle. This suggested that c-myb is an intracellular regulator of proliferation in pro-B cells. 
Since pro-B cells exhibited alterations in proliferation and cell cycle profiles, we were interested in determining whether cells were exiting the cell cycle and beginning to differentiate. Our next goal was to determine whether c-myb was an intracellular regulator of differentiation in early $B$ lymphocytes. One way to follow $B$ cell maturation is to follow changes in cell surface markers. C1.92 cells express low levels of B220, high levels of CD43, low levels of CD24 (HSA), and low levels of flt-3. If phenotypic maturation is occurring, B220, CD24, and flt-3 levels should increase while CD43 expression should decrease. However, after downregulation of c-myb, no alterations in these cell surface molecules were observed. Although phenotypic maturation was not observed, we investigated genotypic alterations. As pro-B cells mature into immunoglobulin bearing $B$ cells, rearrangement of the immunoglobulin genes occurs. Genetic reorgantization and juxtaposition of a single variable (V), diversity (D), and joining $(J)$ region from the $\lg$ heavy chain gene is required for expression of immunoglobulin. Tracking rearrangement of the heavy chain genes is the most reliable way to follow B cell maturation. Utilizing PCR, we determined that downregulation of cmyb by DMSO treatment resulted in rearrangement of Ig heavy chain genes. In addition, surface immunoglobulin was detected on $\mathrm{C} 1.92$ cells with downregulated cmyb expression. These data indicated that downregulation of c-myb resulted in genotypic maturation of pro-B cells to Ig expression. However, phenotypic maturation was uncoupled from genotypic maturation because c-myb downregulation did not alter the cell surface phenotype of pro B cells. These data suggest that c-myb is an intracellular regulator of differentiation in pro-B cells, but that add additional signals are required for completion of phenotypic (and maybe functional) maturation.

The next objective of this report was to determine whether c-myb was an intracellular regulator of survival in developing B lymphocytes. It is known that pro-B cells require stromal cell contact for their continued survival. And, we have previously shown that stromal cells regulate c-myb expression in pro-B cells. We wanted to determine if the survival signals provided by stromal cells were c-myb dependent. When c-myb was downregulated by DMSO or antisense treatment, $\mathrm{C} 1.92$ cells exhibited no decrease in cell viability. In addition, staining with propidium iodide and examination of DNA did not reveal the onset of apoptosis. This indicates that, although 
stromal cells regulate c-myb expression in pro-B cells, c-myb does not regulate the survival of developing B lymphocytes.

Finally, we wanted to utilize the currently available myb knockout models and determine whether lymphopoiesis occurred in these mutant animals. C-myb knockout mice die at day 15 of embryogenesis due to loss of erythropoiesis in the fetal liver. However, B lymphopoiesis has not been described in these animals. Examinations of the fetal livers of day 13.5 mutant c-myb animals revealed that no lymphopoiesis was occurring in these animals. No CFU-IL-7 progenitors were present in c-myb null animals and no clonable IL-7 responsive pro-B cells were present. These data suggest that the loss of c-myb during embryogenesis completely ablated B lymphopoiesis in the fetal liver. Conversely, when the fetal livers of day 13.5 a-myb null fetal livers were examined, B lymphopoiesis was completely intact. This indicates that c-myb is necessary for $\mathrm{B}$ lymphopoiesis while a-myb is dispensable. Although a-myb and c-myb exhibit high homology and share affinity for the same consensus DNA binding site, they are not redundant in their role in $\mathrm{B}$ lymphopoiesis.

Taken together, these data provide a working model for the role of c-myb in B cell development. Pro-B cells require stromal cell interactions for maturation within the bone marrow microenvironment. Stromal cell contacts are responsible for maintaining high levels of c-myb in early pro-B cells and this expression is directly related to observed high proliferative capacity of these cells. Pro-B cells are the primary expanding cell compartment of the $B$ lineage, therefore a high proliferative capacity is necessary to produce enough progenitor cells to populate the entire animal. However, as pro-B cells loose their dependence on stromal cells, they exhibit decreased proliferative potential. It is at this time that c-myb levels decrease. As c-myb levels abate, proliferation ceases and genotypic maturation occurs. These changes allow pro-B cells to differentiate into surface immunoglobulin positive $B$ cells. These data clearly demonstrate that cellular interactions between stromal cells and pro-B cells regulate molecular events within developing B cells. In turn, these changes in molecular molecules, particularly in c-myb expression, determine the fate of immature $B$ linage cells. 


\section{APPENDIX: PRIMERS AND ANTIBODIES}


RNA Primers

\begin{tabular}{|c|c|c|}
\hline $\begin{array}{c}\text { Primer } \\
\text { Name }\end{array}$ & Sense Primer Sequence (5'- 3') & Antisense Primer Sequence (5'- 3') \\
\hline $\begin{array}{c}\text { C-myb } \\
\text { exon } 4\end{array}$ & GAGCTTGTCCAGAAATATGGTCCGAAG & GGCTGCCGCAGCCGGCTGAGGGAC \\
\hline $\begin{array}{c}\text { C-myb } \\
\text { exon 8/10 }\end{array}$ & ACCCTGAGAAGGAAAAGCGAA & GTTTTCACAGTCTGGTCTCGA \\
\hline $\begin{array}{c}\text { C-myb } \\
\text { exon } 8 / 9\end{array}$ & AAGCGAATAAAGGAGCTGGAGT & TGGTGGACGATCATGCACCT \\
\hline $\begin{array}{c}\text { C-myb } \\
\text { start site }\end{array}$ & ATGGGCGCCCCACTCAACT & TATCAGTCCGTCCGGGCA \\
\hline $\begin{array}{c}\text { B-myb } \\
\text { B-myb }\end{array}$ & ATGTCTCGGCGGACGCGCTGCGAG & CTGTTCCTTGTCCTCCAGCTCCAGG \\
\hline Actin & ACGAGCCTGCCCTACAAGTG & TGGCGTGTGGGGAGTGTTGT \\
\hline IGF-1 & GACCCTTTGCGGGGCTGAGCTGGT & CTTCTGAGTCTTGGGCATGTCAGT \\
\hline IL-6 & AACAGACCTGTCTATACC & GGATCTTCATGAGGTAGTCTGTC \\
\hline IL-7 & GCCTGTCACATCATCTGAGTGCC & CAGGAGGCATCCAGGAACTTCTG \\
\hline
\end{tabular}

DNA primers

\begin{tabular}{|c|c|c|}
\hline $\begin{array}{c}\text { Primer } \\
\text { Name }\end{array}$ & Sense Primer Sequence (5' - 3') & Antisense Primer Sequence (5' - 3') \\
\hline GAPDH & TGAAGGTCGGTGTGAACGGATTTGG & ACGACATACTCAGCACCGGCCTCAC \\
\hline $\mathrm{D}_{\mathrm{FL} 16.1}$ & GCCTGGGGAGTCACTCAGCAGC & GTGTGGAAAGCTGTGTATCCCC \\
\hline $\mathrm{JH}_{1}$ & CCCGGACAGAGCAGGCAGGTGG & GGTCCCTGCGCCCCAGACA \\
\hline $\mathrm{Syr}$ & AAGCGCCCCATGAATGCATT & TCCCAGCTGCTTGCTGATCT \\
\hline $\mathrm{Neo}$ & GATGGATTGCACGCAGGTTCTCCGG & ATGGGCAGGTAGCCGGATCAAGCGT \\
\hline $\mathrm{C}$-myb & GCAAGGTGGAACAGGAAGGCTACC & GTGCTTCGGCGATGTGGTAATAGG \\
\hline A-myb & GTATACTTAAATTTGGGCTAATTT & TAAATTTTTTCAAAAGAATATGAA \\
\hline
\end{tabular}


Antibodies:

\begin{tabular}{|c|c|c|c|c|c|}
\hline Antibody & & Isotype & Tag & Clone & Supplier \\
\hline GAPDH & $\begin{array}{c}\text { Monoclonal } \\
\text { mouse anti } \\
\text { rabbit }\end{array}$ & $\operatorname{lgG} 2 b$ & Purified & $6 \mathrm{C} 5$ & $\begin{array}{c}\text { Research } \\
\text { Diagnostics } \\
\text { Inc. }\end{array}$ \\
\hline C-myb & $\begin{array}{c}\text { Mouse } \\
\text { monoclonal }\end{array}$ & $\lg 22 a \kappa$ & Purified & $1-1$ & $\begin{array}{c}\text { Upstate } \\
\text { Biotechnology }\end{array}$ \\
\hline CD45R & $\begin{array}{l}\text { Rat anti } \\
\text { mouse }\end{array}$ & $\lg 2 \mathrm{ak}$ & FITC & RA3-6B2 & Pharmingen \\
\hline CD45R & $\begin{array}{l}\text { Rat anti } \\
\text { mouse }\end{array}$ & $\lg G 2 a \kappa$ & R-PE & RA3-6B2 & Pharmingen \\
\hline RAG-2 & $\begin{array}{c}\text { Mouse } \\
\text { monoclonal }\end{array}$ & $\operatorname{lgG} 2 b$ & Purified & G110-461 & Pharmingen \\
\hline RAG-1 & $\begin{array}{l}\text { Mouse anti- } \\
\text { mouse }\end{array}$ & $\operatorname{lgG} 2 \mathrm{~b}$ & Purified & G109-256 & Pharmingen \\
\hline $\begin{array}{l}\text { Ly-51 } \\
\text { (BP-1) }\end{array}$ & $\begin{array}{l}\text { Rat anti- } \\
\text { mouse }\end{array}$ & $\lg 2 a \kappa$ & FITC & $6 \mathrm{C} 3$ & Pharmingen \\
\hline $\begin{array}{l}\text { CD24 } \\
\text { (HSA) }\end{array}$ & $\begin{array}{c}\text { Rat anti- } \\
\text { mouse }\end{array}$ & $\lg G 2 \mathrm{cK}$ & Purified & $30-\mathrm{F} 1$ & Pharmingen \\
\hline $\begin{array}{l}\text { CD24 } \\
\text { (HSA) }\end{array}$ & $\begin{array}{l}\text { Rat anti- } \\
\text { mouse }\end{array}$ & $\operatorname{lgG} 2 b \kappa$ & FITC & M1/69 & Pharmingen \\
\hline CD43 & $\begin{array}{l}\text { rat anti- } \\
\text { mouse }\end{array}$ & $\lg$ G2aк & FITC & S7 & Pharmingen \\
\hline CD43 & $\begin{array}{l}\text { rat anti- } \\
\text { mouse }\end{array}$ & $\operatorname{lgG} 2 а к$ & PE & S7 & Pharmingen \\
\hline $\begin{array}{l}\text { CD135 } \\
\text { (Flt-3) }\end{array}$ & $\begin{array}{l}\text { Rat anti- } \\
\text { mouse }\end{array}$ & $\operatorname{lgG} 2 a \kappa$ & PE & A2F 10.1 & Pharmingen \\
\hline IL-7R & & & Purified & & \\
\hline
\end{tabular}


Isotype Antibodies:

\begin{tabular}{|c|c|c|c|c|}
\hline Antibody & Isotype & Tag & Clone & Supplier \\
\hline Mouse IgG1 Isotype & $\lg G 1, \kappa$ & Purified & $15 \mathrm{H} 6$ & Southern Biotechnology \\
\hline Mouse IgG2a Isotype & $\lg G 2 a, \kappa$ & Purified & HOPC-1 & Southern Biotechnology \\
\hline rat lgG2a isotype & $\operatorname{lgG} 2 \mathrm{a}, \mathrm{K}$ & R-PE & R35-95 & Pharmingen \\
\hline Rat lgG2b isotype & $\lg G 2 b, \kappa$ & Purified & A95-1 & Pharmingen \\
\hline Rat IgM & $\lg M, \kappa$ & Purified & $\mathrm{R} 4-22$ & Pharmingen \\
\hline $\begin{array}{c}\text { Mouse IgG2b isotype } \\
\text { (anti-dansyl) }\end{array}$ & $\operatorname{lgG} 2 b, \kappa$ & Purified & $27-35$ & Pharmingen \\
\hline Goat anti-rat $\lg M+\lg G$ & $\begin{array}{c}\lg M+\lg G \\
(\mathrm{H}+\mathrm{L} \text { chain } \\
\text { specific) }\end{array}$ & Purified & & Southern Biotechnology \\
\hline Goat anti mouse Ig & $\begin{array}{l}\lg (\mathrm{H}+\mathrm{L}) \\
\text { Chain } \\
\text { specific }\end{array}$ & Purified & & Southern Biotechnology \\
\hline
\end{tabular}


CUMULATIVE REFERENCES 
Abramson S, Miller, RG, Phillips, RA: The identification in adult bone marrow of pluripotent and restricted stem cells of the myeloid and lymphoid systems. J Exp Med $145: 1567,1977$

Akashi K, Traver D, Miyamota T, Weissman IL: A clonogenic common myeloid progenitor that gives rise to all myeloid lineages. Nature 404:193, 2000

Allen RD, Bender TP, Siu G: c-Myb is essential for early T cell development. Genes and Dev 13:1073, 1999

Alitalo K, Winquist R, Linn C, de la Caapelle A, Schwab M, Bishop JM: Aberrant expression of an amplified c-myb oncogene in two cell lines from a colon carcinoma. PNAS 81:4534, 1984

Anton IA, Frampton J: Tryptophans in myb proteins. Nature 336:719, 1988

Arsura M, Introna M, Passerini F, Mantovani A, Golay J: B-myb antisense oligonucleotides inhibit proliferation of human hematopoietic cell lines. Blood 79:2708, 1992

Aurigemma RE, Blair DG, Ruscetti SK: Transactivtion of erythroid transcription factor GATA-1 by a myb-ets-containing retrovirus. J Virol 66:3056, 1992

Badiani P, Corbella P, Kioussis D, Marvel J, Weston K: Dominant interfering alleles define a role for c-Myb in T-cell development. Genes and Dev 8:770, 1994

Barzilay J, Kushtai G, Plaksin D, Feldman M, Eisenbach L: Expression of major histocompatibility class I genes in differentiating leukemic cells is temporally related to activation of c-fos proto-oncogene. Leukemia 1:198, 1987 
Bender TP, Kuehl WM: Differential expression of the c-myb proto-oncogene marks the pre-B cell/B cell junction in murine B lymphoid tumors. J Immunol 139:3822, 1987

Bevan MJ, Hogquist KA, Jameson SC: Selecting the T cell receptor repertoire. Science 264:796, 1994

Bidenkapp H, Borgmeyer U, Sippel AE, Klempnauer KH: Viral myb oncogene encodes a sequence specific DNA binding activity. Nature 335:835, 1988

Billips LG, Petitte D, Landreth KS: Bone marrow stromal cell regulation of $B$ lymphopoiesis: interleukin-1 (IL-1) and IL-4 regulate stromal cell support of pre-B cell production in vitro. Blood 75:611, 1990

Billips LG, Petitte D, Dorshkind K, Narayanan R, Chiu C-P, Landreth KS: Differential roles of stromal cells, interleukin-7, and kit-ligand in the regulation of B lymphopoiesis. Blood 79:1185, 1992

Boyd AW, Sullivan JR: Leukemic cell differentiation in vivo and in vitro: arrest of proliferation parallels the differentiation induced by the antileukemic drug Harringtonine. Blood 63:384, 1984

Bradford GB, Williams B, Rossi R, Bertoncello I: Quiescence, cycling, and turnover in the primitive hematopoietic stem cell compartment. Exp Hematol 25:445, 1997

Brelvi ZS, Studzinski GP: Coordinate expression of c-myc, c-myb, and histone H4 genes in reversibly differentiating HL 60 cells. J Cell Physiol 131:43, 1987

Brown KE, Kindy MS, Sonenshein GE: Expression of the c-myb proto-oncogene in bovine vascular smooth muscle cells. J Biol Chem 267:4625, 1992 
Catron KM, Purkerson JM, Isakson PC, Bender TP: Constitutive versus cell cycle regulation of c-myb mRNA expression correlates with developmental stages in murine $B$ lymphoid tumors. J Immunol 148:934, 1992

Chen J, Bender TP: A novel system to identify myb target promoters in friend murine erythroleukemia cells. Blood Cell Mol Disease 27:429, 2001

Chen LT, Weiss L: The development of vertebral bone marrow of human fetuses. Blood 46:389, 1975

Churilla AM, Braciale TJ, Braciale VL: Regulation of T lymphocyte proliferation. Interleukin 2-mediated induction of c-myb gene expression is dependent on T lymphocyte activation state. J Exp Med 170:105, 1989

Clark MF, Kukowska-Latallo JF, Westin E, Smith M, Prochownik EU: Constitutive expression of a c-myb cDNA blocks friend murine erythroleukemia cell differentiation. Mol Cell Biol 8:884, 1988

Collins, LS and Dorshkind, K: A stromal cell line from myeloid long-term bone marrow cultures can support myelopoiesis and B lymphopoiesis. J Immunol 138: 1082-1087, 1987

Collins SJ, Gallo RC, Gallagher RE: Continuous growth and differentiation of human myeloid leukaemic cells in suspension culture. Nature 27:347, 1977

Craig RW, and Bloch A: Early decline in c-myb oncogene expression in the differentiation of human myeloblastic leukemia (ML-1) cells induced with 12-Otetradecanoylphorbol-13-acetate. Cancer Res 44:442, 1984 
Cumano A, Ferraz JC, Klaine M, Di Santo JP, Godin I: Intraembryonic, but not yolk sac hematopoietic precursors, isolated before circulation, provide long-term multilineage reconstitution. Immunity 15:477, 2001

Cumano A, Godin I: Pluripotent hematopoietic stem cell development during embryogenesis. Curr Opin Immunol 13:166, 2001 a

DeRocco SE, lozzo R, Ma XP, Schwarting R, Peterson D, Calabretta B: Ectopic expression of A-myb in transgenic mice causes follicular hyperplasia and enhanced $B$ lymphocyte proliferation. PNAS 94:3240, 1997

Dini PW, Lipsick JS: Oncogenic truncation of the first repeat of c-Myb decreases DNA binding in vitro and in vivo. Mol Cell Biol 13:7334, 1993

Dorshkind K: Regulation of hemopoiesis by bone marrow stromal cells and their products. Annu Rev Immunol 8:111, 1990

Dyson PJ, Poirier F, Watson RJ: Expression of C-myb in embryonal carcinoma cells and embryonal stem cells. Differentiation 42:24, 1989

Evans JT, Moore TL, Kuehl WM, Bender T, Ting JPY: Functional analysis of c-Myb protein in T-lymphocytic cell lines shows that it trans-activates the c-myb promoter. Mol Cell Biol 10:5747, 1990

Favier D, Gonda TJ: Detection of proteins that bind to the leucine zipper motif of c-Myb. Oncogene 9:305, 1994

Gellert M: Recent advances in understanding V(D)J recombination. Adv Immunol 64:39, 1997 
Gewirtz AM, Anfossi G, Venturelli D, Valpreda S, Sims R, Calabretta: G1/S transition in normal human T-lymphocytes required the nuclear protein encoded by c-myb. Science 245:180, 1989

Gewirtz AM, Calabretta B: Role of the c-myb and c-ab/ protooncogenes in human hematopoiesis. Ann NY Acad Sci 628:63, 1991

Gewirtz AM: Antisense oligonucleotides therapeutics for human leukemia. Curr Opin Hematol 5:59, 1998

Gewirtz AM, Calabretta B: A c-myb antisense oligodeoxynucleotide inhibits normal human hematopoiesis in vitro. Science 242: 1303, 1988

Ghia P, Boekel E, Rolink AG, Melchers F: B-cell development: a comparison between mouse and man. Immunol Today 19:480, 1998

Gibson LF, Piktel D, Landreth KS: Insulin-like growth factor-1 potentiates expansion of interleukin-7-dependent pro-B cells. Blood 82:3005, 1993

Gibson LF, Piktel D, Narayanan R, Nunez G, Landreth KS: Stromal cells regulate $b c /-2$ and bax expression in pro-B cells. Exp Hematol 24:628, 1996

Godfrey DI, Kennedy J, Suda T, Zlotnik A: A developmental pathway involving four phenotypically and functionally distinct subsets of CD3-CD4-CD8-triple-negative adult mouse thymocytes defined by CD44 and CD25 expression. J Immunol 150:4244, 1993

Godin IE, Garcia-Porrero JA, Coutinho A, Dieterlen-Lievre F, Marcos MA: Para-aortic splanchnopleura from early mouse embryos contains B1a cell progenitors. Nature 364:67, 1993 
Godin I, Garcia-Porrero JA, Dieterlen-Lievre F, Cumano A: Stem cell emergence and hematopoietic activity are incompatible in mouse intraembryonic sites. J Exp Med 190:43, 1999

Golay J, Capucci A, Arsura M, Casetellano M, Rizzo V, Introna M: Expression of C-myb and B-myb, but not A-myb, correlates with proliferation in human hematopoietic cells. Blood 7:149, 1991

Golay J, Loffarelli L, Luppi M, Castellano M, Introna M: The human A-myb protein is a strong activator of transcription. Oncogene 9:2469, 1994

Gonda TJ, Bishop JM: Structure and transcription of the cellular homolog (c-myb) of the avian myeloblastosis virus transforming gene (v-myb). J Virol 46:212, 1983

Gonda TJ, Metcalf D: Expression of $m y b, m y c$, and fos proto-oncogenes during the differentiation of a murine myeloid leukaemia. Nature 310:249, 1984

Grabstein KH, Waldschmidt TJ, Finkelman FD, Hess BW, Alpert AR, Boiani NE, Namen AE, Morrissey PJ: Inhibition of murine B and T lymphopoiesis in vivo by an antiinterleukin 7 monoclonal antibody. J Exp Med 178:257, 1993

Grawunder U, Rolink A, Melchers F: Induction of sterile transcription from the kappa L chain gene locus in $\mathrm{V}(\mathrm{D}) \mathrm{J}$ recombinase-deficient progenitor $\mathrm{B}$ cells. Int Immunol 7:1915, 1995

Greco C, Gandolfo GM, Mattei F, Gradilone F, Gradilone A, Alvino S, Pastore LI, Casale V, Casole V, Casole P, Grassi A, Cianciulli AM: Detection of c-myb genetic alterations and mutant p53 serum protein in patients with benign and malignant colon lesions. Anticancer Res 14:1433, 1994 
Griffin CA, Baylin SB: Expression of the c-myb oncogene in human small cell ling carcinoma. Cancer Res 45:272, 1985

Guidos CJ, Wissman IL, Adkins B: Developmental potential of CD4-8-thymocytes. Peripheral progeny include mature CD4-8-T cells bearing alpha beta T cell receptor. J Immunol 142:3773, 1989

Gurein M, Sheng ZM, Andrieu N, Riou G: Strong association between c-myb and estrogen-receptor expression in human breast cancer. Oncogene 5:131, 1990

Hardy RR, Carmack CE, Shinton SA, Kemp JD, Hayakawa K: Resolution and characterization of pro-B and pre-pro-B cell stages in normal mouse bone marrow. J Exp Med 173:1213, 1991

Hardy RR, Hayakawa K: B cell development pathways. Annu Rev Immunol 19:595, 2001

Howe KM, Watson RJ: Nucleotide preferences in sequence-specific recognition of DNA by c-myb protein. Nucleic Acids Res 19:3913, 1991

Huang E, Nocka K, Beire DR, Chu T-Y, Buck J, Lahm H-W, Wellner D, Leder P, Besmer P: The hematopoietic growth factor $\mathrm{KL}$ is encoded at the $\mathrm{SI}$ locus and is the ligand of the c-kit receptor, the gene product of the W locus. Cell 63:225, 1990

Jacobsen LO, Marks EK, Robson MJ, et al: Effect of spleen protection on mortality following x-irradiation. J Lab Clin Med 34:1538, 1949

Johnson A, Dorshkind K: Stromal cells in myeloid and lymphoid long-term bone marrow cultures can support multiple hemopoietic lineages and modulate their production of hemopoietic growth factors. Blood 68:1348, 1986 
Jordan CT, Astle CM, Zawadzki J, Mackarehtschian K, Lemischka IR, Harrison DE: Long-term repopulating abilities of enriched fetal liver stem cells measured by competitive repopulation. Exp Hematol 23:1011, 1995

Kamano H, Burk B, Noben-Trauth K, Klempnauer KH: Differential splicing of the mouse B-myb gene. Oncogene 11:2575, 1995

Kanei-IshiiC, Sarai A, Sawazaki T, Nakagoshi H, He DN, Ogata K, Nishimura Y, Ishii S: The tryptophan cluster: a hypothetical structure of the DNA-binding domain of the myb protooncogene product. J Biol Chem 265:19990, 1990

Kanei-Ishii C, Macmillan EM, Nomura T, Sarai A, Ramsay RG, Aimoto S, Ishii S, Gonda TJ: Transactivation and transformation by Myb are negatively regulated by a leucine zipper structure. PNAS 89:3088, 1992

Kanei-Ishii C, Nomura T, Ogata K, Sarai A, Yasukawa T, Tashiro S, Takahashi T, Tanaka Y, Ishii S: Structure and function of the proteins encoded by the myb gene family. 1995

Kina T, Majumdar AS, Heimfeld S, Kaneshima H, Holzmann B, Katsura Y, Weissman IL: Identification of a 107-kD glycoprotein that mediates adhesion between stromal cells and hematolymphoid cells. J Exp Med 173:373, 1991

Kincade, PW, Lee G, Paige CJ, Scheid MP: Cellular interactions affecting the maturation of B lymphocyte precursors in vitro. J Immunol 127:255, 1981

Kincade PW, Lee G, Peitrangeli CE, Hayashi S, Gimble JM: Cells and molecules that regulate B lymphopoiesis in bone marrow. Annu Rev Immunol 7:111, 1989

Kirsch IR, Bertness V, Silver J, Hollis GF: Regulated expression of the c-myb and cmyc oncogenes during erythroid differentiation. J Cell Biochem 32:11, 1984 
Kishi H, Jin ZX, Nagata T, Matsuda T, Saito S, Muraguchi A: Cooperative binding of cMyb and Pax-5 activates the RAG-2 promoter in immature B cells. Blood 99:576, 2002

Klempnauer KH, Gonda TD, Bishop JM: Nucleotide sequence of the retroviral leukemia gene v-myb and its cellular progenitor c-myb: the architecture of a transduced oncogene. Cell 31:453, 1982

Kondo M, Weissman IL, Akashi K: Identification of clonogenic common lymphoid progenitors in mouse bone marrow. Cell 91:661, 1997

Ku D-H, Wen S-C, Englehard A, Nicolaides NC, Lipson KE, Marion TA, Calabretta B: $\mathrm{C}$-myb transactivation of $c d c 2$ expression via myb binding sites in the 5 ' flanking region of the human cd2 gene. J Biol Chem 268:2255, 1993

Lam EW, Robinson C, Watson RJ: Characterization and cell cycle-regulated expression of mouse B-myb. Oncogene 7:1885, 1992

Landreth KS, Rosse C, Clagett J: Myelogenous production and maturation of B lymphocytes in the mouse. J Immunol 127:126, 1981

Landreth KS, Kincade PW, Lee G, Gathings WE, Fu SM: Enrichment of human marrow lymphocytes with monoclonal antibodies to murine antigens. PNAS 79:2370, 1982

Landreth KS, Narayanan R, Dorshkind K: Insulin-like growth factor-1 regulates pro-B cell differentiation. Blood 80:1207, 1992

Lee G, Namen AE, Gillis S, Ellingsworth LR, Kincade PW: Normal B cell precursors responsive to recombinant murine IL-7 and inhibition of IL-7 activity by transforming growth factor-beta. J Immunol 142:3875, 1989 
Lipsick JL, Boyle WJ: c-Myb protein expression is a late event during T-lymphocyte activation. Mol Cell Biol 7:3358, 1987

Lipsick JS: One billion years of Myb. Oncogene 13:223, 1996

Lorenz E, Uphoff D, Reid TR, et al: Modification of irradiation injury in mice and guinea pigs by bone marrow injections. J Natl Cancer Inst 12:197, 1951

Lu M, Kawamoto H, Datsube Y, Ikawa T, Katsura Y: The common myelolymphoid progenitor: a key intermediate stage in hemopoiesis generating T and B cells. J Immu 169:3519, 2002

McClinton D, Stafford J, Brents L, Bender TP, Duehl WM: Differentiation of mouse erythroleukemia cells is blocked by late up-regulation of a c-myb transgene. Mol Cell Biol 10:705, 1990

Medvinsky AL, Samoylina NL, Muller AM, Dzierzak EA: An early pre-liver intraembryonic source of CFU-S in the developing mouse. Nature 364:64, 1993

Melotti P, Ku DH, Calabretta B: Regulation of the expression of the hematopoietic stem cell antigen CD34: role of c-myb. J Exp Med 179:1023, 1994

Metcalf D, Moore MA: Factors modifying stem cell proliferation of myelomonocytic leukemic cells in vitro and in vivo. J Natl Cancer Inst 44:801, 1970

Mettus RV, Litvin J, Wali A, Toscani A, Latham K, Hatton K, Reddy EP: Murine A-myb: evidence for differential splicing and tissue-specific expression. Oncogene 9:3077, 1994 
Micklem HS, Ford CE, Evans EP, Gray J: Interrelationships of myeloid and lymphoid cells: studies with chromosome-marked cells transplanted into lethally irradiated mice. Proc R Soc Lond B Biol Sci 165:78, 1966

Miyajima I, Levitt L, Hara T, Bedell MA, Copeland NG, Jenkins NA, Miyajima A: The murine interleukin-3 receptor alpha subunit gene: chromosomal localization, genomic structure, and promoter function. Blood 85:1246, 1995

Miyake K, Medina K, Ishihara K, Kimota M, Auerbach R, Kincade PW: A VCAM-like adhesion molecule on murine bone marrow stromal cells mediates binding of lymphocyte precursors in culture. J Cell Biol 114:557, 1991

Mombaerts P, lacomini J, Johnson RS, Herrup K, Tonegawa S, Papaioannou VE: RAG-1-deficient mice have no mature B and T lymphocytes. Cell 68:869, 1992

Moore MA, Metcalf D: Ontogeny of the haemopoietic system: yolk sac origin of in vivo and in vitro colony forming cells in the developing mouse embryo. $\mathrm{Br} \mathrm{J}$ Haematol $18: 279,1970$

Morrison SJ, Uchida N, Weissman IL: The biology of hematopoietic stem cells. Annu Rev Cell Dev Biol 11:35, 1995

Mucenski ML, McLain K, Kier AB, Swerdlow SH, Schereiner CM, Miller TA, Pietryga DW, Scott WJ, Potter SS: A functional c-myb gene is required for normal murine fetal hepatic hematopoiesis. Cell 65:677, 1991

Nagasawa T, Kaisho T, Kishimoto T, Kikutani H: Generation and characterization of a monoclonal antibody that inhibits stromal cell-dependent B lymphopoiesis. J Immunol 152:2788, 1994 
Nagasawa T, Hirota S, Tachibana K, Takakura N, Nishikawa S, Kitamura Y, Yoshida N, Kikutani $\mathrm{H}$, Kishimoto $\mathrm{T}$ : Defects of B-cell lymphopoiesis and bone-marrow myelopoiesis in mice lacking the CXC chemokine PBSF/SDF-1. Nature 382:635, 1996

Namen AE, Lupton S, Hjerrild K, Wignall J, Mochizuki DY, Schmierer A, Mosley B, March CJ, Urdal D, Gillis S, Cosman D, Goodwin RG: Stimulation of B-cell progenitors by cloned murine interleukin-7. Nature 333:571,1988

Ness SA, Marknell A, Graf T: The v-myb oncogene product binds to and activates the promyelocyte-specific mim-1 gene. Cell 59:1115, 1989

Ness SA: The myb oncoprotein: regulating a regulator. Biochimica et Biophysica Acta 1288:F123, 1996

Nicolaides NC, Correa I, Casadevall C, Travali S, Soprano KJ, Calabretta B: The Jun family members, c-Jun and JunD, transactivate the human c-myb promoter via an Ap1like element. J Biol Chem 267:19665, 1991

Nomura T, Sakai N, Sarai A, Sudo T, Kanei-Ishii C, Ramsay RG, Favier D, Gonda TJ, Ishii S: Negative autoregulation of c-myb activity by homodimer formation through the leucine zipper. J Biol Chem 268:21914, 1993

Oettinger MA: V(D)J recombination: on the cutting edge. Curr Opin Cell Biol 11:325, 1999

Oettinger MA, Schatz DG, Gorka C, Baltimore D: RAG-1 and RAG-2, adjacent genes that synergistically activate $V(D) J$ recombination. Science 248:1517, 1990

Osgood EE: A unifying concept of the etiology of the leukaemias, lymphomas and cancers. J Natl Cancer Inst 18:155, 1957 
Osmond DG: B cell development in the bone marrow. Semin Immunol 2:173, 1990

Page KC, Makris JM, Chernin ML: Effects of retinoids on expression of the protooncogene c-myb in rat Sertoli cells. Recent Prog Horm Res 50:465, 1995

Patel G, Dreider B, Rovera G, Reddy P: v-myb blocks granulocyte colony-stimulating factor-induced myeloid differentiation but not proliferation. Mol Cell Biol 13:2269, 1993

Peschon JJ, Morrissey PJ, Grabstein KH, Ramsdell FJ, Maraskovsky E, Gliniak BC, Park LS, Ziegler SF, Williams DE, Ware CB, et al: Early lymphocyte expansion is severely impaired in interleukin 7 receptor-deficient mice. J Exp Med 180:1955, 1994

Rahal MD, Osmond DG: Maturation of bone marrow lymphocytes. IV. Kinetics of maturation and renewal of lymphocytes expressing la and $\mathrm{H}-2 \mathrm{~K}$ antigens. Immunology 44:463, 1981

Ramsay RG, Ikeda K, Rifkind RA, Marks PA: Changes in gene expression associated with induced differentiation of erythroleukemia: protooncogenes, globin genes, and cell division. PNAS 83:6849, 1986

Ramsay RG, Ishii S, Gonda TJ: Increase in specific DNA binding by carboxyl truncation suggests a mechanism for activation of Myb. Oncogene 6:1875, 1991

Ramsay RG, Morrice N, Van Eeden P, Kanagasundaram V, Nomura T, De Blaquiere J, Ishii S, Wettenhall R: Regulation of c-Myb through protein phosphorylation and leucine zipper interactions. Oncogene 11:2113, 1995

Ray RJ, Paige CJ, Furlonger C, Lyman SD, Rottapel R: FIt3 ligand supports the differentiation of early B cell progenitors in the presence of interleukin-11 and interleukin-7. Eur J Immunol 26:1504, 1996 
Reiss K, Travali S, Calabretta B, Baserga R: Growth regulated expression of B-myb in fibroblasts and hematopoietic cells. J Cell Physiol 148:338, 1991

Robey E, Fowlkes BJ: Selective events in T cell development. Annu Rev Immunlo $12: 675,1994$

Rosson D, Dugan D, Reddy EP: Aberrant splicing events that are induced by proviral integration: implications for myb oncogene activation. PNAS 84:3171, 1987

Russell ES: Hereditary anemias of the mouse: a review for geneticists. Adv Genet 20:357, 1979

Sabin FR: Bone marrow. Physiol Rev 8:191, 1928

Saikumar P, Murali R, Reddy EP: Role of tryptophan repeats and flanking amino acids in myb-DNA interactions. PNAS 87:8452, 1990

Sakura H, Kanei-Ishii C, Nagase T, Nakagoshi H, Gonda TJ, Ishii S: Delineation of three functional domains of the transcriptional activator encoded by the c-myb protooncogene PNAS 86:5758, 1989

Salomoni P, Perrotti D, Martinez R, Franceschi C, Calabretta B: Resistance to apoptosis in CTLL-2 cells constitutively expressing c-Myb is associated with induction of BCL-2 expression and Myb-dependent regulation of bcl-2 promoter activity. PNAS 94:3296, 1997

Sasaki K, Sonoda Y: Histometrical and three-dimensional analyses of liver hematopoiesis in the mouse embryo. Arch Histol Cytol 63:137, 2000 
Sczylik C, Skorski T, Ku D-H, Nicolaides NC, Wen S-C, Rudnicka L, Bonati A, Malaguarnera L, Calabretta B: Regulation of proliferation and cytokine expression of bone marrow fibroblasts: role of c-myb. J Exp Med 178:997, 1993

Sheiness D, Gardinier M: Expression of a proto-oncogene (proto-myb) in hematopoietic tissues of mice. Mol Cell Biol 4:1206, 1984.

Shinikai Y, Rathbun G, Lam KP, Oltz EM, Stewart V, Mendelsohn M, Charron J, Datta M, Young F, Stall AM, et al: RAG-2-deficient mice lack mature lymphocytes owing to inability to initiate $V(D) J$ rearrangement. Cell 68:855, 1992

Siminovitch L, McCulloch EA, Till JE: The distribution of colony-forming cells among spleen colonies. J Cell Comp Physiol 62:327, 1963

Sitzmann J, Noben-Trauth K, Kamano H, Klempnauer KH: Expression of B-Myb during mouse embryogenesis. Oncogene 12:1889, 1996

Siu G, Wurster AL, Lipsick JL, Hendrick SM: Expression of the CD4 gene requires a Myb transcription factor. Mol Cell Biol 12:1592, 1992

Slamon DJ, deKernion JB, Verma IM, Cline MJ: Expression of cellular oncogenes in human malignancies. Science 224:256, 1984

Slamon KJ, Boone TC, Murdock DC, Keith DE, Press MF, Lavson RA, Souza LM: Studies of the human c-myb gene and its product in human acute leukemias. Science 233: 347,1986

Spangrude GJ, Heimfeld S, Weissman IL: Purification and characterization of mouse hematopoietic stem cells. Science 241:58, 1988 
Stern JB, Smith KA: Interleukin-2 induction of T-cell G1 progression and c-myb expression. Science 233:203, 1986

Sudo T, Ito M, Ogawa Y, lizuka M, Kodama H, Kunisada T, Hayashi S, Ogawa M, Sakai K, Nishikawa S, Nishikawa S-I: Interleukin 7 production and function in stromal celldependent B cell development. J Exp Med 170:333, 1989

Sudo T, Nishikawa S, Ohno N, Akiyama N, Tamakoshi M, Yoshida H, Nishikawa S: Expression and function of the interleukin 7 receptor in murine lymphocytes. PNAS 90:9125, 1993

Tanikawa J, Yasukawa T, Enari M, Ogata K, Nishimura Y, Ishii S, Sarai A: Recognition of specific DNA sequences by the c-myb protooncogene product: role of three repeat units in the DNA-binding domain. PNAS 90:9320, 1993

Tavassoli M: Studies on hemopoietic microenvironments. Exp Hematol 3:213, 1975

Thiele CJ, McKeon C, Triche TJ, Ross RA, Reynolds CP, Israel MA: Differential protooncogene expression characterizes histopathologically indistinguishable tumors of the peripheral nervous system. J Clin Invest 80:804, 1987

Thiele CJ, Cohen PS, Israel MA: Regulation of c-myb expression in human neuroblastoma cells during retinoic acid induced differentiation. Mol Cell Biol 8:1677, 1988

Thompson CB, Challoner PB, Neiman PE, Groudine M: Expression of the c-myb protooncogene during cellular differentiation. Nature 319:374, 1986

Till JE, McCulloch EA: A direct measurement of the radiation sensitivity of normal mouse bone marrow cells. Radiation Res 14:213, 1961 
Torelli G, Venturelli D, Colo A, Zanni C, Selleri L, Moretti L, Claabretta B, Troelli U: Expression of c-myb proto-oncogene and other cell cycle-related genes in normal and neoplastic human colonic mucosa. Cancer Res 47:5266, 1987

Toscani A, Mettus RV, Coupland R, Simpkins H, Litvin J, Orth J, Hatton KS, Reddy EP: Arrest of spermatogenesis and defective breast development in mice lacking A-myb. Nature 386:713, 1997

Trauth K, Mutschler B, Jenkins NA, Gilbert DJ, Copeland NG, Klempnauer KH: Mouse A-myb encodes a trans-activator and is expressed in mitotically active cells of the developing central nervous system, adult testis, and B lymphocytes. EMBO J 13:5994, 1994

Wang D-M, Lipsick JS: Mutational analysis of the transcriptional activation domains of v-Myb. Oncogene 21:1611, 2002

Wang QF, Lauring J, Schlissel MS: c-Myb binds to a sequence in the proximal region of the RAG-2 promoter and is essential for promoter activity in T-lineage cells. Mol Cell Biol 20:9203, 2000

Westin EH, Gallo RC, Arya SK, Eva A, Souza LM, Baluda MA, Aaronson SA, WongStaal F: Differential expression of the amv gene in human hematopoietic cells. PNAS 79:2194, 1982

Whitlock CA, Witte ON: Long-term culture of B lymphocytes and their precursors from murine bone marrow. PNAS 79:3608, 1982

Wilson A, Held W, MacDonald HR: Two waves of recombinase gene expression in developing thymocytes. J Exp Med 179:1355, 1994

Wintrobe MM: Blood, Pure and Eloquent, McGraw-Hill. New York 1980 
Witte PL, Robinson M, Henley A, Low MG, Stiers DL, Perkins S, Fleischman RA, Kincade PW: Relationships between B-lineage lymphocytes and stromal cells in longterm bone marrow cultures. Eur J Immunol 17:1473, 1987

Wu AM, Till JE, Siminovitch L, McCulloch EA: A cytological study of the capacity for differentiation of normal hemopoietic colony-forming cells. J Cell Physiol 69:177, 1967

Wu L, Antica M, Johnson GR, Scollay R, Shortman K: Developmental potential of the earliest precursor cells from the adult mouse thymus. J Exp Med 174:1617, 1991

Yancopoulos GD, Alt FW: Regulation of the assembly and expression of variableregion genes. Annu Rev Immunol 4:339, 1986 